\title{
IMPACTOS DA EXPLORAÇÃO MADEIREIRA PREDATÓRIA E PLANEJADA SOBRE O CRESCIMENTO E DIVERSIDADE DE ESPÉCIES ARBÓREAS NA AMAZÔNIA ORIENTAL
}

EDSON JOSÉ VIDAL DA SILVA

Dissertação apresentada à Escola Superior de Agricultura "Luiz de Queiroz", Universidade de São Paulo, para a obtenção do título de Mestre em Ciências, Área de Concentração: Ciências Florestais.

$P|R A C| C A B A$

Estado de São Paulo - Brasil

setembro

$-1998$ 
Dados Internacionais de Catalogação na Publicação (CIP)

DIVISÃO DE BIBLIOTECA E DOCUMENTAÇÃO - Campus "Luiz de Queiroz"/USP

\section{Silva, Edson José Vidal da}

Impactos da exploraçao madeireira predatória e planejada sobre o crescimento e diversidade de espécies arbóreas na Amazônia Oriental / Edson José Vidal da Silva. - . Piracicaba, 1998.

81 p. il.

Dissertação (mestrado) - - Escola Superior de Agricultura Luiz de Queiroz, 1998. Bibliografia.

1. Crescimento vegetal 2. Diversidade vegetal 3. Exploração florestal 4. Extração madeireira 5. Floresta Amozônica 6. Planejamento florestal I. Título 


\title{
IMPACTOS DA EXPLORAÇÃO MADEIREIRA PREDATÓRIA E PLANEJADA SOBRE O CRESCIMENTO E DIVERSIDADE DE ESPÉCIES ARBÓREAS NA AMAZÔNIA ORIENTAL
}

\author{
EDSON JOSÉ VIDAL DA SILVA \\ Engenheiro Agrônomo
}

Orientador: Prof. Dr. VIRGILIO MAURICIO VIANA

Dissertação apresentada à Escola Superior de Agricultura "Luiz de Queiroz", Universidade de São Paulo, para a obtenção do título de Mestre em Ciências, Área de Concentração: Ciências Florestais.

P I R A C I C A B A Estado de São Paulo - Brasil

Outubro - 1998 


\title{
IMPACTOS DA EXPLORAÇÃO MADEIREIRA PREDATÓRIA E PLANEJADA SOBRE O CRESCIMENTO E DIVERSIDADE DE ESPÉCIES ARBÓREAS NA AMAZÔNIA ORIENTAL
}

\author{
EDSON JOSÉ VIDAL DA SILVA
}

Aprovada em:

Comissão julgadora:

Prof. Dr. Fernando Seixas

ESALQ/USP

Dr. Robert Buschbacker

WWF - Brasil

Prof. Dr. Virgilio Mauricio Viana

ESALQ/USP

Prof. Dr. Virgilio Mauricio Viana

Orientador 


\section{Dedico}

À minha querida esposa, Gerlane, pelo companheirismo, paciência, compreensão, dispensados ao longo da realização deste trabalho e em todos os outros momentos de nossa vida;

\section{Ofereço}

Ao meu pai, Raimundo Ribeiro, aos meus irmãos, demais familiares e a todos aqueles que contribuiram de uma maneira ou de outra para que esta obra fosse realizada. 


\section{SUMÁRIO}

Página

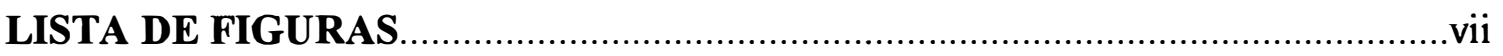

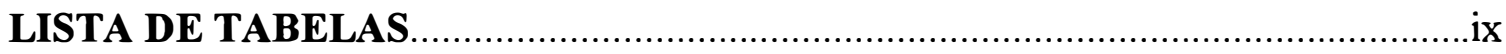

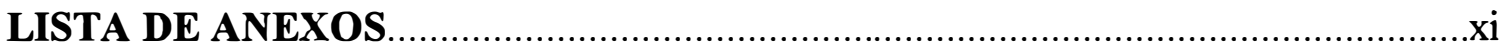

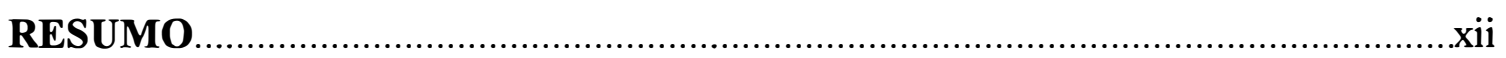

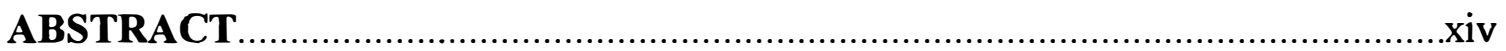

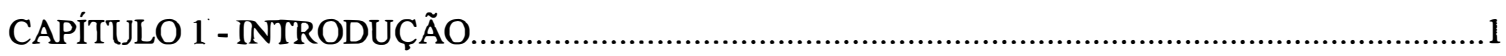

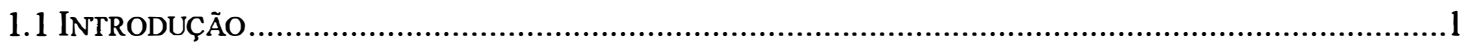

1.2 ORGANIZAÇÃO DA DISSERT AÇÃO........................................................................................

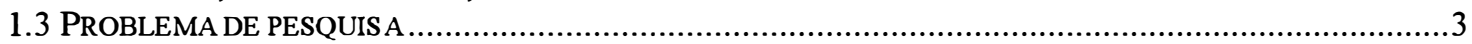

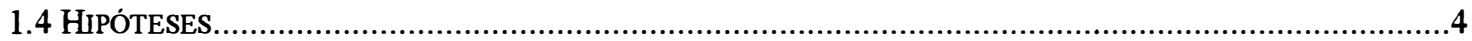

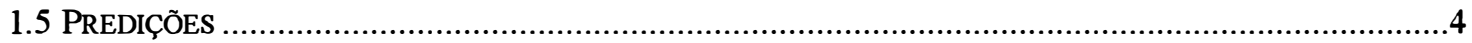

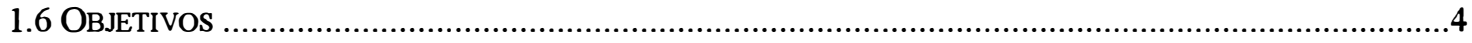

CAPÍTULO 2 - REVISÃO DE LITERATURA...........................................................................

2.1 COMPORTAMENTO DA FLORESTA APÓS DISTÚRBIOS NATURAIS E ANTRÓPICOS .................................5

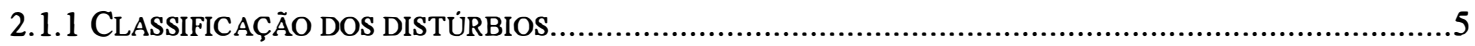

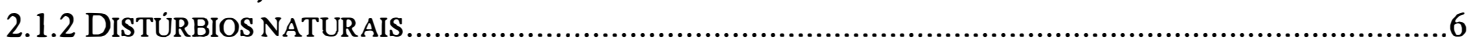

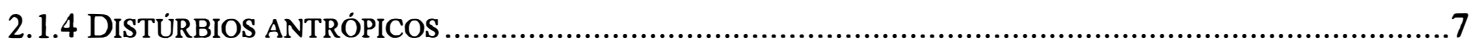

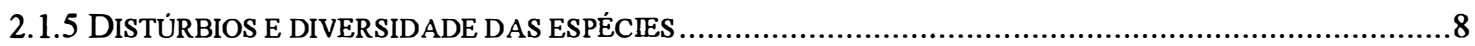

2.1.6 DIVERSIDADE EM ÁREAS PERTURBADAS COM ATIVIDADE MADEIREIRA......................................9

2.1.7 DISTÚRBIOS E CRESCIMENTO DAS ÁRVORES …….........................................................

2.1.8 CRESCIMENTO DAS ÁRVORES EM CONDIÇÕES NATURAIS NAS DIFERENTES REGIÕES DE FLORESTAS

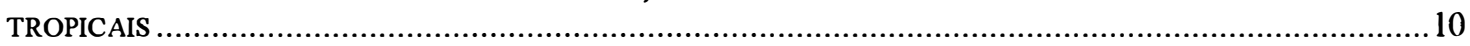

2.1.9 CRESCIMENTO DAS ÁRVORES NAS ÁREAS PERTURBADAS COM ATIVIDADE MADEIREIRA...................11

CAPÍTULO 3 - CRESCIMENTO DE FLORESTA TROPICAL APÓS TRÊS ANOS DE EXPLORAÇÃO MADEIREIRA PREDATÓRIA E PLANEJADA NA AMAZÔNIA ORIENTAL ……………………....16

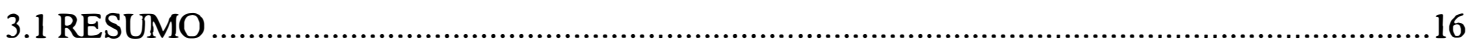

3.3 INTRODUÇÃO.

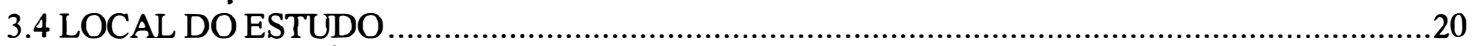

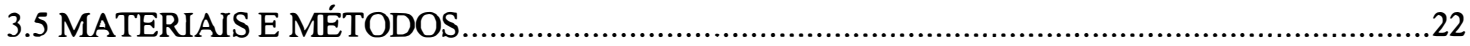

3.5.1 Descrição dos sistemas de exploração realizados na área: .................................................22

3.5.1.1 Exploração predatória ..............................................................................................24

3.5.1.2 Colheita planejada ...............................................................................................24

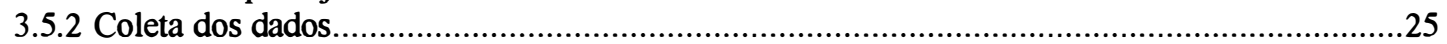

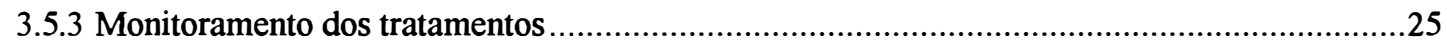

3.5.4 Crescimento de espécies com presença e ausência de cipós ………………………………....25

3.5.6 Crescimento de árvores por tipo de iluminação da copa ....................................................26

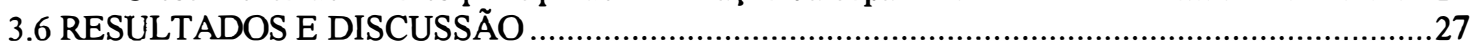

3.6.1 Crescimento diamétrico das árvores com presença e ausência de cipós e de danos ....................30

3.6.3 Crescimento de espécies por tipo de iluminação da copa ……………………….................32

3.6.4 Incremento das principais espécies madeireiras após a exploração …………………………....34

3.7 CONCLUSÃO.

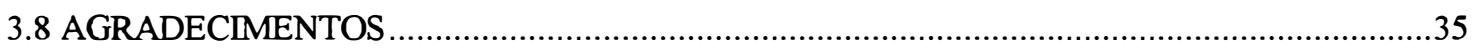


CAPÍTULO 4 - IMPACTOS DA EXPLORAÇÃO MADEIREIRA PREDATÓRIA E PLANEJADA SOBRE A DIVERSIDADE DE ESPÉCIES NA AMAZÔNIA ORIENTAL .........................................40

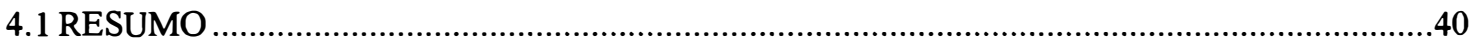

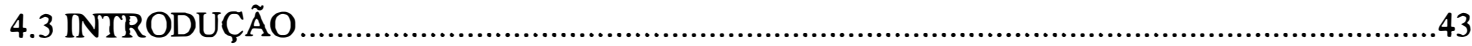

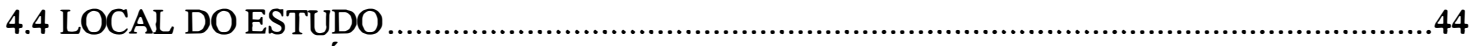

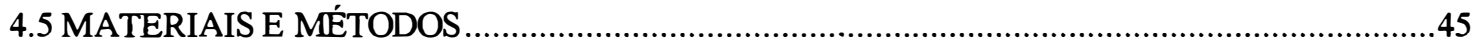

4.5.1 Descrição dos sistemas de exploração realizados na área: ...................................................45

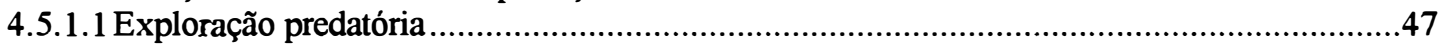

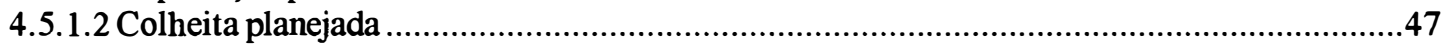

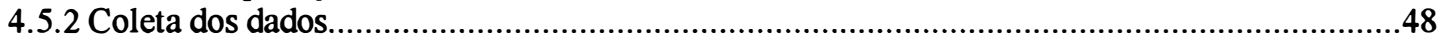

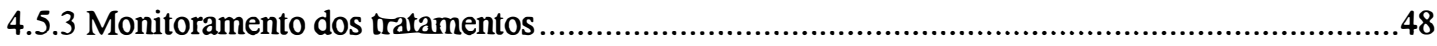

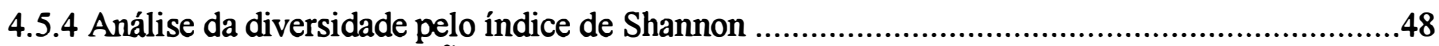

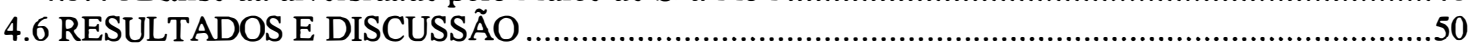

4.6.1 Densidade de indivíduos antes e após a exploração ....................................................50

4.6.2 Riqueza florística, dominância e diversidade de espécies antes e após a exploração .................51

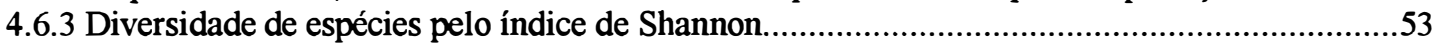

4.6.4 Estrutura diamétrica antes e após a intervenção ...............................................................5.

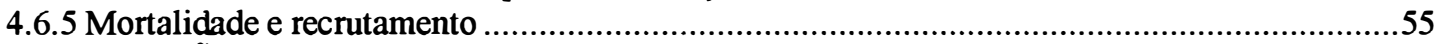

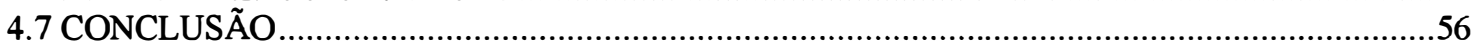

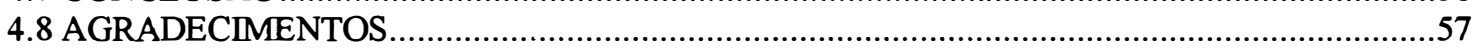

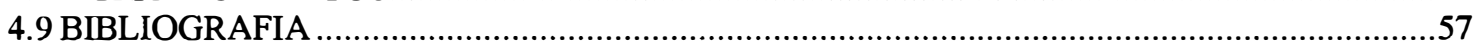

CAPÍTULO 5 - CONCLUSÕES E RECOMENDAÇÕES ...................................................................68

5.1 AS VANTAGENS DA COLHEITA PLANEJADA DE MADEIRA NA AMAZÔNIA ................68

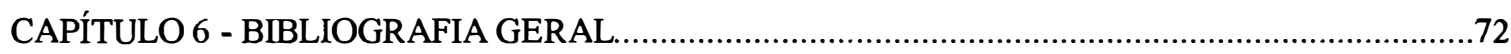




\section{LISTA DE FIGURAS}

\section{CAPÍTULO III}

Página

Figura 01: Localização da área de estudo

Figura 02: $\quad$ Mapa da área de estudo com os tratamentos aplicados e localização das áreas reservadas para instalação das parcelas.

Figura 03: Tipos de iluminação da copa considerada no estudo

Figura 04: Área basal das árvores por tratamento (convencional, manejo) e testemunha nos períodos antes da exploração, logo após a exploração e 3 anos após a exploração na fazenda Agrosete em Paragominas, Pará-Brasil.

Figura 05: Incremento corrente anual por tratamento (exploração predatória, colheita planejada) e testemunha nos três períodos de medição na Fazenda Agrosete em Paragominas/Pará.

Figura 01. Localização da área de estudo

\section{CAPÍTULO IV}

Figura 02. Mapa da área de estudo com distribuição dos tratamentos aplicados e das áreas reservadas para instalação das parcelas.

Figura 03. Densidade de indivíduos (n/ha) para (A) todas as espécies, (B) somente as espécies de valor madeireiro e, (C) somente espécies sem valor madeireiro na Fazenda Agrosete em Paragominas/Pará.

Figura 04. Mortalidade anual e recrutamento de árvores acima de $10 \mathrm{~cm}$ de diâmetro na Fazenda Agrosete em Paragominas, Pará-Brasil. 


\section{CAPÍTULO V}

Figura 01: Incremento Corrente Anual por tipo de intervenção na floresta (exploração predatória, colheita planejada) e testemunha nos 3 períodos de medição na Fazenda Agrosete em Paragominas, Pará. 


\section{LISTA DE TABELAS}

Página

\section{CAPÍTULO II}

Tabela 01: Taxa de crescimento em florestas naturais e com intervenção nas principais florestas tropicais do mundo.

\section{CAPÍTULO III}

Tabela 01: Incremento Corrente Anual e Incremento Médio Anual de espécies de valor comercial em cada tratamento durante 3 anos na Fazenda Agrosete, Paragominas, Pará.

Tabela 02: Crescimento das árvores com e sem cipós por faixa de DAP na fazenda Agrosete em Paragominas, Pará.

Tabela 03: Crescimento de árvores com e sem danos medidas anualmente durante 3 anos após a exploração de madeira na Fazenda Agrosete em Paragominas, Pará, Brasil.

Tabela 04: Crescimento em DAP das árvores por tipo de iluminação da copa na Fazenda Agrosete em Paragominas, Pará, Brasil.

Tabela 05: Incremento médio anual $\left(\mathrm{cm} / \mathrm{ano}^{-1}\right)$, intervalo de incremento e número de indivíduos amostrados (n) das espécies madeireiras que apresentaram pelo menos 6 indivíduos com DAP acima de $30 \mathrm{~cm}$ na fazenda Agrosete em Paragominas, Pará, Brasil.

\section{CAPÍTULO IV}

Tabela 01. Número de indivíduos, número de espécies e índice de Shannon dos tratamentos colheita planejada e exploração predatória na Fazenda Agrosete, em Paragominas, Pará - Brasil. 


\section{CAPÍTULO V}

Tabela 01. Crescimento em DAP das árvores com e sem cipós, durante 3 anos, em Paragominas, Pará.

Tabela 02. Balanço do número de espécies por tipo de intervenção na floresta 3 anos após a exploração, na Fazenda Agrosete, em Paragominas, Pará. 


\section{LISTA DE ANEXOS}

Página

\section{CAPÍTULO IV}

Anexo 01: Densidade de indivíduos com e sem valor madeireiro com DAP acima de $10 \mathrm{~cm}$ de diâmetro por tratamento e por período de medição na fazenda Agrosete em Paragominas, Pará-Brasil.

Anexo 02: Nomes científicos, nomes vulgares, famílias e número de indivíduos das espécies encontradas na área testemunha (I), manejo (II) e convencional (III) antes (A), após a extração (B) e três anos após a extração na fazenda Agrosete em Paragominas, Pará.

Anexo 03: Distribuição dos indivíduos por classe diamétrica antes da exploração, um ano após e três anos após por tratamento em Paragominas, Pará/Brasil. 


\title{
IMPACTOS DA EXPLORAÇĀO MADEIREIRA PREDATÓRIA E PLANEJADA SOBRE O CRESCIMENTO E DIVERSIDADE DE ESPÉCIES NA AMAZÔNIA ORIENTAL
}

\author{
Autor: EDSON JOSÉ VIDAL DA SILVA \\ Orientador: Prof. Dr. VIRGILIO MAURICIO VIANA
}

\section{RESUMO}

Esta dissertação compara o comportamento do crescimento e da diversidade das árvores com DAP maior que $10 \mathrm{~cm}$ entre áreas naturais e áreas exploradas com o emprego de colheita planejada e extração madeireira predatória na Amazônia oriental. A região de estudo fica na Fazenda Agrosete $\left(3^{0} \mathrm{~S}, 50^{\circ}\right.$ W), no Município de Paragominas.

O experimento foi realizado numa área de 210 hectares, sendo 75 ha com exploração predatória, 105 ha com colheita planejada e 30 ha com área testemunha. A exploração predatória consistiu do seguinte: após definida a área, uma equipe de motosserristas entrou na floresta e derrubou as árvores, sem o conhecimento prévio de sua localização, pois não conduziu-se o mapeamento e o censo das árvores. Em seguida, construiu-se as estradas e os pátios de estocagem, de onde as toras foram transportadas até a serraria. Finalmente, os operadores das máquinas saíram à procura das árvores. Por não terem a localização exata das árvores derrubadas, o arraste das toras ocasionou muitos danos e desperdícios de madeira. Na colheita planejada foi empregado o planejamento das atividades com as seguintes medidas: censo das árvores de valor madeireiro com DAP > $25 \mathrm{~cm}$; preparação de um mapa de colheita com traçado de estradas, ramais de arraste e localização de pátios de estocagem; uso da derrubada direcional; corte de cipós 1,5 anos antes da colheita; arraste feito com tratores florestais com guincho e torre. A exploração predatória e a colheita planejada aconteceram no ano de 1993, e os tratamentos foram monitorados até 1996, sendo realizadas medições anuais de DAP, mortalidade e sanidade das árvores. Avaliou-se o comportamento da 
floresta em relação ao crescimento em DAP das árvores e diversidade de espécies, através do número das espécies e do índice de Shannon.

Os resultados das comparações de diversidade através do índice de Shannon, para cada tipo de intervenção, indicaram que o tratamento colheita planejada não apresentou diferença significativa na comparação de médias pelo teste $t$ no período logo após a exploração (1994) e três anos após (1996) apresentando diferença no tratamento exploração predatória. A diversidade de espécies (considerando indivíduos com DAP acima de $10 \mathrm{~cm}$ ) na área com manejo sofreu menor redução do que na área com exploração predatória. Isso indica menos danos à biodiversidade.

O Incremento Médio Anual para todas as árvores na área manejada foi o dobro da testemunha e 1,5 superior ao da exploração predatória. A colheita de madeira levou à uma redução em área basal de $31 \%$ na exploração predatória, enquanto que, na manejada a redução foi de apenas $17 \%$. O incremento em área basal na colheita planejada foi 2,2 vezes superior à exploração predatória $\left(1,02 \mathrm{~m}^{2} / \mathrm{ha} \mathrm{e} 0,45 \mathrm{~m}^{2} / \mathrm{ha}\right.$, respectivamente).

Esses resultados demonstram mais vantagens no emprego de manejo florestal em relação à exploração predatória de madeira. Se o comportamento do crescimento da floresta manejada continuar neste ritmo, menos tempo será necessário para o segundo corte de madeira na área. Esse fato reforça a necessidade de políticas públicas voltadas para o apoio à adoção de um sistema de manejo florestal nessa região. 


\title{
THE IMAPCTS OF PLANNED AND UNPLANNED LOGGING ON FOREST \\ GROWTH AND SPECIES DIVERSITY IN AN EASTERN AMAZONIAN TROPICAL RAIN FOREST
}

\author{
Author: EDSON JOSÉ VIDAL DA SILVA \\ Adviser: Prof. Dr. VIRGILIO MAURICIO VIANA
}

\section{ABSTRACT}

This dissertation compares the impacts of planned and unplanned logging on the growth and diversity of trees $>10 \mathrm{~cm}$ dbh in a tropical rain forest. This study was carried out near the city of Paragominas $\left(3^{\circ} \mathrm{S}, 50^{\circ} \mathrm{W}\right)$, in eastern Amazonia. The study area included 210 ha of forest of which 105 ha was subjected to planned logging, 75 ha to unplanned logging, and 30 ha was left as an unlogged control.

Unplanned logging consisted of a chainsawyer who walked through the forest felling trees as he encountered them. This step was followed by the construction of logging roads and logs landings. Finally, bulldozer operators drove into the forest in search of felled logs that they transported to the log landings. Because the tractor drivers were working without knowledge as to the locations of the felled trees, the process of transporting the logs to the landings resulted in much damage to the remaining stand. Planned logging included the following modifications to the unplanned scenario: an initial census of all trees $>25 \mathrm{~cm}$ DBH with commercial value was conducted; based on this census a map of all commercial trees was produced; the locations of all logging roads, log landings, and skid trails was located on this map; directional felling was employed; all lianas were cut 1.5 years prior to logging; and extraction was conducted using a rubber-tired forest tractor with a winch. All logging occurred during 1993 and tree diameter increment, mortality, and recruitment were monitored until 1996.

Impacts of the two logging treatments on tree species diversity were determined by comparing changes following logging in Shannon diversity indices for both logged areas and the control area. Significant declines in diversity following logging were 
found in the unplanned logging but not in the planned logging area. The total reduction in tree species diversity following logging was less in the planned logging area than in the unplanned.

During the study period, the planned logging area showed a 50\% greater increase in basal area than the unplanned logging area. Also in the planned logging area, mean annual diameter increment averaged over all species was twice that of the control area and 1.5 times that of the unplanned logging area. Timber extraction resulted in a decrease in total basal area of $31 \%$ in the unplanned logging area and only $17 \%$ in the planned. There were no significant changes in the control plots. Annual basal area increment following Logan was $1.02 \mathrm{~m}^{2} / \mathrm{ha}$ in the planned logging area and $0.45 \mathrm{~m}^{2} /$ ha in the unplanned.

This study demonstrates that planned logging can result in increased annual diameter increments in the remaining forest when compared to unplanned logging. This, in turn, can result in shorter cutting cycles. Also, planned logging results in a smaller reduction in tree species diversity than its unplanned counterpart. Although the benefits of planned logging are abundant, unplanned logging continues to be the norm. This fact reinforces the idea that public policies are needed that support the adoption of planned logging practices. 


\section{CAPÍtUlo 1 \\ INTRODUÇÃO}

\subsection{Introdução}

A extração de madeira em tora no Brasil tem crescido nos últimos anos. Houve um aumento de $18 \%$ na produção de 1988 a 1995. Somente na Amazônia, este aumento foi de $46 \%$. Em 1996, foram extraídos cerca de 29,5 milhões de metros cúbicos de madeira na Amazônia. Esse volume corresponde a cerca de 7,3 milhões de árvores (considerando o volume médio por árvore de 4 metros cúbicos) (Barreto et al. 1998).

Atualmente, a Amazônia responde por $85 \%$ de todo o volume de madeira em tora produzido no Brasil. A participação do Brasil no mercado externo é de apenas $4 \%$ no entanto, este percentual irá aumentar na próxima década, principalmente devido ‘a exaustão dos estoques dos países asiáticos e africanos (Veríssimo et al. 1992; Prado, 1995; Stone, 1996; Barreto et al. 1998; Veríssimo e Lima, 1998). Há cerca de 2.300 empresas madeireiras operando na Amazônia. De acordo com as estimativas de produção, 90\% das indústrias da Amazônia estão no Estado do Pará (Veríssimo e Lima, 1998).

A indústria madeireira do Pará processa cerca de 330 espécies madeireiras, sendo que $64 \%$ dessas espécies ocorrem apenas na terra-firme, $10 \%$ são restritas da várzea, e o restante, $26 \%$, ocorre nos dois ambientes. A maioria dessas espécies (90\%) têm valor inferior a US $\$ 300 /$ metro cúbico de madeira na forma serrada na serraria, sendo que a espécie de maior valor é o mogno (Swietenia macrophylla King) (Martini et al. 1993; Martini et al. 1994), que tem um valor médio na forma serrada de US\$1000-1100/metro 
cúbico $^{1}$.

Apesar da importância econômica inquestionável da atividade madeireira (Silva et al. 1995), os impactos ambientais são significativos e podem se agravar. A extração predatória, a susceptibilidade ao fogo e a caça podem reduzir significativamente as chances de regeneração natural das florestas exploradas. Além do mais, a exploração tem sido catalítica de assentamento de agricultores e de fazendeiros que convertem a floresta em agricultura e pastagem (Barreto et al. 1998).

A exploração madeireira, apesar de menos nociva que outros usos do solo, transforma profundamente as florestas primárias, comprometendo a sua regeneração e produtividade. Para se manejar a floresta tropical de forma auto-sustentada, deve-se conhecer o impacto das intervenções sobre a regeneração e a estrutura da floresta (Batista, 1989). Os métodos de exploração madeireira afetam drasticamente o incremento futuro de madeira, se for inadequado diminui as taxas de crescimento da floresta remanescente, contribuindo, assim, para que os ciclos de corte sejam mais longos (Hutchinson, 1986; Panayotou e Ashton, 1992)

A atividade madeireira predatória na Amazônia afeta significativamente o ecossistema florestal. Os impactos começam com a destruição ou danos às árvores pela preparação da infra-estrutura da exploração (p. ex.: vias de acesso, ramais de arraste), pátios de estocagem, movimentação das máquinas e derrubada das árvores. Todavia, com o uso de técnicas de manejo florestal, os danos ecológicos à estrutura da floresta e os desperdícios de madeira foram reduzidos em $30 \%$. Houve diminuição nos riscos de acidentes e incêndios e a exploração com manejo é $35 \%$ mais rentável que a exploração predatória, tais técnicas permitem atender a demanda de madeira com o uso de apenas um terço da área que é explorada de forma predatória (Uhl et al. 1991; Veríssimo et al. 1992; Veríssimo et al. 1995; Barros \& Uhl, 1995; Johns et al. 1996; Gerwing et al. 1996; Vidal et al. 1997; Barreto et al. 1994; Uhl et al. 1996; Barreto et al. no prelo).

Uma parte importante do manejo florestal sustentável é uma informação confiável do crescimento e rendimento da floresta para diferentes sistemas de manejo. Tal informação é fundamental tanto para a definição do ciclo de corte como para

${ }^{1}$ BUSHBACHER, R. (WWF. Fundo Mundial para a Natureza, Brasília). Comunicação pessoal, 1998. 
entendimento da dinâmica da floresta manejada e para a definição de sistemas silviculturais (Higuchi et al. 1997).

No entanto, muitos dos estudos realizados na região compararam exploração madeireira com o uso de algumas técnicas de manejo por exemplo o mapeamento das árvores, derruba direcional, liberação de árvores reservadas e monitoramento, e a dinâmica da floresta natural. Outros compararam apenas a exploração predatória com a floresta natural. Desta forma, fica difícil a comparação da eficiência da exploração com o uso de técnicas de manejo e a exploração sem o uso dessas técnicas. Esse tipo de comparação é importante, pois além de dar subsídios para analisar a viabilidade técnica do manejo florestal, fornece informações de como vai se comportar a floresta nestes métodos de exploração.

Esta dissertação é a continuação de um projeto mais amplo do Instituto do Homem e Meio Ambiente da Amazônia - IMAZON. Primeiro foi avaliado a viabilidade do manejo florestal em termos técnicos e econômicos, nas etapas antes e durante a exploração. Depois foi acompanhado o desenvolvimento da floresta após a exploração, para avaliar de forma comparativa o comportamento das árvores após a exploração madeireira predatória, colheita planejada e área testemunha.

\subsection{Organização da dissertação}

Esta dissertação está dividida em 5 capítulos. No capítulo I é feita uma introdução geral do assunto tratado na dissertação. No capítulo II é realizada uma revisão de literatura sobre comportamento da floresta após os distúrbios. O capítulo III mostra a comparação de crescimento das árvores na exploração predatória e a colheita planejada de madeira. O capítulo IV enfoca os impactos da exploração madeireira sobre a diversidade de espécies. E no capítulo final, enfoca-se de forma geral, as vantagens da colheita planejada de madeira em relação à exploração predatória.

\subsection{Problema de pesquisa}

O planejamento da exploração de madeira, dentro das atividades de colheita planejada, pode permitir a redução do número de árvores danificadas e a área afetada. 
No entanto, os conhecimentos sobre o comportamento do estoque de árvores remanescentes, o crescimento das árvores e a diversidade das espécies em áreas que foram exploradas de forma predatória e com emprego de colheita planejada são ainda incipientes.

\subsection{Hipóteses}

Há diferenças significativas em termos de estoque de indivíduos (densidade), diversidade de espécies e crescimento de árvores acima de $10 \mathrm{~cm}$ de DAP, entre áreas submetidas a exploração predatória, colheita planejada e áreas não perturbadas.

\subsection{Predições}

$\mathrm{O}$ crescimento das árvores e a diversidade das espécies e estoque de indivíduos acima de $10 \mathrm{~cm}$ de DAP serão maiores na colheita planejada do que na exploração predatória, devido à redução dos danos derivados do planejamento pré-exploratório e corte de cipós.

\subsection{Objetivos}

Avaliar comparativamente a dinâmica da floresta três anos após a exploração predatória, a colheita planejada e a área não explorada, especialmente o estoque de árvores, o crescimento das árvores e a diversidade de espécies acima de $10 \mathrm{~cm}$ de DAP. 


\section{CAPÍTULO 2 \\ REVISÃO DE LITERATURA}

\subsection{Comportamento da floresta após distúrbios naturais e antrópicos}

Os distúrbios têm papel fundamental no desenvolvimento da floresta, pois podem eliminar a vegetação e liberar espaço para as plantas crescerem. A composição florística de determinada floresta é diretamente influenciada pelos distúrbios (Oliver e Larson, 1990, Oliver e Larson, 1996).

A resposta das árvores a determinados distúrbios varia de acordo com as características das espécies e o tipo de distúrbio (Oliver e Larson, 1990).

Os principais tipos de distúrbios naturais observados em florestas tropicais são: ciclones ou furacões, tempestades, vendavais, secas, inundações, deslizamentos de terra e fogo (Bazzaz, 1983; White e Pickett, 1985; Attiwill, 1994; Oliver e Larson, 1990; Oliver e Larson, 1996).

\subsubsection{Classificação dos distúrbios}

Os distúrbios podem ser classificados por sua frequência, distribuição, área coberta, intervalo de retorno, magnitude e outros fatores (Bazzaz, 1983; White e Pickett, 1985; Attiwill, 1994; Oliver e Larson, 1996).

Segundo Oliver e Larson (1996), os distúrbios podem ser divididos em 2 tipos baseados na quantidade de cobertura vegetal removida:

Distúrbios maiores - são os distúrbios que removem ou eliminam todas as árvores existentes acima do solo; 
Distúrbios menores - são os que removem ou eliminam apenas uma parte das árvores existentes.

O desenvolvimento da floresta em distúrbios menores é mais complexo do que em distúrbios maiores por influenciar a estrutura, composição das espécies e a taxa de crescimento, dependendo de quanto da floresta foi eliminada, que espécies existem e a posição da copa das árvores (Oliver e Larson, 1996).

\subsubsection{Distúrbios naturais}

Alguns pesquisadores concluíram que as florestas são um produto de uma série de distúrbios. Wiltmore (1990), por exemplo afirma que a floresta tropical sem perturbações é considerada um mito. Lugo (1995), concorda com esta afirmação dizendo que as florestas não são primárias e sim produto de distúrbios e manejo pelas antigas populações indígenas. Sendo assim, pode-se afirmar que as florestas tropicais são um produto de uma série de distúrbios ou perturbações.

Estas transformações oriundas dos distúrbios mudam, a curto e longo prazo, a riqueza florística e a diversidade (Oliver e Larson, 1990). Segundo esses mesmos autores, para espécies florestais, uma nova geração é geralmente produzida quando um distúrbio significante ocorre na floresta. Portanto, a composição florística em florestas tropicais varia em pequenas e médias escalas temporais e espaciais.

Para Nelson (1994), nas florestas da Amazônia brasileira, os distúrbios ocorrem numa escala de décadas para séculos e, o fenômeno natural $E l$ niño, juntamente com algumas atividade de uso do solo, têm contribuído para o surgimento de distúrbios através do fogo.

Além dos efeitos dos distúrbios na composição florística e diversidade, estes afetam também a estrutura e os processos naturais do ecossistema florestal, resultando em efeitos sobre a reprodução, o crescimento e a morte das árvores.

Segundo Lugo (1995) as florestas tropicais são resilientes, isto é, são capazes de absorver mudanças e voltar ao estágio original, assim, precisam ser manejadas uma vez que evoluíram na presença de distúrbios, deste modo se uma floresta é manejada ocorrem mudanças em sua estrutura e riqueza. Todavia, as florestas absorvem estas 
mudanças bastando estabelecer práticas adequadas para conduzir a direção e magnitude das mudanças na biodiversidade.

\subsubsection{Distúrbios provocados pela queda de árvores}

Para Uhl et al, (1988) a queda de árvores formando clareiras é o principal agente de distúrbio natural nas florestas tropicais. Denslow (1987) identificou a luz como o fator mais imediato e, talvez, o mais importante efeito da abertura de clareiras. Já Fox, (1976) disse que o fenômeno de clareiras em florestas tropicais naturais estimula o crescimento de todas as espécies.

\subsubsection{Distúrbios antrópicos}

Na Amazônia brasileira, a junção de fenômeno natural (p.ex. El niño) juntamente com atividades de uso da floresta (p.ex. exploração madeireira, agricultura de corte e queima e a pecuária extensiva) são agentes causadores de distúrbios através do fogo. Apesar da floresta ter alta quantidade de água - o que dificulta a penetração do fogo - a estação seca do ano de 1983 e 1997 ocasionada pelo El niño, propiciou a entrada do fogo numa área maior que $500 \mathrm{Km}^{2}$ de floresta (para maiores detalhes ver Figueroa e Nobre, 1990).

A exploração madeireira é um dos distúrbios mais freqüentes nas florestas tropicais da Amazônia brasileira. E de acordo com a divisão de Oliver e Larson (1996), nesta atividade existem áreas onde ocorrem os distúrbios maiores, que removem todas as árvores, pátios e estradas, em menor escala, e também os distúrbios menores, área da derrubada, ramais de arraste, que ocorrem em maior escala.

Segundo Veríssimo (1992), nas florestas tropicais da região de Paragominas, Estado do Pará, as perturbações à floresta provocada pela exploração madeireira predatória são muito altos. A abertura do dossel nas áreas de exploração fica em torno de $50 \%$. Para cada árvore derrubada, cerca de 30 outras são danificadas. As grandes aberturas nas áreas florestadas aumentam a incidência de fogo (Holdwodth e Uhl, 1997). Sendo a região de Paragominas rica em cipós, as grandes aberturas criam um ambiente propício para a proliferação destes. Putz (1984), estudando cipós na Malásia, observou 
uma proliferação maciça nas grandes aberturas provocadas pela retirada de madeira. No entanto, em Paragominas, Johns et al. (1996) conseguiu mostrar que os impactos da exploração madeireira ao ecossistema podem ser largamente diminuído. Esses autores estudando de forma comparativa os danos em exploração predatória e com uso de técnicas de manejo, concluíram que os danos ecológicos à estrutura da floresta podem ser diminuídos em $30 \%$.

\subsubsection{Distúrbios e diversidade das espécies}

Para efeito de esclarecimento, especialmente nesta dissertação, será tratada a diversidade somente das árvores acima de $10 \mathrm{~cm}$ de DAP. Não por se achar irrelevante a diversidade dos indivíduos abaixo desse tamanho e, sim, para demonstrar que existe também diferença na diversidade das espécies acima de $10 \mathrm{~cm}$ de DAP, especialmente quando essas áreas são submetidas à intervenção com exploração madeireira.

Segundo Gajaseni e Boonpragob (1995) existem numerosas definições de diversidade: diversidade de espécies, diversidade genética e diversidade ao nível do ecossistema. Estudar-se-á nesta dissertação a diversidade de espécies.

Segundo Denslow (1995), o efeito imediato da morte natural de árvores diminui localmente a densidade e aumenta a disponibilidade de recursos, o que resulta na liberação de plantas suprimidas e germinação de sementes em estoque no solo. Assim, densidade e diversidade aumentam de acordo com disponibilidade de recursos. Portanto, clareiras também podem promover sítios de estabelecimentos raros, o que aumenta a diversidade da regeneração além daquela esperada pelo efeito apenas da densidade. Se a morte for de árvores suprimidas, ocorre redução na densidade de árvores, sem necessariamente aumentar a diversidade, por não haver aumento da disponibilidade de luz para as árvores menores. Isso é importante porque as árvores pequenas mostram maior taxa de mortalidade por supressão do que as árvores maiores, e o risco de extinção por esta fonte de mortalidade é maior para espécies raras do que para as comuns.

De modo geral, os distúrbios naturais, principalmente a queda de árvores, apresentam um papel importante na manutenção da diversidade de espécies em florestas tropicais úmidas (Denslow, 1995). 


\subsubsection{Diversidade em áreas perturbadas com atividade madeireira}

Segundo Roberts e Gillian (1995), os distúrbios são fatores essenciais para a manutenção da diversidade de espécies e são de suma importância para o manejo florestal, uma vez que as atividades de manejo nada mais são que distúrbios aplicados sob diferentes formas e intensidade.

Um estudo recente de Martini et al. (1994), avaliando o impacto da atividade madeireira sobre 'as espécies preconiza como sendo três os principais impactos: (i) eliminação dos indivíduos de grande porte, os quais são importantes para a produção de sementes, (ii) danos aos indivíduos jovens durante a exploração, causando prejuízo ao estoque remanescente e, dessa forma, reduzindo a população de certa espécie e, finalmente, (iii) a abertura do dossel cria condições para a entrada do fogo na floresta, comprometendo espécies menos resistentes ao fogo. Nesta pesquisa, avaliou-se características biológicas de 305 espécies madeireiras através de um sistema de pontuação. Das 305 espécies avaliadas, 47 podem manter e talvez aumentar sua população através da atividade madeireira, 217 são capazes de resistir à pressão da exploração e 41 são potencialmente ameaçadas pela exploração.

As recomendações desse estudo para o manejo florestal são: (i) controlar a retirada de madeira das espécies potencialmente ameaçadas, até que existam dados suficientes para os seus monitoramentos, (ii) delimitar áreas de proteção para manter as populações das espécies madeireiras e, (iii) caso se confirme perdas genéticas, iniciar urgentemente a criação de um banco de germoplasma de indivíduos selecionados destas, para assegurar a preservação das características biológicas dessas espécies.

\subsubsection{Distúrbios e crescimento das árvores}

Os fatores necessários para o crescimento das árvores são: luz, água, certos nutrientes minerais, temperaturas adequadas, oxigênio e dióxido de carbono. Para o crescimento das espécies em clima e em solo apropriado, é possível que mais de um fator é necessários para aumentar o crescimento em tamanho e em número de indivíduos (Oliver e Larson, 1990). 
$\mathrm{O}$ crescimento em diâmetro das árvores, geralmente aumenta em árvores que sobreviveram à um pequeno distúrbio, todavia este aumento pode não ser imediato se ocorrer choque fisiológico (p.ex. mudança drástica de iluminação na copa) no crescimento provocado por quebra de galhos ou raízes, reduzindo assim o espaço de crescimento ocupado sob diferentes condições, isso poderá causar um declínio temporário de crescimento (Oliver e Larson, 1990).

\subsubsection{Crescimento das árvores em condições naturais nas diferentes regiões}

\section{de florestas tropicais}

Há vários estudos documentando taxa de crescimento nas florestas tropicais, com seu regime natural de queda de árvores por mortalidade. A tabela 1 menciona os principais estudos realizados em florestas tropicais, tanto de crescimento em floresta natural como em florestas manejadas.

Malásia - Em Sarawak, ao longo de 2 anos, Hutchinson (1987) acompanhou o crescimento diamétrico de espécies comerciais nas florestas naturais de dipterocarpaceas. Este encontrou ainda um crescimento diamétrico anual de 0,3 cm (Tabela 1).

Indonésia - Miller (1981) encontrou um crescimento médio de $0,5 \mathrm{~cm} /$ ano nas florestas de dipterocarpaceas, para todas as espécies, num período de 6 anos.

América Latina - DeGraaf (1986), pesquisando na região de Tonka, no Suriname, observou que, por um período de 2 anos, as espécies madeireiras em florestas naturais cresciam num intervalo de 0,1 à $0,4 \mathrm{~cm} /$ ano. Nas florestas naturais de Porto Rico, região de Cambalache, Weaver (1989) encontrou durante um período de 26 anos, um crescimento de $0,1 \mathrm{~cm} /$ ano para todas as espécies (Tabela 1).

Brasil - Na Amazônia brasileira, De Carvalho (1992) verificou o crescimento durante 8 anos na Floresta Nacional do Tapajós - Santarém/PA, encontrando uma média de $0,2 \mathrm{~cm} /$ ano para todas as espécies e Higuchi et al. (1997) na região de Manaus, analisou no período de 9 anos o crescimento das árvores em floresta natural de 0,17 $\mathrm{cm} /$ ano (Tabela 1). 


\subsubsection{Crescimento das árvores nas áreas perturbadas com atividade} madeireira

É de se esperar um bom crescimento das árvores após exploração madeireira, onde pode-se encontrar a formação de várias clareiras. No entanto, se não forem usadas técnicas de manejo apropriadas, as clareiras podem ser relativamente grandes e, neste caso, poderá surgir uma grande proliferação de espécies pioneiras sem valor madeireiro e de cipós que competirão com as espécies arbóreas.

A atividade de manejo da floresta pode aumentar ou diminuir o crescimento total das árvores na área, todavia a colheita de madeira pode reduzir o crescimento total quando ocorre danos severos nas árvores e na estrutura do solo, ou pode ainda ocorrer a redução de nutrientes (Oliver e Larson, 1990).

$\mathrm{Na}$ atividade de manejo florestal para produção de madeira, o corte de cipós realizado antes da colheita, para minimizar os danos que causam durante a derrubada das árvores, pode ser uma grande fonte de nutrientes, pois estes cipós serão depositados na superfície da floresta (liteira), onde irão se decompor.

A seguir, enumera-se o crescimento das árvores após as perturbações oriundas de exploração madeireira nas várias regiões de florestas tropicais do mundo, e em diversos tipos de sistemas silviculturais.

Ásia - Na Malásia Peninsular o crescimento diamétrico das espécies de valor comercial em sistema de manejo seletivo foi de $0,8-1,0 \mathrm{~cm}$ ao ano ou 2,0-2,5 $\mathrm{m}^{3} / \mathrm{ano}$, durante o período de 4 anos. Nesse sistema de manejo, o limite mínimo de corte ficava na faixa de 45 a $50 \mathrm{~cm}$ de diâmetro, deixando-se em torno de 32 árvores com DAP entre $30-45 \mathrm{~cm}$ por hectare com boas características. O sistema silvicultural a adotar era decidido mediante resultado de inventário pós-exploratório. (Abdul Rashid, 1983; Tang, 1987; Silva, 1989).

Em Sarawak foi aplicado o sistema malaio modificado em florestas pantanosas. Este sistema priorizava a liberação, não somente das mudas, mas também da regeneração avançada, e consistia de um ano após a exploração realizar refinamentos com o objetivo de aumentar as taxas de crescimento das espécies comerciais, e eliminação das árvores acima de $20 \mathrm{~cm}$ que estavam danificadas. Era feito um inventário 
10 anos após a exploração para avaliar a necessidade de outro tratamento. O sistema sofreu modificações a partir de 1974 com a adoção de desbaste de liberação. Com as modificações esse sistema seguiu o seguinte cronograma: corte das árvores com DAP acima de $60 \mathrm{~cm}$, um ano após desbaste de liberação, e o ciclo de corte estipulado foi de 30 anos (Hutchinson, 1981; Silva, 1993). Nas florestas que foram exploradas sem tratamentos silviculturais, o incremento foi de $0,6 \mathrm{~cm} /$ ano (Bryan, 1981), já nas florestas com retirada de madeira comercial e desbaste, o crescimento diamétrico foi de 0,7 $\mathrm{cm} /$ ano (Tabela 1).

África - Na Nigéria, foi testado o sistema tropical "shelterwood"; ele consistia na exploração de 5 árvores por hectare com um DAP acima de $80 \mathrm{~cm}$, removendo-se 20 $\mathrm{m}^{3} / \mathrm{ha}$. Após essa exploração, eram realizados tratamentos silviculturais de envenenamento e corte de cipós repetidos durante um período de 8 anos (Lowe, 1978). $\mathrm{O}$ crescimento diamétrico verificado foi de $0,6 \mathrm{~cm} /$ ano para um período de 5 anos de monitoramento (Mevart, 1974). Dentre as inúmeras dificuldades desse sistema, os pesados tratamentos facilitaram o crescimento de espécies pioneiras e de cipós, com baixa proporção de espécies de valor na regeneração. Como este sistema necessitava de áreas extensas com o objetivo de favorecer o crescimento da regeneração. As dificuldades para fiscalizar o trabalho nas extensas áreas foi muito dificil (Silva, 1993).

Em Ghana, as árvores cresceram em diâmetro o equivalente a $0,6 \mathrm{~cm} / \mathrm{ano}$, para um período de 6 anos de acompanhamento (OSAFO, 1970). O sistema testado foi "shelterwood" modificado, que consistia em mapear, em compartimentos de 128 ha, todas as espécies comerciais com CAP acima de $65 \mathrm{~m}$. Os cipós e árvores sem valor eram eliminadas após a exploração para liberar as espécies comerciais com CAP entre 10 e $45 \mathrm{~m}$. Removiam-se $53 \mathrm{~m}^{3} / \mathrm{ha}$ (Tabela 1).

América Latina - No Suriname, com o emprego do Sistema Silvicultural CELOS, o crescimento em diâmetro nas áreas manejadas com o emprego de tratamentos silviculturais foi de 0,6 a 1,0 cm/ano. DeGraaf, (1986) e Jonkers, (1987), observaram que quando foi realizado um tratamento silvicultural através de refinamento, o incremento médio anual no DAP das árvores aumentou de 4 a $42 \%$. Neste sistema, recomendava-se a retirada de $20 \mathrm{~m}^{3} /$ ha das espécies de maior valor comercial, seguido 
de desbastes com um ciclo de corte de 20-25 anos. Recomenda-se três refinamentos, sendo o primeiro 2 anos após a exploração para promover o aparecimento de espécies de valor comercial madeireiro, o segundo realizado no oitavo ano, com objetivo de melhorar o crescimento das espécies de valor madeireiro e o terceiro, que é basicamente um corte de cipós, é realizado poucos anos antes do segundo corte, de 20-25 anos (Tabela 1).

Brasil - Pesquisas silviculturais com monitoramento do crescimento da floresta na Amazônia começaram no início da década de 70 , todavia somente análises preliminares foram realizadas (Silva et al., 1995).

Infelizmente o estudo mais antigo de intervenção da floresta tropical na Amazônia brasileira, realizada pelo Governo Brasileiro e a Organização para Alimentação e Agricultura das Nações Unidas (FAO), teve problemas de continuidade, o que dificultou a análise do comportamento da floresta após a intervenção (Dubois, 1971).

$\mathrm{Na}$ década de 70, o antigo IBDF/PRODEPEF iniciou uma pesquisa com intervenção da floresta tropical, ampliada em seguida pelo CPATU/Embrapa. Esta intervenção consistiu da retirada de $40 \mathrm{~m}^{3} / \mathrm{ha}$, seguindo os procedimentos de mapeamento das árvores, derrubada direcional e desbaste das espécies sem valor que estavam competindo com as remanescentes, 1 ano após a intervenção. $O$ crescimento das espécies comerciais e de todas as espécies após 6 anos foi de $0,5 \mathrm{~cm} /$ ano (Tabela 1). Foi observado uma grande variação no crescimento em DAP das espécies (Silva, 1989; Silva, 1993). Esta grande variação é explicada pela presença de vários fatores em operação, como fatores ambientais da própria árvore (posição em relação à luz) e fatores genéticos. As espécies sem valor madeireiro que mais cresceram foram Cecropia leucoma e Cecropia sciadophylla com 1,4 e 2,1 cm/ano, respectivamente (Silva, 1993).

A partir de 1987, o Instituto de Pesquisas da Amazônia (INPA), através do Projeto Bionte, iniciou várias estudos na Amazônia Central relacionados as implicações da exploração madeireira predatória sobre a ecologia e manejo florestal. Esses estudos consistiram na retirada gradativa da área basal da floresta, sendo 4 tratamentos: (i) sem remoção de área basal (testemunha), (ii) remoção de $25 \%$ de área basal, (iii) remoção de 
$50 \%$ de área basal e (iv) remoção de $75 \%$ de área basal. Houve um incremento volumétrico da floresta como um todo a partir do quarto ano após o corte, quando a taxa de recrutamento se igualou a de mortalidade. $\mathrm{O}$ crescimento das espécies comerciais nestes estudos foram, para testemunha de $0,17 \mathrm{~cm} / \mathrm{ano}$, remoção de $25 \%$ de área basal, $0,31 \mathrm{~cm} / \mathrm{ano}$, remoção de $50 \%$ de área basal, $0,29 \mathrm{~cm} /$ ano e remoção de $75 \%$ de área basal, 0,30 cm/ano (Tabela 1).

Em Paragominas, na Amazônia Oriental, Barreto et al. (1994) observaram que o crescimento de árvores sem cipós e danos foi o dobro das árvores com cipós e danos, 0,32 e $0,6 \mathrm{~cm}$, respectivamente, para um período de 2 anos após exploração madeireira(Tabela 1). 
Tabela 1: Taxa de crescimento nas florestas naturais e com intervenção nas principais florestas tropicais.

\begin{tabular}{|c|c|c|c|c|c|c|c|}
\hline Local & Grupo de espécies & Tipo de floresta & $\begin{array}{l}\text { Sistema de } \\
\text { exploração }\end{array}$ & $\begin{array}{l}I P A \\
(\mathrm{~cm})\end{array}$ & $\begin{array}{c}\text { Periodo de } \\
\text { monitoramento }\end{array}$ & $\begin{array}{c}\text { Intensidade } \\
\text { de } \\
\text { exploração }\end{array}$ & Autores \\
\hline \multicolumn{8}{|l|}{ Ásia } \\
\hline Malásia & Dipterocarpacea & $\begin{array}{l}\text { Floresta de } \\
\text { planícies }\end{array}$ & $\begin{array}{l}\text { Manejo } \\
\text { seletivo }\end{array}$ & $\begin{array}{l}0,80- \\
1,00 \\
\end{array}$ & 4 anos & $\begin{array}{c}60-150 \\
\mathrm{~m}^{3} / \mathrm{ha} \\
\end{array}$ & $\begin{array}{l}\text { Abdul Rashid } \\
\text { (1983); }\end{array}$ \\
\hline Malásia & Dipterocarpacea & De colinas & $\begin{array}{l}\text { Manejo } \\
\text { seletivo }\end{array}$ & 0,50 & 1 ano & $\begin{array}{c}60-150 \\
\mathrm{~m}^{3} / \mathrm{ha} \\
\end{array}$ & Tang (1987) \\
\hline Indonésia & Todas as espécies & Dipterocarpacea & $\begin{array}{c}\text { Floresta } \\
\text { natural }\end{array}$ & 0,50 & 6 anos & - & $\begin{array}{l}\text { Miller (1981); } \\
\text { Johson } \\
\text { Dyckstra } \\
(1978)\end{array}$ \\
\hline Sarawak & Todas as espécies & $\begin{array}{c}\text { Floresta } \\
\text { montanhosa }\end{array}$ & $\begin{array}{c}\text { Malaio } \\
\text { modificado }\end{array}$ & 0,60 & 4 anos & $10-50 \mathrm{~m}^{3} / \mathrm{ha}$ & Bryan (1981) \\
\hline Sarawak & Comercial & $\begin{array}{c}\text { Floresta } \\
\text { montanhosa }\end{array}$ & $\begin{array}{l}\text { Exploração } \\
\text { madeireira } \\
\text { + desbaste }\end{array}$ & 0,70 & 2 anos & $\begin{array}{c}11,8-127,6 \\
\mathrm{~m}^{3} / \mathrm{ha}\end{array}$ & $\begin{array}{l}\text { Hutchinson } \\
\text { (1987) }\end{array}$ \\
\hline Sarawak & Comercial & $\begin{array}{c}\text { Floresta } \\
\text { montanhosa }\end{array}$ & $\begin{array}{c}\begin{array}{c}\text { Floresta } \\
\text { natural }\end{array} \\
\end{array}$ & 0,30 & 2 anos & - & \begin{tabular}{|l|}
$\begin{array}{l}\text { Hutchinson } \\
(1987)\end{array}$ \\
\end{tabular} \\
\hline \multicolumn{8}{|l|}{ África } \\
\hline Ghana & Comercial & $\begin{array}{c}\text { Floresta de } \\
\text { Celtis }\end{array}$ & $\begin{array}{c}\text { Tropical de } \\
\text { cobertura } \\
\text { modificado }\end{array}$ & 0,60 & 6 anos & $53 \mathrm{~m}^{3} / \mathrm{ha}$ & Osafo (1970) \\
\hline Nigéria & Comercial & Floresta alta & $\begin{array}{c}\text { Sistema } \\
\text { tropical de } \\
\text { cobertura }\end{array}$ & 0,60 & 5 anos & $20 \mathrm{~m}^{3} / \mathrm{ha}$ & $\begin{array}{l}\text { Mevart } \\
\text { (1974); Lowe } \\
(1984)\end{array}$ \\
\hline \multicolumn{8}{|l|}{ América Latina } \\
\hline $\begin{array}{l}\text { Porto Rico } \\
\text { - Cambalache }\end{array}$ & Todas as espécie & - & $\begin{array}{c}\text { Floresta } \\
\text { natural }\end{array}$ & 0,10 & 26 anos & - & $\begin{array}{l}\text { Weaver } \\
\text { (1979) }\end{array}$ \\
\hline Suriname & Comercial & Tropical alta & CELOS & $\begin{array}{l}0,60- \\
1,00\end{array}$ & 2 anos & $20 \mathrm{~m}^{3} / \mathrm{ha}$ & \begin{tabular}{|l|}
$\begin{array}{l}\text { DeGraaf } \\
(1986)\end{array}$ \\
\end{tabular} \\
\hline $\begin{array}{l}\text { Suriname } \\
\text {-Tonka }\end{array}$ & Comerciais & Floresta alta & $\begin{array}{c}\text { Floresta } \\
\text { natural }\end{array}$ & 0,40 & 2 anos & - & $\begin{array}{l}\text { Jonkers } \\
\text { (1987); De } \\
\text { Graaf (1991) }\end{array}$ \\
\hline $\begin{array}{l}\text { Brasil } \\
\text { - Santarém } \\
\end{array}$ & Todas as espécie & $\begin{array}{c}\text { Amazônica } \\
\text { brasileira }\end{array}$ & $\begin{array}{c}\text { Floresta } \\
\text { natural }\end{array}$ & 0,20 & 8 anos & $40 \mathrm{~m}^{3} / \mathrm{ha}$ & $\begin{array}{l}\text { De Carvalho } \\
(1992)\end{array}$ \\
\hline - Santarém & Todas as espécies & $\begin{array}{c}\text { Amazônica } \\
\text { brasileira }\end{array}$ & $\begin{array}{l}\text { Manejo } \\
\text { seletivo }\end{array}$ & 0,40 & 8 anos & $40 \mathrm{~m}^{3} / \mathrm{ha}$ & \begin{tabular}{|l|} 
De Carvalho \\
$(1992)$
\end{tabular} \\
\hline - Paragominas & Comerciais & $\begin{array}{c}\text { Amazônica } \\
\text { brasileira }\end{array}$ & $\begin{array}{l}\text { Exploração } \\
\text { madeireira } \\
\text { predatória }\end{array}$ & 0,32 & 2 anos & $38 \mathrm{~m}^{3} / \mathrm{ha}$ & $\begin{array}{l}\text { Barreto et al., } \\
\text { (1993) }\end{array}$ \\
\hline - Paragominas & Comerciais & $\begin{array}{c}\text { Amazônica } \\
\text { brasileira }\end{array}$ & $\begin{array}{c}\text { Exploração } \\
\text { madeireira } \\
\text { predatória }+ \\
\text { corte de } \\
\text { cipós }\end{array}$ & 0,60 & 2 anos & $38 \mathrm{~m}^{3} / \mathrm{ha}$ & $\begin{array}{l}\text { Barreto et al. } \\
\text { (1993) }\end{array}$ \\
\hline - Santarém & Comerciais & $\begin{array}{c}\text { Amazônica } \\
\text { brasileira }\end{array}$ & $\begin{array}{l}\text { Manejo } \\
\text { seletivo }\end{array}$ & 0,40 & 11 anos & $40 \mathrm{~m}^{3} / \mathrm{ha}$ & \begin{tabular}{|l}
$\begin{array}{l}\text { Silva et al. } \\
(1995)\end{array}$ \\
\end{tabular} \\
\hline - Santarém & Todas as espécies & $\begin{array}{c}\text { Amazônica } \\
\text { brasileira }\end{array}$ & $\begin{array}{l}\text { Manejo } \\
\text { seletivo }\end{array}$ & 0,30 & 11 anos & $40 \mathrm{~m}^{3} / \mathrm{ha}$ & $\begin{array}{l}\text { Silva et al. } \\
(1995)\end{array}$ \\
\hline - Manaus & Comerciais & $\begin{array}{c}\text { Amazônica } \\
\text { brasileira }\end{array}$ & $\begin{array}{c}\text { Floresta } \\
\text { natural }\end{array}$ & 0,17 & 9 anos & - & $\begin{array}{l}\text { Higuchi et al. } \\
\text { (1997) }\end{array}$ \\
\hline - Manaus & Comerciais & $\begin{array}{c}\text { Amazônica } \\
\text { brasileira }\end{array}$ & $\begin{array}{l}\text { Exploração } \\
\text { predatória }\end{array}$ & 0,31 & 9 anos & $\begin{array}{c}\text { Remoção de } \\
25 \% \text { área } \\
\text { basal }\end{array}$ & $\begin{array}{l}\text { Higuchi et al. } \\
\text { (1997) }\end{array}$ \\
\hline - Manaus & Comerciais & $\begin{array}{c}\text { Amazônica } \\
\text { brasileira }\end{array}$ & $\begin{array}{l}\text { Exploração } \\
\text { predatória }\end{array}$ & 0,29 & 9 anos & $\begin{array}{c}\text { Remoção de } \\
50 \% \text { área } \\
\text { basal }\end{array}$ & $\begin{array}{l}\text { Higuchi et al. } \\
\text { (1997) }\end{array}$ \\
\hline - Manaus & Comerciais & $\begin{array}{c}\text { Amazônica } \\
\text { brasileira }\end{array}$ & $\begin{array}{l}\text { Exploração } \\
\text { predatória }\end{array}$ & 0,30 & 9 anos & $\begin{array}{c}\text { Remoção de } \\
75 \% \text { área } \\
\text { basal }\end{array}$ & $\begin{array}{l}\text { Higuchi et al. } \\
\text { (1997) }\end{array}$ \\
\hline
\end{tabular}




\title{
CAPÍTULO 3
}

\section{CRESCIMENTO DE FLORESTA TROPICAL APÓS TRÊS ANOS DE EXPLORAÇÃO MADEIREIRA PREDATÓRIA PLANEJADA NA AMAZÔNIA ORIENTAL*}

\section{GROWTH OF A TROPICAL RAIN FOREST IN EASTERN AMAZONIA THREE YEARS AFTER UNPLANNED AND PLANNED LOGGING}

\author{
E. Vidal ${ }^{1,2}$, V. M. Viana ${ }^{3}$, J.L.F. Batista ${ }^{3}$ \\ ${ }^{1}$ Mestrando da ESALQ/USP. \\ ${ }^{2}$ Pesquisador do IMAZON - Instituto do Homem e do Meio Ambiente da Amazônia, \\ Caixa Postal 1015, Belém-Pará, Brasil \\ ${ }^{3}$ Professor da ESALQ/USP, Departamento Ciências Florestais, Av. Pádua Dias, 11, \\ Piracicaba, SP, 13418-900, Brasil. \\ * artigo submetido à Revista Scentia Forestales.
}

\subsection{RESUMO}

Avaliou-se o comportamento da floresta em relação ao crescimento em DAP das árvores após a exploração madeireira predatória planejada em Paragominas $\left(3^{\circ} \mathrm{S}, 50^{\circ}\right.$ W), na Amazônia Oriental.

O experimento foi realizado numa área de 210 hectares, sendo 75 ha com exploração predatória, 105 ha com colheita planejada e 30 ha como área testemunha. A exploração predatória consistiu do seguinte: após definida a área, uma equipe de motosserristas entrou na floresta e derrubou as árvores, sem o conhecimento prévio de sua localização, pois não se conduziu o mapeamento e o censo das árvores. Em seguida, 
se construiu as estradas e os pátios de estocagem, de onde as toras serão transportadas até a serraria. Finalmente, os operadores das máquinas saem à procura das árvores. Por não terem a localização das árvores derrubadas, o arraste das toras ocasiona muitos danos e desperdícios de madeira. $\mathrm{Na}$ colheita planejada foi empregado o planejamento das atividades com as seguintes medidas: censo das árvores de valor madeireiro com DAP maior que $25 \mathrm{~cm}$; preparação de um mapa de colheita com traçado de estradas, ramais de arraste e localização de pátios de estocagem; uso da derrubada direcional; corte de cipós 1,5 anos antes da colheita; arraste feito com tratores florestais com guincho e torre.

A exploração predatória e a colheita planejada aconteceram no ano de 1993, e os tratamentos foram monitorados até 1996, sendo realizadas medições anuais de DAP, mortalidade e sanidade das árvores. Avaliou-se ainda o comportamento da floresta em relação ao crescimento em DAP das árvores.

A colheita de madeira levou a uma redução em área basal de $31 \%$ na exploração predatória, enquanto que na planejada a redução foi de apenas $17 \%$. O crescimento em área basal na colheita planejada foi $50 \%$ superior ao crescimento da exploração predatória. $\mathrm{O}$ incremento médio anual para todas as espécies na área com colheita planejada foi o dobro da testemunha e 1,5 superior ao da exploração predatória. As árvores sem cipós na copa cresceram o triplo das que tinham cipós na copa, e as árvores com danos tiveram crescimento inferior das sem danos. No crescimento por espécie, destaca-se a Parkia gigantocarpa com um incremento de $1,4 \mathrm{~cm} / \mathrm{ano}^{-1}$. A espécie que menos cresceu foi a Lecythis lurida, com um incremento de $0,14 \mathrm{~cm} / \mathrm{ano}^{-1}$ nos três anos de coleta de dados.

Este estudo demonstra uma vantagem do emprego de manejo florestal para a produção de madeira na Amazônia. Se o crescimento das árvores continuar neste ritmo haverá uma diminuição de tempo para o segundo corte de madeira na área.

Os benefícios da exploração com manejo florestal são evidentes. Todavia, a forma mais comum de exploração de madeira em toda a Amazônia brasileira é a predatória. Esse fato reforça a necessidade de políticas públicas voltadas para o apoio à adoção de manejo florestal. 


\subsection{ABSTRACT}

This chapter evaluates the impacts of planned and unplanned logging on tree diameter growth in a tropical forest near the town of Paragominas $\left(3^{\circ} \mathrm{S}, 50^{\circ} \mathrm{W}\right)$, in eastern Amazonia. The study area included 210 ha of forest of which 105 ha was subjected to planned logging, 75 ha to unplanned logging, and 30 ha was left as an unlogged control.

Unplanned logging consisted of a chainsawyer who walked through the forest felling trees as he encountered them. This step was followed by the construction of logging roads and logs landings. Finally, bulldozer operators drove into the forest in search of felled logs that they transported to the log landings. Because the tractor drivers were working without knowledge as to the locations of the felled trees, the process of transporting the logs to the landings resulted in much damage to the remaining stand. Planned logging included the following modifications to the unplanned scenario: an initial census of all trees $>25 \mathrm{~cm}$ DBH with commercial value was conducted; based on this census a map of all commercial trees was produced; the locations of all logging roads, log landings, and skid trails was located on this map; directional felling was employed; all lianas were cut 1.5 years prior to logging; and extraction was conducted using a rubber-tired forest tractor with a winch.

All logging occurred during 1993 and tree diameter increment, mortality, and recruitment were monitored until 1996. During this period, the planned logging area showed a $50 \%$ greater increase in basal area than the unplanned logging area. Also in the planned logging area, mean annual diameter increment averaged over all species was twice that of the control area and 1.5 times that of the unplanned logging area. Timber extraction resulted in a decrease in total basal area of $31 \%$ in the unplanned logging area and $17 \%$ in the planned. Trees without lianas in their crowns grew an average of three times as much as trees with lianas and damaged trees generally grew less than undamaged trees. The fastest growing species was Parkia gigantocarpa with a mean annual diameter increment of $1.4 \mathrm{~cm}$; the slowest growing species, Lecythis lurida, averaged only $0.14 \mathrm{~cm}$ of diameter growth per year. 
This study demonstrates that planned logging can result in increased annual diameter increments in the remaining forest when compared to unplanned logging. This, in turn, can result in shorter cutting cycles. Although the benefits of planned logging are abundant, unplanned logging continues to be the norm. This fact reinforces the idea that public policies are needed that support the adoption of planned logging practices.

Palavras chaves: Amazônia; floresta de terra firme; crescimento de árvores; exploração de madeira; silvicultura tropical; manejo florestal.

Key words: Amazon rain forest; terra firme forest; logging; tropical silviculture; tree yield and growth; forest management.

\subsection{INTRODUÇÃO}

Nas últimas décadas, a atividade madeireira na Amazônia vem ocupando lugar de destaque na produção nacional. Até meados dos anos 70 , o volume extraído era modesto. Entretanto, nos anos 90 a região assumiu a liderança na produção de madeira no país, principalmente por causa da exaustão das florestas de outras regiões do Brasil e países como Malásia e Tailândia, na Ásia (Lisboa, et al. 1991; Prado, 1995). Atualmente a Amazônia produz cerca de 25 milhões de metros cúbicos de madeira em tora, o que equivale a $80 \%$ da produção do país (IBGE, 1992; Veríssimo e Amaral, 1996).

No Pará, o setor já contribuiu com $13 \%$ do PIB do Estado com projeções de crescimento em torno de $10 \%$ ao ano (Stone, 1997). Porém, a importância econômica contrasta com os grandes impactos que essa atividade causa na floresta (Veríssimo e Amaral, 1996). Numa extração típica de madeira, os danos ecológicos 'a estrutura da floresta são altos: para cada árvore derrubada, 28 com DAP maior que $10 \mathrm{~cm}$ são danificadas. Além disso o dossel da floresta é reduzido à metade criando grandes aberturas que deixam a floresta remanescente suscetível ao vento e ao fogo (Veríssimo et al., 1992; Johns et al. 1997). Com o emprego de técnicas de manejo, os danos ecológicos à estrutura da floresta, bem como os desperdícios de madeira foram reduzidos em 30\% (Johns et al. 1997; Gerwing et al. 1996; Vidal et al. 1997b); houve uma diminuição nos riscos de acidentes e incêndios; e a demanda de madeira pode ser 
atendida com o uso de apenas um terço da área que é explorada de forma predatória. Os estudos revelaram também que a exploração com manejo é cerca de $35 \%$ mais rentável (Barreto et al. no prelo). No entanto, os conhecimentos sobre o crescimento da floresta ainda são incipientes (Silva et al. 1995), especialmente o crescimento comparativo da floresta remanescente, explorada de forma predatória e o emprego de manejo florestal.

Este trabalho avalia o crescimento de árvores na floresta natural e a exploração de madeira predatória e planejada, testando a hipótese de que há diferenças significativas em termos de crescimento de árvores acima de $10 \mathrm{~cm}$ de DAP, entre áreas submetidas a exploração predatória, colheita planejada e áreas não perturbadas. Inicialmente, foi feito uma comparação por tratamento quanto à redução e crescimento em área basal, incrementos médios anuais e incrementos correntes anuais. Em seguida comparou-se o crescimento individual das árvores de acordo com algumas características, como ausência e presença de danos e cipós e tipo de iluminação da copa.

Informações detalhadas da produção florestal são fundamentais para a formulação de políticas e investimentos públicos e privados coerentes. Este estudo pretende preencher parte desta lacuna e, assim, contribuir para a formulação de políticas públicas apropriadas para o manejo florestal para a produção de madeira na Amazônia.

\subsection{LOCAL DO ESTUDO}

A região de estudo fica em Paragominas, no nordeste do Estado do Pará, entre as coordenadas $2^{0} 25^{\prime}$ e $4^{0} 09^{\prime} \mathrm{S}$ e $46^{\circ} 25^{\prime}$ e $48^{0} 54^{\prime} \mathrm{W}$. O município é drenado por duas bacias, a do rio Capim e a do rio Gurupi. O estudo fica na Fazenda Sete $\left(3^{0} \mathrm{~S}, 50^{0} \mathrm{~W}\right)$, distante $30 \mathrm{~km}$ do centro do município de Paragominas (Figura 1). 


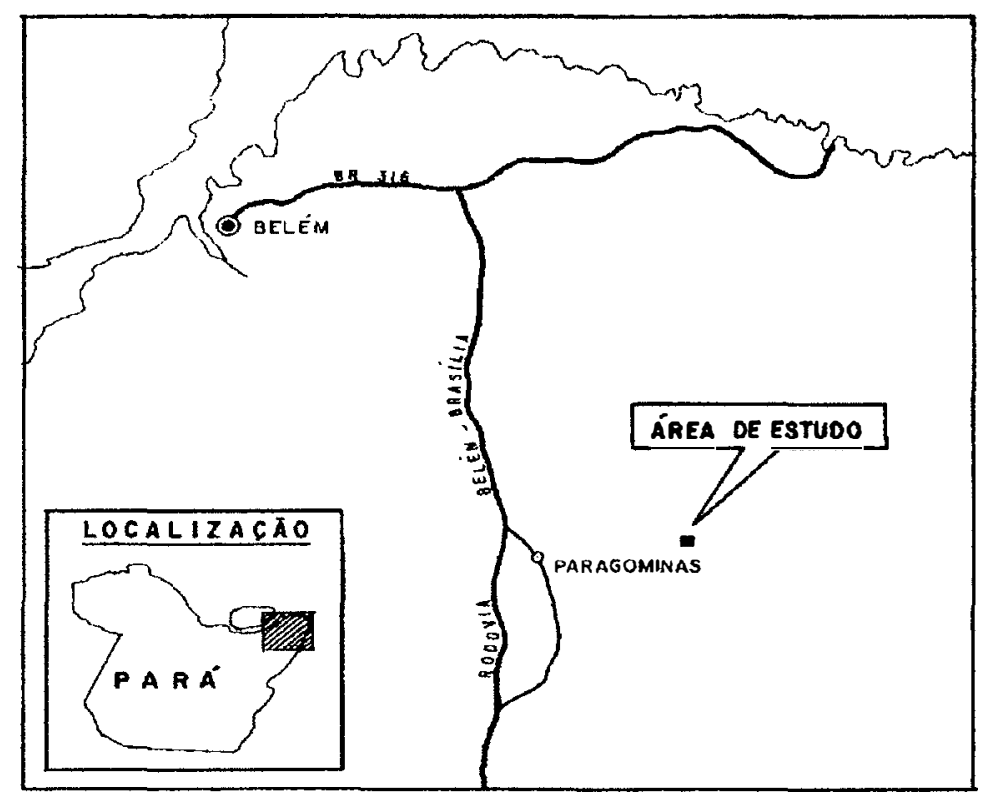

Figura 1: Localização da área de estudo.

O relevo é plano e os solos são do grupo do Latossolo Amarelo. São solos pobres, porém bem profundos. A textura vai de média a muito argilosa (Brasil, 1974).

O clima é caracterizado por um período com chuvas regulares e um período mais seco, de junho a novembro, com pluviosidade média mensal de $40 \mathrm{~mm}$. A pluviosidade média anual soma cerca de $1700 \mathrm{~mm} /$ ano e ocorre principalmente durante os meses de janeiro a maio (Embrapa/CPATU no período de 1973-1982).

As florestas da região são tropicais de terra firme, com altura do dossel variando entre 25-40 metros, com uma biomassa acima do solo de aproximadamente 300 t/ha (Uhl et al. 1989).

A floresta apresenta-se heterogênea quanto 'a estrutura, podendo ter quatro categorias distintas: floresta alta, floresta média, floresta baixa e clareira Os pontos básicos de diferenciação de uma classe para outra são a densidade e a altura das árvores e a abundância de cipós. Desta maneira, a floresta alta é a parte da floresta com árvores grandes, com altura total podendo chegar a 45 metros, e geralmente com menos cipós. A floresta média é como uma transição para a floresta baixa, com altura total de copa em 
torno de 10 a 20 metros. A floresta baixa apresenta árvores menores, com altura de no máximo 10 metros e um alto índice de cipós ((Vidal et al, 1997a; Barreto et al, no prelo). $\mathrm{E}$ as clareiras seriam qualquer abertura maior do que 25 metros quadrados, com arvoretas menores que 2 metros de altura (Brokaw, 1987). Existem, em média, quatro clareiras por hectare (Barreto et al. em preparação). Estudos preliminares indicam que o dossel das florestas na área de estudo era composto de $18 \%$ na fase de floresta alta, $46 \%$ na fase de floresta média, $28 \%$ na fase de floresta baixa e $8 \%$ na fase de clareiras (Vidal et al. $1997_{\mathrm{a}}$ ).

\subsection{MATERIAIS E MÉTODOS}

\subsubsection{Descrição dos sistemas de exploração realizados na área:}

O estudo foi realizado em uma área de 210 ha, sendo 75 ha com exploração predatória, 105 ha com colheita planejada e 30 ha como área testemunha (Figura 2). 

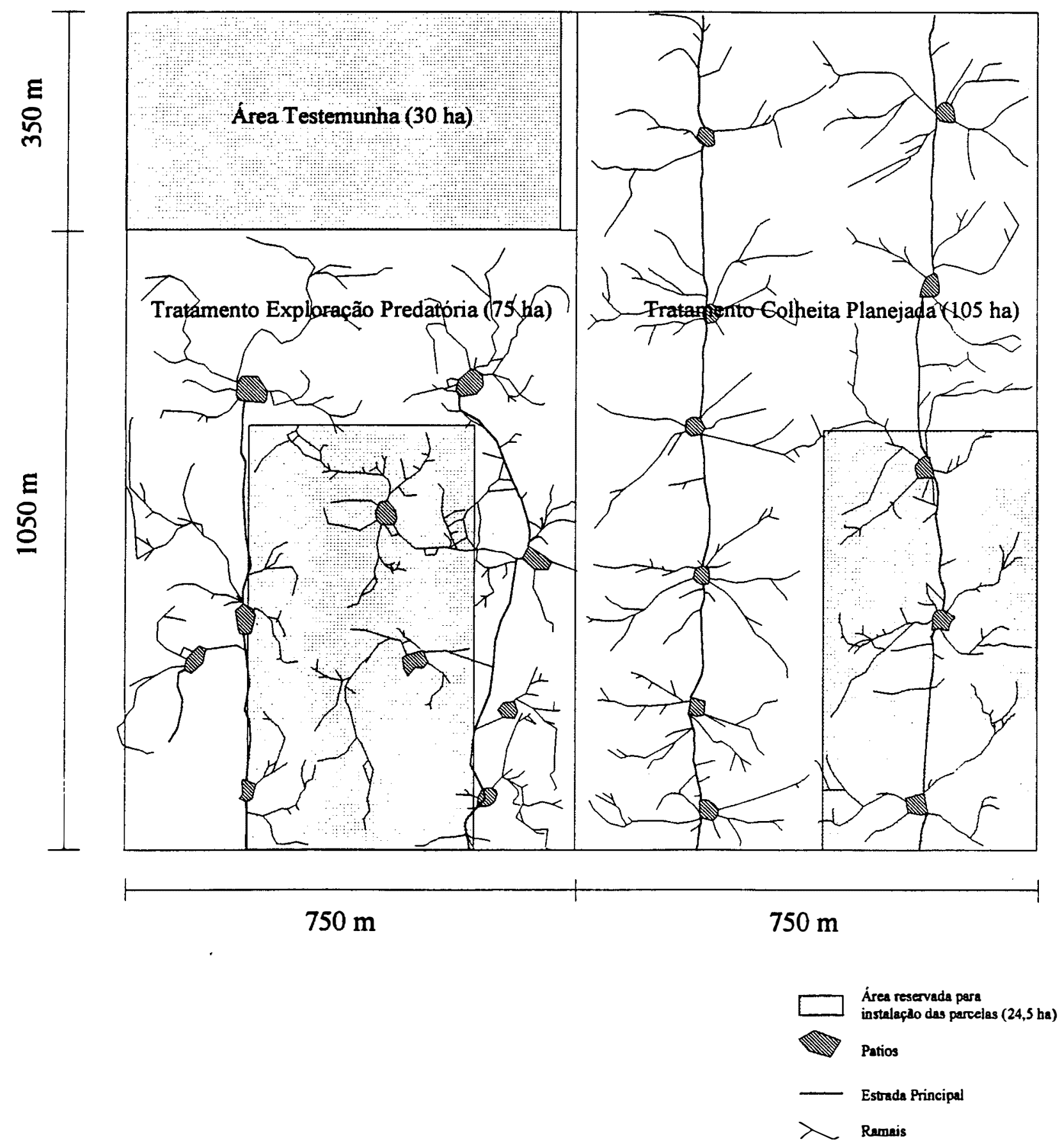

Figura 2: Mapa da área de estudo com os tratamentos aplicados e localização das áreas reservadas para instalação das parcelas. 


\subsubsection{Exploração predatória}

Este é o sistema utilizado atualmente na região de Paragominas e na maior parte da Amazônia brasileira. A exploração predatória ocorre da seguinte maneira: após definida a área de exploração anual (talhão), uma equipe de motosserristas entra na floresta e derruba as árvores sem o conhecimento prévio de sua localização, pois não conduz o mapeamento e o censo das árvores. Em seguida, constrói as estradas. Ao encontrar um aglomerado de árvores procura um local com topografia boa e com poucas árvores grandes para abrir um pátio de estocagem de madeira dentro da floresta, de onde as toras serão transportadas até as serrarias. Para finalizar, os operadores das máquinas (trator de esteira sem guincho) saem `a procura das árvores derrubadas. Por não terem a localização das árvores derrubadas, o arraste das toras ocasiona muitos danos e desperdícios de madeira na floresta.

\subsubsection{Colheita planejada}

A colheita planejada seguiu o modelo de manejo desenvolvido pelo (IMAZON) Instituo do Homem e do Meio Ambiente da Amazônia na região da Amazônia Oriental. Este modelo compreende três etapas que estão divididas em atividades antes, durante e após a exploração.

- Atividades antes da exploração florestal - Dois anos antes da exploração, a equipe entra na floresta e delimita o talhão. Em seguida, abre trilhas dentro da floresta para realizar o censo dos indivíduos $>25 \mathrm{~cm}$ de DAP. Com 1 a 2 anos antes da exploração faz-se o corte de cipós $>2 \mathrm{~cm}$ de diâmetro presentes nas árvores a serem derrubadas. E, com 3 meses antes da exploração da área, conduz-se o planejamento da exploração que compreende a delimitação das estradas principais e pátios de estocagem de madeira, bem como a seleção das árvores a serem derrubadas.

- Atividades durante a exploração florestal - Poucos dias antes da exploração, uma equipe de planejamento entra na floresta e faz a orientação da colheita. Essa equipe orienta no campo pequenas trilhas marcadas com balizas e fitas plásticas coloridas, além de confeccionar um mapa simples que é usado pela 
equipe de derrubada e pela equipe de arraste das toras. As orientações são distribuídas na abertura de estradas principais para caminhões, nos pátios de estocagem, nos ramais de arraste e na direção ideal de queda das árvores.

\subsubsection{Coleta dos dados}

Em cada sistema de exploração e na área testemunha, foi reservada uma área de 24,5 ha $(350 \times 700 \mathrm{~m})$, onde foram estabelecidas as parcelas. A localização foi de forma aleatória.

Medimos o DAP das árvores com fita diamétrica. Todas as árvores acima de 10 cm de DAP foram identificadas, localizadas através de um sistema x e y e marcadas com uma placa de alumínio. A parte inferior da placa foi o local reservado para marcar a coleta do DAP. Foram medidos também outros fatores que interferem no crescimento das árvores como: sanidade das árvores (danos no fuste, danos na copa), iluminação da copa, e presença de cipós.

\subsubsection{Monitoramento dos tratamentos}

O estabelecimento das parcelas e a exploração nas áreas foram realizadas em 1993. Os DAPs foram medidos em 1994, 1995 e 1996. As árvores medidas são espécies de valor comercial ( 20 parcelas de $0,5 \mathrm{ha}$ ) e sem valor comercial ( 21 parcelas 0,25 ha) acima de $10 \mathrm{~cm}$ de DAP.

\subsubsection{Crescimento de espécies com presença e ausência de cipós}

Classificou-se, nos tratamentos exploração predatória e colheita planejada as árvores com ausência e presença de cipós na copa. Recebiam o número "1" as árvores sem cipós conectados em suas copas e número "2" as árvores com bastante cipós em suas copas. Como no tratamento colheita planejada fora realizado o corte de cipós antes da colheita, todas as árvores não tinham cipós em suas copas. Já na exploração predatória, como não foi realizado o corte de cipós, encontrava-se árvores com e sem cipós em sua copa. Todavia, para esta análise foram incluídas apenas as árvores que apresentavam bastante cipós em suas copas. 
A seguir, para os três tratamentos juntos, analisar-se-á o crescimento das árvores de acordo com alguns de seus atributos: danos e incidência de luz. Portanto, a árvore será a unidade de pesquisa.

\subsubsection{Crescimento diamétrico de árvores por tipo de dano}

$\mathrm{O}$ crescimento das árvores com danos baseou-se na medida das árvores com DAP acima de $10 \mathrm{~cm}$ em quatro classes distintas, sendo "classe 1" sem danos, "classe 2" com danos leves, "classe 3" com danos moderados e "classe 4" com danos severos.

\subsubsection{Crescimento de árvores por tipo de iluminação da copa}

Classificou-se, dentro dos tratamentos, árvores que se mantiveram com o mesmo tipo de abertura do dossel da floresta, isto é, árvores que continuaram ao longo dos 3 anos (A) fazendo parte do dossel e recebendo luminosidade total; (B) árvores recobertas parcialmente por outra maior, recebendo luminosidade em uma das laterais ou no topo de suas copas; e (C) árvores que, ao longo deste período, estavam totalmente recobertas por outras, recebendo apenas luz difusa (Figura 3).

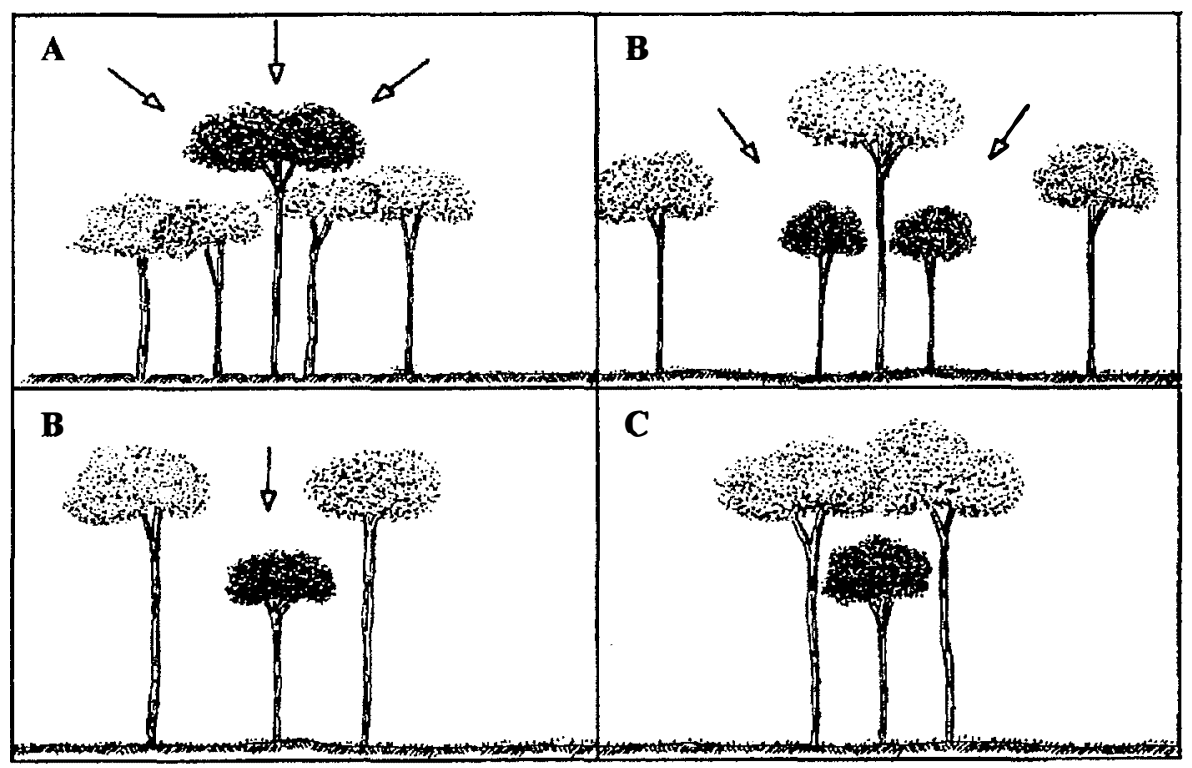

Figura 3: Tipos de iluminação da copa considerados no estudo 


\subsection{RESULTADOS E DISCUSSÃO}

As áreas basais entre os tratamentos apresentaram diferenças significativas antes da exploração $(p<0,0008)$, logo após $(p<0,042)$ e três anos após $(p<0,006)$ (Figura 5$)$.

A redução em área basal do tratamento com exploração predatória foi maior do que na colheita planejada $(\mathrm{p}<0,0001)$. A exploração predatória ocasionou perda de $31 \%$ da área basal inicial $\left(6,00 \mathrm{~m}^{2} / \mathrm{ha}\right.$ ) (Figura 5), enquanto que na colheita planejada a redução foi de apenas $17 \%$ da área basal inicial $\left(3,07 \mathrm{~m}^{2} / \mathrm{ha}\right)$. Essa perda se deve ao excesso de aberturas de estradas, derrubada de árvores sem planejamento da direção de queda, danos às árvores e desperdícios de madeira. Uma menor perda na área com colheita planejada foi possível através do planejamento da colheita e do treinamento de pessoal (Vidal et al. 1997b; Gerwing et al. 1996; Barreto et al. no prelo).

$\mathrm{O}$ incremento em área basal após três anos de monitoramento foi cerca de duas vezes superior na área com colheita planejada $\left(1,02 \mathrm{~m}^{2} / \mathrm{ha}\right)$, em relação à área com exploração predatória $\left(0,45 \mathrm{~m}^{2} / \mathrm{ha}\right.$ ) (Figura 5). Isso é explicado pelo maior número de árvores crescendo e o bom crescimento da floresta remanescente após a extração. A área basal no tratamento testemunha permaneceu estável ao longo dos 3 anos. Se o incremento médio em área basal continuar nas condições atuais, a colheita planejada recuperará a área basal perdida durante a colheita num prazo de 9 anos, enquanto que a exploração predatória precisará de pelo menos 40 anos. 


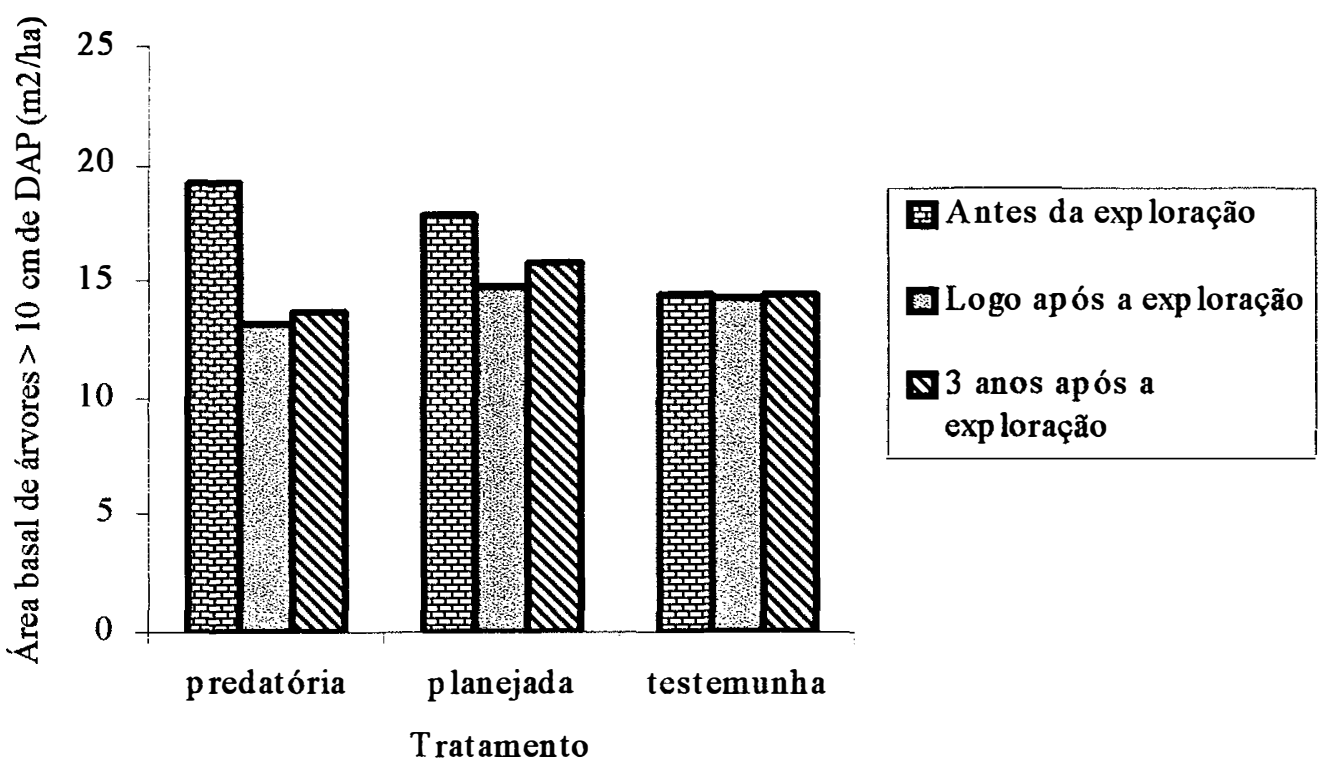

Figura 4: Área basal das árvores por tratamento (predatória, manejo) e testemunha nos períodos antes da exploração, logo após a exploração e 3 anos após a exploração na fazenda Agrosete em Paragominas, Pará-Brasil.

As árvores na área de colheita planejada apresentaram incremento médio anual em DAP $(0,63 \mathrm{~cm} / \mathrm{ano})$ quase duas vezes maior do que nos tratamentos testemunha, $(0,33 \mathrm{~cm} / \mathrm{ano})$ e com exploração predatória, $(0,37 \mathrm{~cm} / \mathrm{ano})$ (teste $t ; \mathrm{p}<0,00001)$. As árvores na área de exploração predatória tiveram incremento maior do que na área testemunha(teste $t ; \mathrm{p}<0,021$ ) (Anexo 1, Figura 4). 


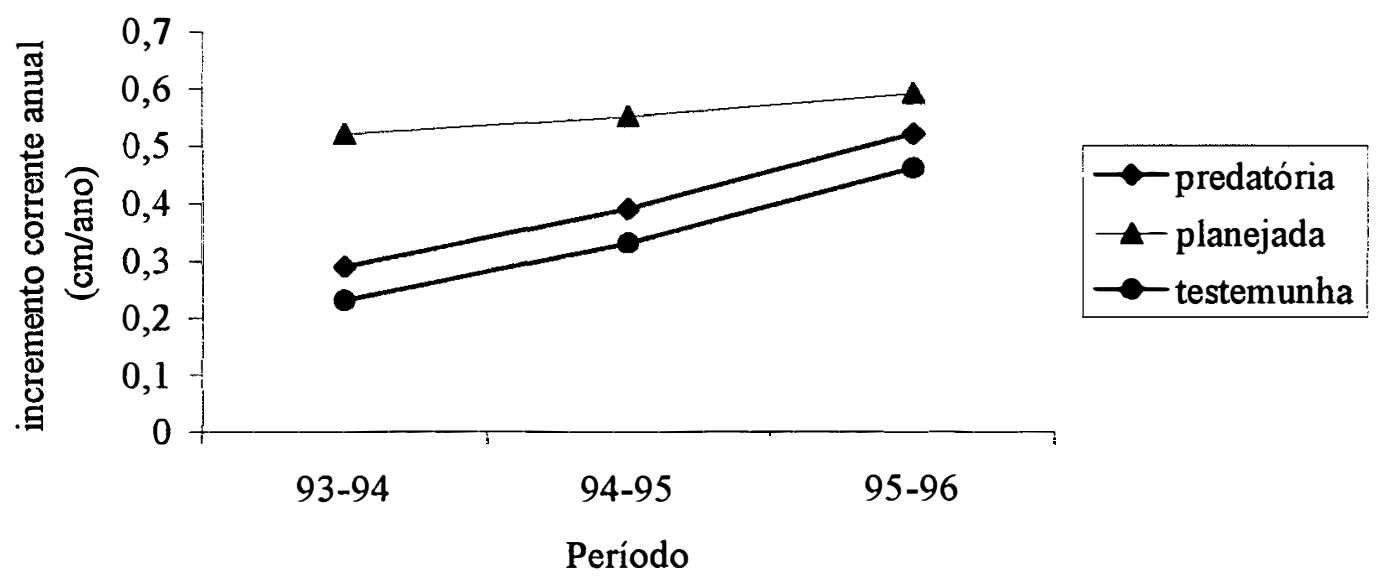

Figura 5: Incremento Corrente Anual por tratamento (predatória, manejo) e testemunha nos três períodos de medição na Fazenda Agrosete em Paragominas/Pará.

Os resultados encontrados são comparáveis aos de Higuchi et al. (1997) na Amazônia central onde as árvores na área com colheita planejada cresceram o dobro da testemunha. De Carvalho (1992), na Floresta Nacional do Tapajós, encontrou incremento igual a $0,4 \mathrm{~cm} /$ ano para área com colheita planejada e $0,2 \mathrm{~cm} /$ ano para testemunha; e De Graaf (1981) no Suriname, encontrou 0,6-1,0 cm/ano com tratamentos silviculturais e sem tratamento $0,1-0,4 \mathrm{~cm} /$ ano. $O$ aumento do incremento médio anual, na área com manejo, foi mais acentuado nas árvores com DAP entre 10-50 cm (Figura 4, Tabela 1). 


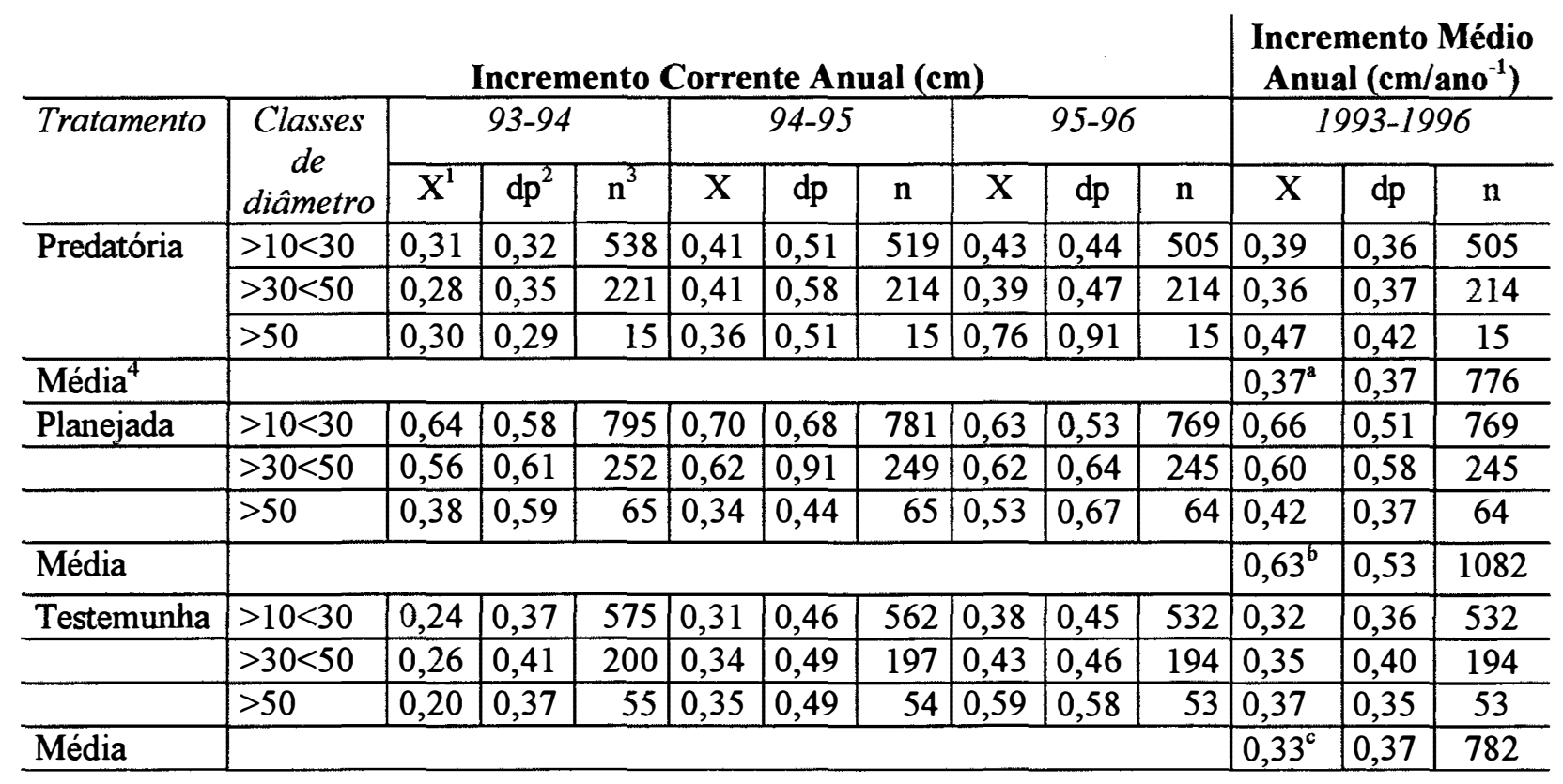

Notas:

médias que repartem letras diferentes são altamente significativas ( $t$-test, $p<0,00001$ ).

1 - média

2 - desvio padrão

${ }^{3}$ - número total de indivíduos

${ }^{4}$ - média geral incluindo todas as classes diamétrica

Tabela 1: Incremento Corrente Anual e Incremento Médio Anual de espécies de valor comercial, em cada tratamento, durante 3 anos, na fazenda Agrosete, Paragominas-Pará, Brasil.

\subsubsection{Crescimento diamétrico das árvores com presença e ausência de cipós e} de danos

Haviam cipós na copa de $36 \%$ das árvores com DAP acima de $10 \mathrm{~cm}(\mathrm{n}=2477)$. $O$ incremento médio anual das árvores sem cipós na copa foi cerca de duas vezes maior do que das árvores com cipós na copa: $0,52 \mathrm{~cm}$ e $0,23 \mathrm{~cm}$, respectivamente (t-test, $\mathrm{p}<0,00001$ ) (Tabela 2). Barreto et al. (1993) encontraram resultados semelhantes na fazenda Vitória, em Paragominas, em áreas que sofreram exploração predatória, avaliando 286 árvores com diâmetro $>20 \mathrm{~cm}$ : as árvores dominadas por cipós e com 
danos leves na copa cresceram $0,35 \mathrm{~cm} / \mathrm{ano}$, enquanto as árvores livres de cipós e danos cresceram $0,6 \mathrm{~cm} /$ ano.

A competição entre cipós e árvores também foi verificada por Putz (1984) na Malásia. Os cipós competem com luz, nutrientes e causam danos no momento da colheita das árvores. O corte de cipós é importante para a diminuição de danos no momento da colheita das árvores (Vidal et al, 1997a). Todavia, os cipós tem funções importante na natureza. Eles servem de suporte para movimentação de animais, principalmente os primatas, funcionam como verdadeiras bombas d'água na floresta, buscando água nas camadas mais profundas do solo (Reston, 1998); algumas espécies tem valor etnobotânico (Paz y Miño et al, 1995); são fundamentais para manutenção dos processos ecológicos, especialmente a viabilidade de polinização e dispersão de sementes (Putz, 1984; Peres, 1993). Sendo assim, estudos que avaliam os impactos do corte de cipós nas funções da floresta precisam ser realizados para melhorar a eficiência desta técnica, em termos de diminuição dos impactos ao ambiente florestal como um todo.

\begin{tabular}{l|lll|lll}
\hline \multirow{2}{*}{$\begin{array}{c}\text { Classes } \\
\text { diamétrica }\end{array}$} & \multicolumn{2}{|c|}{$\begin{array}{c}\text { Crescimento de árvores com cipós } \\
\text { na copa no tratamento exploração } \\
\text { predatória (cm/ano) }\end{array}$} & $\begin{array}{l}\text { Crescimento de árvores sem cipós na } \\
\text { copa no tratamento colheita planejada } \\
\text { (cm/ano) }\end{array}$ \\
\cline { 2 - 8 } & média & Desvio & $\mathrm{n}$ & média & desvio & $\mathrm{n}$ \\
\hline$>10<30 \mathrm{~cm}$ & 0,22 & 0,27 & 344 & 0,57 & 0,48 & 1141 \\
\hline$>30<50$ & 0,22 & 0,28 & 494 & 0,54 & 0,52 & 385 \\
\hline$>50$ & 0,27 & 0,25 & 55 & 0,45 & 0,39 & .58 \\
\hline Média geral & $0,23^{\mathrm{a}}$ & 0,38 & 893 & $0,52^{\mathrm{b}}$ & 0,52 & 1584 \\
\hline
\end{tabular}

Nota: números que repartem letras diferentes foram altamente significativos através do teste $t$ de Student $(\mathrm{p}<0,00001)$.

Tabela 2: Crescimento das árvores com cipós na copa (exploração predatória) e sem cipós na copa (colheita planejada) por faixa de DAP, na fazenda Agrosete, em Paragominas, Pará. 


\subsubsection{Crescimento diamétrico de árvores por tipo de dano}

As árvores sem danos cresceram em média $0,72 \mathrm{~cm} / \mathrm{ano}$; já as árvores com danos leves cresceram $0,51 \mathrm{~cm} / \mathrm{ano}$; as com danos moderados cresceram $0,47 \mathrm{~cm} / \mathrm{ano}$; e as com danos severos $0,33 \mathrm{~cm} /$ ano. Não houve diferença entre as árvores com danos leves e com danos moderados $(p<0,4664)$. Todavia houve uma diferença significativa entre as árvores que não apresentaram danos e as que apresentaram danos severos $(p<0,00001)$ (Tabela 3).

\begin{tabular}{l|ccc}
\hline & \multicolumn{3}{|c}{ Crescimento de árvores por tipo de dano (cm/ano) } \\
Tipos de danos & Média & Desvio & $n$ \\
\hline Sem danos & $0,72^{\mathrm{a}}$ & 0,55 & 467 \\
Danos leves & $0,51^{\mathrm{b}}$ & 0,44 & 266 \\
Danos moderados & $0,47^{\mathrm{b}}$ & 0,44 & 193 \\
Danos severos & $0,33^{\mathrm{c}}$ & 0,39 & 100 \\
\hline
\end{tabular}

Nota: os números com letras diferentes foram altamente significativos $(p<0,0001)$ através do teste $t$ de Student.

Tabela 3: Crescimento de árvores com e sem danos medidas anualmente durante 3 anos após a exploração de madeira na Fazenda Agrosete, em Paragominas, Pará, Brasil.

As árvores sem danos crescem 2 vezes mais do que as árvores com danos. Numa exploração predatória, cerca de $30 \%$ das árvores com DAP acima de $10 \mathrm{~cm}$ foram danificadas indevidamente (Johns et al, 1996). Isto é, árvores que deixaram de ser danificadas na colheita planejada. Dessa forma, cerca de um terço das árvores terão um crescimento menor. Isso implicará em mais tempo necessário para uma segunda colheita na área, quando for comparado com a colheita planejada, na qual haverá mais árvores crescendo sadias, consequentemente, menor tempo será necessário para a segunda colheita.

\subsubsection{Crescimento de espécies por tipo de iluminação da copa}

Das 1841 árvores que permaneceram com o mesmo tipo de abertura do dossel, 881 receberam luminosidade total e cresceram, em média, $0,55 \mathrm{~cm} / \mathrm{ano} ; 664$ receberam luminosidade parcial e cresceram $0,31 \mathrm{~cm} / \mathrm{ano}$; e 296 , que receberam apenas luz difusa, 
cresceram 0,22 $\mathrm{cm} /$ ano (Tabela 4). Esses resultados demonstram que a nossa classificação conseguiu captar bem a posição da copa das árvores em relação à luz.

\begin{tabular}{l|l|ccc}
\hline \multirow{2}{*}{$\begin{array}{l}\text { Tipo de iluminação } \\
\text { da copa }\end{array}$} & $\begin{array}{c}\text { Classes } \\
\text { diamétrica }\end{array}$ & \multicolumn{3}{|c}{ Crescimento de árvores em cm/ano (1993-1996) } \\
\cline { 3 - 5 } & $>10<30$ & & desvio & $n$ \\
\hline Iluminação total & $>30<50$ & 0,58 & 0,51 & 572 \\
& $>50$ & 0,57 & 0,56 & 278 \\
& & $0,55^{\mathrm{a}}$ & 0,37 & 31 \\
\hline Média & 0,40 & 0,52 & 881 \\
\hline Iluminação parcial & $>10<30$ & 0,28 & 0,39 & 490 \\
& $>30<50$ & 0,25 & 0,36 & 155 \\
& $>50$ & $0,31^{\mathrm{b}}$ & 0,31 & 19 \\
\hline Média & & 0,16 & 0,38 & 664 \\
\hline Iluminação difusa & $>10<30$ & 0,09 & 0,20 & 235 \\
& $>30<50$ & 0,21 & 0,10 & 58 \\
& $>50$ & $0,15^{\mathrm{c}}$ & 0,20 & 03 \\
\hline Média & & 0,19 & 296 \\
\hline
\end{tabular}

Nota: os números com letras diferentes foram altamente significativos $(\mathrm{p}<0,0001)$ através do teste $t$ de Student.

Tabela 4: Crescimento em DAP das árvores por tipo de iluminação da copa na Fazenda Agrosete, em Paragominas, Pará, Brasil.

O entendimento do comportamento das árvores em relação a iluminação é muito importante no manejo florestal. Muitos tratamentos são recomendados para diminuir a competição entre espécies comerciais e não comerciais (Silva et al. 1989; De Carvalho et al. 1981). Um deles é a liberação de copa. Entretanto, é necessário ser criterioso nas recomendações de tratamentos silviculturais de liberação de copa, em virtude da entrada de novas espécies no mercado e da resposta não satisfatória de outras árvores à entrada de luz (Oliver e Larson, 1990; Oliver e Larson; 1996). Assim, uma análise minuciosa da qualidade das árvores que estão competindo será necessária para que o tratamento tenha sucesso. 


\subsubsection{Incremento das principais espécies madeireiras após a exploração}

As espécies Parkia gigantocarpa e Tachigalia myrmecophylla tiveram maior crescimento entre as espécies comerciais $(1,40 \mathrm{~cm} /$ ano e $1,38 \mathrm{~cm} /$ ano, respectivamente). As que apresentaram um crescimento muito baixo foram Lecythis lurida e Cordia bicolor, crescendo 0,14 e 0,18 cm, respectivamente (Tabela 4).

\begin{tabular}{lccc}
\hline \multicolumn{1}{c}{ Espécies } & $\begin{array}{c}\text { IMA } \\
\left(\mathrm{cm} / \mathrm{ano}^{-1}\right)\end{array}$ & Intervalo & $\mathrm{n}$ \\
\hline Parkia gigantocarpa Ducke & 1,40 & $0,06-1,73$ & 31 \\
Tachigalia myrmecophylla Ducke & 1,38 & $0,46-2,00$ & 10 \\
Virola mitchelii Hechel & 0,75 & $0,50-1,13$ & 06 \\
Inga alba (SW) Willd. & 0,70 & $0,13-2,10$ & 18 \\
Trattinikia rhoifolia Willd & 0,51 & $0,13-1,00$ & 11 \\
Syzygiopsis oppositifolia Ducke & 0,44 & $0,16-0,80$ & 08 \\
Tetragastris altissima (Aubl) March & 0,44 & $0,00-1,20$ & 59 \\
Ocotea rubra Mez. & 0,38 & $0,10-0,90$ & 11 \\
Laetia procera (P. et E.) Eichl. & 0,35 & $0,06-0,66$ & 12 \\
Syzygiopsis pachycarpa Pires & 0,31 & $0,03-0,83$ & 22 \\
Cordia goeldiana Huber & 0,28 & $0,00-1,03$ & 13 \\
Copaifera duckei Dwyer & 0,24 & $0,00-0,53$ & 08 \\
Cordia bicolor D.C. & 0,18 & $0,03-0,43$ & 07 \\
Lecythis lurida (Miers) Mori & 0,14 & $0,00-0,40$ & 29 \\
\hline
\end{tabular}

Nota:

IMA - incremento médio anual das árvores acima de $30 \mathrm{~cm}$ de DAP;

Intervalo - incremento mínimo e máximo por espécie;

$\mathrm{n}$ - espécies madeireiras com pelo menos seis indivíduos com DAP acima de $30 \mathrm{~cm}$ em 10 hectares.

Tabela 5: Incremento Médio Anual $\left(\mathrm{cm} / \mathrm{ano}^{-1}\right)$, intervalo de incremento e número de indivíduos amostrados (n) das espécies madeireiras que apresentaram, pelo menos seis indivíduos com DAP acima de $30 \mathrm{~cm}$ na fazenda Agrosete, em Paragominas, Pará, Brasil.

Silva (1989) acompanhou o crescimento de árvores na Amazônia (Floresta Nacional do Tapajós) e encontrou maior crescimento em DAP para as espécies não madeireiras, Cecropia leucoma e Cecropia sciadophylla, de 1,4 e 2,1 cm/ano respectivamente. Observou-se também uma grande variação de crescimento entre as espécies. No experimento em Paragominas, a variação no crescimento entre as espécies 
foi enorme. Justifica-se isso pela presença de vários fatores em operação, como ambientais, da própria espécie e fatores genéticos.

\subsection{CONCLUSÃO}

As áreas florestais perturbadas com a exploração de madeira modificam a estrutura da floresta e, por conseguinte, o comportamento destas em relação ao crescimento. Observamos que o crescimento diamétrico foi significativamente maior na área com colheita planejada do que na área de exploração predatória. Isso pode ser explicado pelo menor número de árvores danificadas, quantidade menor de árvores com danos na floresta remanescente e, talvez, aberturas ideais para o crescimento das árvores que permaneceram. Isso demonstra uma vantagem do emprego de manejo florestal. Se o crescimento continuar nesse ritmo menos tempo será necessário para que haja o segundo corte de madeira na área. Se o incremento em área basal se comportar como foi observado nos primeiros três anos após a colheita, a colheita planejada recuperará a área basal perdida durante a retirada das árvores em apenas 9 anos, enquanto que na área com exploração predatória, esta recuperação durará pelo menos 40 anos. Essa é uma informação muito importante para os dirigentes da área florestal na região e no país. Essa informação indica que uma exploração com uso de técnicas de manejo pode, além de apresentar vantagens durante a colheita (maior eficiência, menores desperdícios e menores danos), ainda apresenta vantagens após a colheita. Os resultados para colheita planejada são animadores, no entanto ainda não são conclusivos, por isso devem ser vistos com cautela.

Apesar dos benefícios evidentes do sistema de colheita planejada, a forma mais comum de exploração de madeira em toda a Amazônia brasileira é a predatória. Esse fato reforça a necessidade de políticas públicas voltadas para o apoio à adoção desse sistema.

\subsection{AGRADECIMENTOS}

Agradecemos ao WWF (Fundo Mundial para Natureza) e à USAID (Agência Norte Americana de Desenvolvimento Internacional), pelo apoio financeiro para coleta 
dos dados no campo. Ao CNPq pela bolsa de mestrado. A Damião Farias, à Leonor Aguiar, a Manuel Farias e a Miguel Lopes pela ajuda na coleta de dados no campo. A Nelson Rosa pela identificação botânica das espécies florestais. A Adalberto Veríssimo, a Paulo Barreto e a Paulo Amaral pela troca de idéias e pelas revisões dos manuscritos. Meu agradecimento especial ao Prof. Christopher Uhl, por ser o mentor do projeto que deu origem `a este estudo. À Risonele Bahia e Robert Bushbacher (WWF Brasil) pelas revisões dos manuscritos. Aos professores Luiz Carlos Estraviz Rodrigues (ESALQ/USP), a John Paul MacTague (University North of Carolina) e a Antônio Natal Gonçalves, por compartilhar idéias e revisões das versões que deram origem `a este trabalho. Aos colegas do laboratório de silvicultura tropical pelas discussões relacionadas com esse estudo. À colega Kátia Geórgia, pela incansável ajuda com o programa estatístico S_PLUS. A Rodney Reis, pela ajuda na confeç̧ão dos mapas no arqview. À administração do Imazon, pelo apoio logístico. E a Percio Lima, proprietário da área de estudo.

\subsection{BIBLIOGRAFIA}

AMARAL, P., VERÍSSIMO, A., BARRETO, P. \& VIDAL, E. Floresta para sempre: um manual para produção da madeira na Amazônia. Belém: IMAZON, 1998. $137 \mathrm{p}$.

BATISTA, J.L.F., A função Weibull como modelo para distribuição de diâmetro de espécies arbóreas tropicais. Piracicaba, 1989. 115p. Dissertação (M.S.) - Escola Superior de Agricultura "Luiz de Queiroz".

BARRETO, P., UHL, C. \& YARED, J. Avaliação do Potencial para Manejo Florestal em Paragominas, considerando Fatores Ecológicos e Econômicos. In: $1^{\circ}$ CONGRESSO FLORESTAL PANAMERICANO E $7^{\circ}$ CONGRESSO FLORESTAL BRASILEIRO, Curitiba, 1993. Floresta para o desenvolvimento: política, ambiente, tecnologia e mercado, Anais. Curitiba: SBS-SBEF, 1993, p. 387-392. 
BARRETO, P., AMARAL, P., VIDAL, E. \& UHL, C. Costs and benefits of forest management for timber production in eastern Amazonia. Forest Ecology and Management. /No prelo/

BRASIL, Ministério das Minas e Energia. Departamento Nacional de Produção Mineral. Folha AS 22 Belém: geologia, geomorfologia, solos, vegetação e uso potencial da terra. Rio de Janeiro, 1974. (Projeto Radam. Levantamento de Recursos Naturais, 5).

BROKAW, N.V.L. Gap-phase regeneration of three pioneer tree species in a tropical forest. Journal of ecology, v.75, p.9-19, 1987.

DE GRAAF, N. R. 1986. A silvicultural system for natural regeneration of tropical rain forest in Suriname. Wageningem, The Netherlands: Agricultural University.

DE CARVALHO, J. O. P. Anelagem de árvores indesejáveis em floresta tropical densa da Amazônia. EMBRAPA/CPATU, Belém. 1981` Boletim de Pesquisa 22. 11 p.

DE CARVALHO, J.O.P. Structure and dynamics of a logged over Brazilian Amazonian rain forest. Oxford, 1992. Thesis (PhD), Oxford University.

GERWING, J., JOHNS, J. \& VIDAL, E. Reducing waste during logging and log processing towards forest conservation in Eastern Amazon. Unasylva, v. 47, n. 187 p.17-25, 1996.

HIGUCHI, N. Short-term growth of man undisturbed tropical moist forest in the Brazilian Amazon. 1987, Michigan. Ph.D. Thesis, Michigan State University.

JOHNS, J., BARRETO, P. \& UHL, C. Logging damage in planned and unplanned logging operations and its implications for sustainable timber production in the Eastern Amazon. Forest Ecology and Management, v.89 p.59-77, 1997. 
LISBOA, P. L. B., TEREZO, E. F. M. \& SILVA, J. C. A . Madeiras amazônicas: considerações sobre exploração, extinção de espécies e conservação. Boletim do museu paraense Emílio Goeldi, Série Botânica v.7, n.2, p.521-542, 1991.

OLIVER, C.D. \& LARSON, B. C. Forest stand dynanmics. Biological Resource Management Series. McGraw-Hill, 1990, 467 p

PRADO, A.C. Diretrizes para uma política florestal no Brasil. MA/MMA. 1995. 171 p.

PERES, C.A. Diet and feeding ecology of saddle-back (Saguinus fuscicollis)and moustached ( $S$. mystox)tamarins in na Amazonian terra firme forest. Journal of Zoology, v.230, p.567-592, 1993.

PUTZ, F.E. The natural history of lianas on Barro Colorado, Island, Panama. Ecology, v.65, p.1713-1724, 1984.

SILVA, J.N.M. The behavior of the tropical rain forest of the brazilian amazon after logging. Oxford, 1989. Thesis (PhD), Oxford University.

SILVA, J.N.M, DE CARVALHO, J.O.P., LOPES, J. DO C.A. ALMEIDA, B.F. DE, COSTA, D.H.M., OLIVEIRA, L.C. DE, VANCLAY, J.K. \& SKOVSGAARD, J. P. Growth and yield of a tropical rain forest in the brazilian Amazon 13 years after logging. Forest ecology and Management, v.71, n.3, p.267-274, 1995.

STONE, S. 1997. Growth of the timber industry in the eastern Amazon: economic trends and implication for policy. Phd dissertacion. Cornell University. Ithaca, NY, USA.

UHL, C., VERÍSSIMO, A., BARRETO, P., MATTOS, M., TARIFA, R. O desafio da exploração sustentada. Ciência Hoje, v.14, p.53-59, 1992. 
UHL, C., VERÍSSIMO, A., BRANDINO, Z. \& VIEIRA, I. Social, economic, and ecological consequences of logging in the Amazon Frontier: The case of Tailandia. Forest Ecology and Management, v.46, p.243-273, 1991.

UHL, C. BARRETO, P., VERÍSSIMO, A., BARROS, A. C., AMARAL, P., VIDAL, E. \& SOUZA JR., C. Natural resource management in the brazilian Amazon: an integrated research approach. BioScience, v.47, n.3, p.160-199, 1997.

UHL, C. BUSCHBACHER, R. \& SERRÃO, A. Abandoned pastures in Eastern Amazônia. I. Patters of plant sucession. Journal of ecology, v.75, p.663-681, 1988.

UHL, C.; BARRETO, P.; VERÍSSIMO, A.; BARROS, A. C.; AMARAL, P.; VIDAL, E.; SOUZA JR. C. 1996. Uma abordagem integrada de pesquisa sobre manejo dos recursos naturais na Amazônia. Pg. 140-164. In: A. VERÍSSIMO e A. C. Barros, (Ed.). A expansão da atividade madeireira na Amazônia: Impactos e perspectiva para o desenvolvimento do setor florestal no Pará. Belém: IMAZON, 1996. Cap. 5, p.140-164.

VIDAL, E., BARRETO, P., JOHNS, J., GERWING, J. \& UHL, C. Vine management for reduced-impacts logging in Eastern Amazon. Forest Ecology and Management, v.98, p.105-114, 1997a.

VIDAL, E., GERWING, J., BARRETO, P., AMARAL, P. \& JOHNS, J. Redução de desperdícios de madeira na Amazônia. Série Amazônia. Belém: IMAZON, 1997b, $\mathrm{n}^{\mathrm{o}} 5.18 \mathrm{p}$.

WATRIN, O. DOS S. \& ROCHA, A.M.A. DA. Levantamento da vegetação natural e uso da terra no município de Paragominas (PA) utilizando imagens TM/LANDSAT. Belém: EMBRAPA-CPATU, 1991. 40p. Boletim de Pesquisa, 124. 


\title{
CAPÍTULO 4
}

IMPACTOS DA EXPLORAÇÃO MADEIREIRA PREDATÓRIA E PLANEJADA SOBRE A DIVERSIDADE DE ESPÉCIES NA AMAZÔNIA ORIENTAL*

\section{IMPACTS OF PLANNED AND UNPLANNED TIMBER EXTRACTION ON SPECIES DIVERSITY IN EASTERN AMAZONIA}

\author{
E. Vidal ${ }^{1,2}$, V. Viana ${ }^{3}$ \\ ${ }^{1}$ Pos-graduando da ESALQ/USP \\ ${ }^{2}$ Pesquisador do IMAZON, cx. postal 1015, CEP 66017-000, Belém/PA \\ ${ }^{3}$ Professor da ESALQ/USP, Departamento de Ciências Florestais, Av. Pádua Dias, 11, \\ Piracicaba, SP, 13418-900, Brasil. \\ * artigo submetido à Revista Árvore
}

\subsection{RESUMO}

Avaliou-se o impacto da exploração predatória e colheita planejada de madeira sobre a diversidade de espécies em floresta tropical, três anos após a intervenção. $\mathrm{O}$ estudo foi realizado em Paragominas, na Amazônia Oriental, numa área de 210 hectares, sendo 75 ha com exploração predatória, 105 ha com colheita planejada e 30 ha como área testemunha. $\mathrm{Na}$ exploração predatória não foi usado técnicas de manejo florestal sendo usado pela colheita planejada

A exploração e a colheita predatória aconteceram no ano de 1993, e os tratamentos foram monitorados até 1996, sendo realizadas medições anuais de DAP, mortalidade e sanidade das árvores. Avaliou-se ainda comportamento da floresta em relação ao crescimento em DAP das árvores. 
Os resultados das comparações de diversidade através do índice de Shannon, para cada tipo de intervenção, indicaram que o tratamento colheita planejada não apresentou diferença significativa na comparação de médias pelo teste $t$ no período logo após a exploração (1994) e três anos após (1996) apresentando diferença no tratamento exploração predatória. Isso indica menos danos à biodiversidade.

Antes da exploração foram encontrados 432 indivíduos/ha na área testemunha, 498 na área manejada e 449 indivíduos/ha na exploração predatória. Durante o período, houve pequenas oscilações de densidade no tratamento testemunha, no entanto, no tratamento colheita planejada, devido a intervenção, houve redução de $16 \%$ no número de indivíduos e no tratamento exploração predatória, esta redução foi de $20 \%$.

Considerando todos os tratamentos, as famílias com número de espécies reduzido, com apenas uma espécie foram: Araliaceae, Bixaceae, Caricaceae, Cecropiaceae, Celastraceae, Didiapetalaceae, Icacinaceae, Malpighiaceae, Myristicaceae, Rhaminaceae, Simarubaceae e Violaceae e, as mais abundantes, com mais de dez espécies, foram: Caesalpinaceae, Lauraceae, Lecythidaceae, Mimosaceae, Moraceae e Sapotaceae.

O número de espécies encontradas no tratamento testemunha, extração predatória e colheita planejada foi de 145, 123 e 154 respectivamente. A mortalidade foi superior ao recrutamento nos tratamentos exploração predatória e testemunha, sendo inferior no tratamento colheita planejada. Na área testemunha, não desapareceu nenhuma das espécies sendo recrutada uma espécie. Na colheita planejada desapareceram 4 (2,5\%) espécies sendo recrutadas 2 espécies, e na área com exploração predatória, 7 (6,0\%) espécies desapareceram e 2 foram recrutadas.

Em média, desapareceram 8 indivíduos/ha acima de $10 \mathrm{~cm}$ de DAP a mais pela exploração predatória em relação à colheita planejada. Isso contribuiu para que, na colheita planejada, houvesse menor redução de diversidade de espécies do que na exploração predatória. 


\subsection{ABSTRACT}

This chapter evaluates the impacts of planned and unplanned logging on tree species diversity three years following logging. This study was conducted near the city of Paragominas $\left(3^{\circ} \mathrm{S}, 50^{\circ} \mathrm{W}\right)$, in eastern Amazonia. The study area included 210 ha of forest of which 105 ha was subjected to planned logging, 75 ha to unplanned logging, and 30 ha was left as an unlogged control. $\mathrm{Na}$ exploração predatória não foi usado técnicas de manejo florestal sendo usado pela colheita planejada

All logging occurred during 1993 and tree diameter increment, mortality, and recruitment were monitored until 1996. Impacts of the two logging treatments on tree species diversity were determined by comparing changes following logging in Shannon diversity indices for both logged areas. Significant declines in diversity following logging were found in the unplanned logging but not in the planned logging area.

Tree density ranged from 432 individuals/ha in the control area to 498 individuals/ha in the planned logging area. During the study period, there was a reduction in stem density of $16 \%$ in the planned logging area and $20 \%$ in the unplanned logging area owing to mortality caused by timber extraction. The control area showed only slight oscillations in stem density. Considering the entire study area, the most rare plant families with only one species each were Araliaceae, Bixaceae, Caricaceae, Cecropiaceae, Celastraceaea, Didiapetalaceae, Icacinaceae, Malpighiaceae, Myristicaceae, Rhaminacaeae, Simarubaceae, and Violaceae. The most common families were Caesalpinaceae, Lauraceae, Lecythidaceae, Mimosaceae, and Sapotaceae

The total number of species encountered in the control, unplanned logging, and planned logging areas was 145,123 , and 154 , respectively. Timber extraction resulted in a decline in total species diversity of $2.5 \%$ in the planned logging area and $6.0 \%$ in the unplanned. Mortality outpaced recruitment in both the unplanned logging and control areas whereas the reverse was true in the planned logging area. During the study period, one new species appeared in the control area and none disappeared, the planned logging area lost 5 species and gained 2, and the unplanned logging area lost 7 species and gained 2. 
On average, unplanned extraction resulted in the loss of 8 individuals /ha with $\mathrm{dbh}>10 \mathrm{~cm}$. This high loss of individuals resulted in the greater negative impact of unplanned logging on tree species diversity as compared to the lesser impacts of planned logging.

Palavras chaves: Floresta tropical; Amazônia; diversidade; impactos; extração de madeira.

Key words: tropical forest; Amazon; diversity; impacts, logging

\subsection{INTRODUÇÃO}

A importância da atividade madeireira na Amazônia tem crescido rapidamente nos últimos anos. Todavia, a grande maioria das empresas que fazem parte dessa atividade usam práticas predatórias no ambiente. Os impactos no ecossistema são significantes (Johns, 1984; Veríssimo et al. 1992; Barreto et al. 1993; Vidal et al. 1997; Uhl et al. 1997; Martins et al, 1997). Entretanto, a maioria destes estudos não avalia os impactos nas comunidades arbóreas, isto é, o que acontece com as espécies quando as áreas são exploradas de forma predatória e com emprego de técnicas de colheita planejada.

Um estudo sobre o impacto da atividade madeireira nas espécies revelou que das 350 espécies que estão sendo usadas pela indústria madeireira na Amazônia, 41 são potencialmente ameaçadas pela exploração e 19 podem ser favorecidas. Isso se deve em parte aos distúrbios que a atividade madeireira provoca no ecossistema como: abertura de estradas e ramais de arraste e derrubada das árvores. Esses distúrbios modificam o ambiente, favorecendo as condições para umas se desenvolverem e limitando a sobrevivência para outras. $\mathrm{O}$ entendimento na exploração madeireira, do que acontece com a diversidade das espécies e do ambiente como um todo, é importante para que melhorias sejam feitas nos sistemas de manejo, incorporando a diversidade de espécies arbóreas (Martini et al. 1993).

Apesar de sua importância econômica, a exploração madeireira causa muitos impactos nas comunidades de espécies arbóreas. Existe uma grande carência de estudos 
que avaliam esta possibilidade. Esta analisa o comportamento da floresta que foi explorada com colheita planejada e de forma predatória em termos de diversidade de espécies antes e após a intervenção. $O$ estudo testa a hipótese de que há diferenças significativas em termos de estoque de indivíduos (densidade) e diversidade de espécies entre áreas submetidas a exploração predatória, colheita planejada e áreas não perturbadas Para isso serão avaliadas a estrutura diamétrica, a densidade de indivíduos, a composição florística e a diversidade de espécies através do índice de Shannon.

\subsection{LOCAL DO ESTUDO}

O estudo foi realizado em Paragominas, no nordeste do Estado do Pará, entre as coordenadas $2^{0} 25^{\prime}$ e $4^{0} 09^{\prime} \mathrm{S}$ e $46^{\circ} 25^{\prime}$ e $48^{\circ} 54^{\prime}$ Wgr. O município é drenado por duas bacias, a do rio Capim e a do rio Gurupi e é cortado no sentido norte-sul pela rodovia BR-010 (Watrin \& Rocha, 1991) (Figura 1). O experimento foi conduzido na Fazenda Agrosete $\left(3^{0} \mathrm{~S}, 50^{\circ} \mathrm{W}\right)$, distante $30 \mathrm{~km}$ do centro do município de Paragominas.

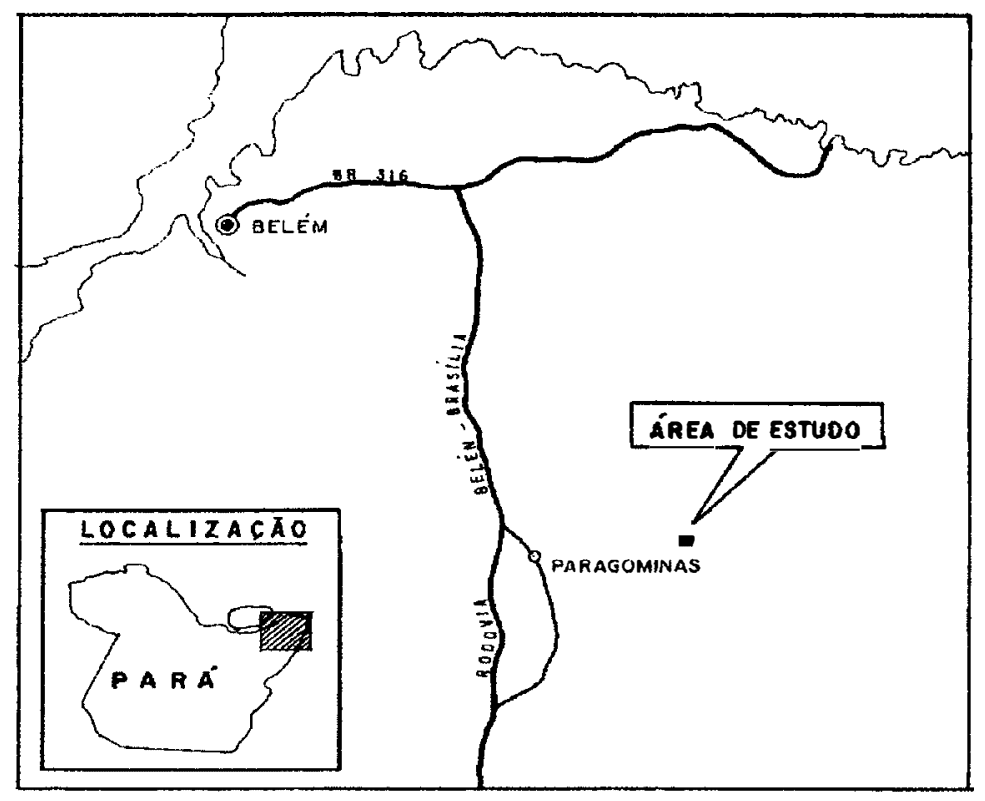

Figura 1. Localização da área de estudo 
O relevo da região de Paragominas é levemente ondulado apresentando planaltos rebaixados e dessecados em litologia sedimentar das formações Barreiras e Itapecuru, com superficies erosivas tabulares e pediplanadas (Brasil, 1974). O relevo plano foi comum nas áreas, bem como o grau de distúrbio natural, sendo $8 \%$ da área formada por clareiras naturais (Vidal et al. 1997a; Barreto et al. em preparação).

O clima é caracterizado por um período com chuvas regulares e um período mais seco, de junho a novembro, com pluviosidade média mensal de $40 \mathrm{~mm}$. somando cerca de $1700 \mathrm{~mm} / \mathrm{ano}$ ocorrendo principalmente durante os meses de janeiro a maio (dados da Embrapa/CPATU no período de 1973-1982, na cidade de Paragominas). A maior parte da atividade madeireira na região é conduzida durante a estação seca, de junho a dezembro (Johns et al. 1996 e Barreto et al. 1997).

As florestas da região são tropicais de terra baixa, com altura do dossel variando entre 25-40 metros com uma biomassa acima do solo de aproximadamente $300 \mathrm{t} / \mathrm{ha}$ (Uhl et al. 1989).

\subsection{MATERIAIS E MÉTODOS}

\subsubsection{Descrição dos sistemas de exploração realizados na área:}

O estudo foi realizado em uma área de 210 ha, sendo 75 ha com exploração predatória, 105 ha com colheita planejada e 30 ha com área testemunha (Figura 2). 

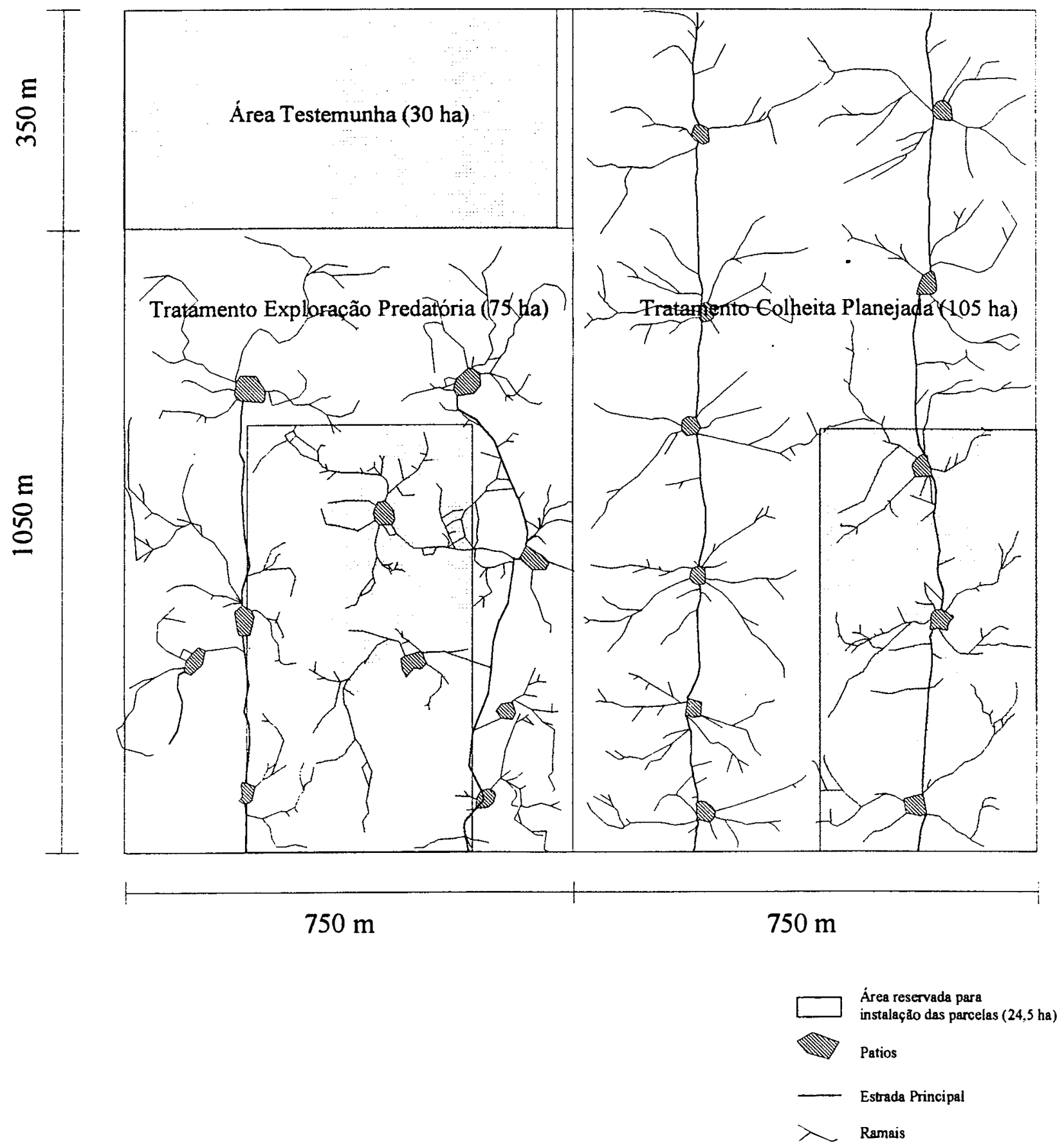

Figura 2: Mapa da área de estudo com os tratamentos aplicados e localização das áreas reservadas para instalação das parcelas. 


\subsubsection{Exploração predatória}

Este é o sistema utilizado atualmente na região de Paragominas e na maior parte da Amazônia brasileira. A exploração predatória consiste no seguinte: após definida a área de exploração anual (talhão), uma equipe de motosserristas entra na floresta e derruba as árvores sem o conhecimento prévio de sua localização, pois não conduz o mapeamento e o censo das árvores. Em seguida, constrói as estradas. Ao encontrar um aglomerado de árvores, procura um local com topografia boa e com poucas árvores grandes para abrir um pátio de estocagem de madeira dentro da floresta, de onde as toras serão transportadas até as serrarias. Por último, os operadores das máquinas (trator de esteira sem guincho) saem 'a procura das árvores. Por não terem a localização das árvores derrubadas, $\mathrm{o}$ arraste das toras ocasiona muitos danos e desperdícios de madeira na floresta.

\subsubsection{Colheita planejada}

A colheita planejada seguiu o modelo de manejo desenvolvido pelo Instituo do Homem e do Meio Ambiente da Amazônia (IMAZON) na região da Amazônia Oriental. Este modelo compreende três etapas que estão divididas em atividades antes, durante e após a exploração.

- Atividades antes da exploracão florestal - Dois anos antes da exploração, a equipe entra na floresta e delimita o talhão. Em seguida, abre trilhas dentro da floresta para realizar do censo dos indivíduos $>25 \mathrm{~cm}$ de DAP. Com 1 a 2 anos antes da exploração faz-se o corte de cipós dos indivíduos $>2 \mathrm{~cm}$ de diâmetro. E, com 3 meses antes da exploração da área, conduz-se o planejamento da exploração que compreende a delimitação das estradas principais e pátios de estocagem de madeira, bem como a seleção das árvores a serem derrubadas.

- Atividades durante a exploração florestal - Poucos dias antes da exploração, uma equipe de planejamento entra na floresta e faz a orientação da colheita. Essa equipe orienta no campo pequenas trilhas marcadas com balizas e fitas plásticas coloridas, além de confeccionar um mapa simples que é usado pela 
equipe de derrubada e pela equipe de arraste das toras. As orientações são distribuídas na abertura de estradas principais para caminhões, nos pátios de estocagem, nos ramais de arraste e na direção ideal de queda das árvores.

\subsubsection{Coleta dos dados}

Para investigar o comportamento da dinâmica da floresta com relação à densidade, composição florística e diversidade foi reservada uma área de 24,5 ha $(350 \mathrm{x}$ $700 \mathrm{~m}$ ) em cada sistema de exploração e na área testemunha. A localização das parcelas foi de forma aleatória, sendo 20 parcelas de 0,5 ha $(50 \times 100 \mathrm{~m})$ para coletar dados das árvores com valor madeireiro acima de $10 \mathrm{~cm}$ de diâmetro e 21 parcelas de $0,25 \mathrm{ha}(25 \mathrm{x}$ $100 \mathrm{~m}$ ) para árvores sem valor madeireiro com diâmetro acima de $10 \mathrm{~cm}$ (Figura 2).

O DAP das árvores foi medido com fita diamétrica. Todas as árvores acima de 10 $\mathrm{cm}$ de DAP foram identificadas, localizadas através de um sistema de coordenadas $\mathrm{x}$ e y e marcadas com uma placa de alumínio. A parte inferior da placa foi o local reservado para marcar a coleta do DAP nos 3 anos subsequentes. Foram medidos também outros fatores que interferem no crescimento das árvores como sanidade das árvores (danos no fuste, danos na copa), iluminação da copa, e presença de cipós.

\subsubsection{Monitoramento dos tratamentos}

O estabelecimento das parcelas e a exploração nas áreas foram realizadas em 1993 e foram medidos os DAPs em 1994, 1995 e 1996. As medidas obedecem o seguinte cronograma para cada coleta: tratamento colheita planejada (setembro); tratamento exploração predatória (outubro) e tratamento testemunha (novembro).

\subsubsection{Análise da diversidade pelo índice de Shannon}

$\mathrm{O}$ índice de Shannon $\left(\mathrm{H}^{\prime}\right)$ é um índice de heterogeneidade que se baseia na abundância proporcional de espécies (Magurran, 1987). Este índice afirma que os indivíduos são aleatoriamente amostrados de uma população infinitamente grande, e que todas as espécies estão representadas na amostra (Magurran, 1987; Southwood, 1978). 
O objetivo desta análise é comparar se houve diferença significativa de diversidade nas áreas após o corte e como esta floresta comporta-se em termos de diversidade, através deste índice, três anos após a exploração.

Para calcular o índice de Shannon foi usado a seguinte fórmula:

$$
H^{\prime}=-\sum_{p l} \ln p i
$$

Onde:

$p_{i}$ é a relação entre o número de indivíduos da espécie $\left(\mathrm{n}_{\mathrm{i}}\right)$ e o número de indivíduos $(\mathrm{N})$, isto é $p_{i}=\mathrm{n}_{\mathrm{i}} / \mathrm{N}$

A variância foi calculada pela seguinte fórmula (Magurran, 1987):

$$
V a r H^{\prime}=\frac{\sum_{p i}(\ln p i)^{2}-\left(\sum_{p i} \ln p i\right)^{2}}{N}-\frac{S-1}{2 N^{2}}
$$

O grau de liberdade foi calculado através da seguinte fórmula (Magurran, 1987):

$$
d f=\frac{\left(\operatorname{VarH}_{1}+\operatorname{VarH}_{2}\right)^{2}}{\left[\left(\operatorname{VarH}_{1}{ }_{1}\right)^{2} / N_{1}\right]+\left[\left(\operatorname{VarH}_{2}{ }_{2}\right)^{2} / N_{2}\right]}
$$

E o teste $t$ para comparar a diversidade das espécies arbóreas da floresta antes e após a exploração de madeira foi o seguinte (Magurram, 1987):

$$
t=\frac{H_{1}^{\prime}-H^{\prime}}{\left(\operatorname{Var}_{{ }^{\prime}}+\operatorname{Var}^{\prime}{ }_{2}\right)^{\frac{1}{2}}}
$$

Onde:

$H_{1}$ ' é o índice de diversidade de Shannon na floresta antes da exploração, $H_{2}$ ' o índice após a exploração; $\operatorname{Var} H_{1}$ ' e $\operatorname{Var} H_{1}$ ' são as variâncias. 


\subsection{RESULTADOS E DISCUSSÃO}

\subsubsection{Densidade de indivíduos antes e após a exploração}

A densidade de indivíduos $(\mathrm{n} / \mathrm{ha})$ entre os tratamentos foram diferentes estatisticamente antes da exploração $(p<0,00001)$, logo após a exploração $(p<0,0001)$ e três anos após $(\mathrm{p}<0,0001)$ (Anexo 1 , Figura 3 ).

Foram encontrados 432 indivíduos/ha na área testemunha, na ocasião do estabelecimento das parcelas e, ao longo do tempo, houve uma pequena redução, sendo de $2 \%$ do primeiro para o segundo ano e de $5 \%$ três anos após à primeira medida. $\mathrm{Na}$ área que sofreu colheita planejada, o número de indivíduos foi $498 /$ ha e a redução no número de indivíduos foi de $16 \%$, principalmente devido a retirada de madeira. Com três anos após o corte a redução aumentou para $20 \%$. Na área com exploração predatória a estimativa foi de 449 indivíduos/ha, a redução por ocasião da exploração foi ainda maior (20\%) e, três anos depois, a redução aumentou para $25 \%$.

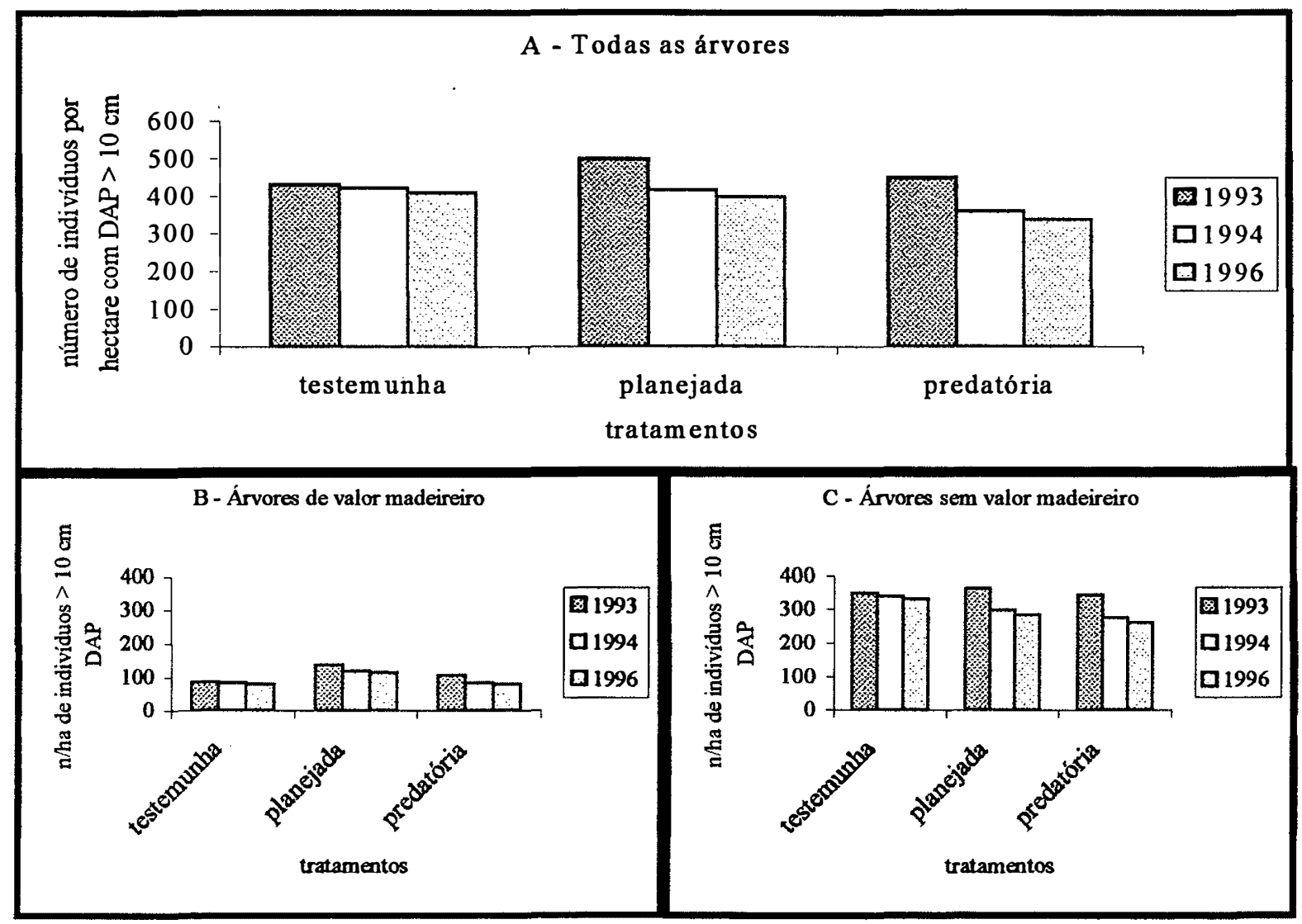


Figura 3. Densidade de indivíduos (n/ha) para (A) todas as espécies,(B) somente as espécies de valor madeireiro e $(C)$ somente espécies sem valor madeireiro na Fazenda Agrosete, em Paragominas/Pará.

Em média, desapareceram 8 indivíduos/ha acima de $10 \mathrm{~cm}$ de DAP a mais pela exploração predatória, sendo que $60 \%$ desses indivíduos eram de valor madeireiro e o restante sem valor madeireiro. No geral, os impactos foram superiores na exploração predatória, em torno de $2 \%$ a mais dos indivíduos arbóreos. Isso significa 8 indivíduos com DAP acima de $10 \mathrm{~cm}$ por hectare que deixaram de ser mortos. Isto resulta em benefícios a longo prazo uma vez que mais madeira poderá ser aproveitada numa próxima exploração, como também menos danos a biodiversidade.

\subsubsection{Riqueza florística, dominância e diversidade de espécies antes e após a} exploração

\subsubsection{Composição florística}

Analisando a área como um todo, As famílias que apresentaram apenas uma espécie foram: Araliaceae, Bixaceae, Caricaceae, Cecropiaceae, Celastraceae, Didiapetalaceae, Icacinaceae, Malpighiaceae, Myristicaceae, Rhaminaceae, Simarubaceae e Violaceae e as mais comuns foram: Caesalpinaceae, Lauraceae, Lecythidaceae, Mimosaceae, Moraceae e Sapotaceae.

A distribuição do número de espécies em relação ao número de indivíduos foi característico de florestas tropicais, isto é, um grande número de espécies com poucos indivíduos (Bawa, 1991; Kageyama \& Gandara, 1994). As espécies com um número elevado de indivíduos, acima de 10 ind./ha, compreenderam apenas 12 espécies, já as espécies com um número reduzido de indivíduos, abaixo de 1 ind./ha, compreenderam 141 espécies (Anexo 2).

Antes da exploração existiam na área testemunha 145 espécies, representando 87 gêneros e 38 famílias ( 7 espécies não identificadas). As famílias que apresentaram apenas uma espécie foram: Araliaceae, Caricaceae, Cecropiaceae, Celastraceae, Combretaceae, Flacourtiaceae, Humicaceae, Icacinaceae, Malpighiaceae, Myristicaceae, 
Rhaminaceae, Simarubaceae, Violaceae e Vochysiaceae. As famílias que apresentaram mais de 10 espécies foram: Caesalpinaceae, Mimosaceae e Sapotaceae, apresentando respectivamente, 13, 17 e 20 espécies respectivamente.

$\mathrm{Na}$ área testemunha, o número de espécies manteve-se praticamente constante no decorrer do período de coleta de dados, não desapareceu nenhuma espécie, sendo recrutada uma espécie da família das Moraceae, Trymatococcus amazonicus P. \& E. (Anexo 2).

$\mathrm{Na}$ colheita planejada foram identificadas 154 espécies, pertencentes a 85 gêneros e 37 famílias (7 espécies não identificadas). As famílias que apresentaram apenas uma espécie foram: Araliaceae, Bixaceae, Caricaceae, Cecropiaceae, Combretaceae, Didiapetalanaceae, Myristicaceae, Olacaceae, Simarubaceae e Violaceae. As famílias que apresentaram mais de 10 espécies foram: Caesalpinaceae, Lecythidaceae, Mimosaceae e Sapotaceae com 13, 12, 22 e 16 espécies (Anexo 2).

$\mathrm{Na}$ área com exploração predatória, o número de espécies encontradas foi menor entre os tratamentos. Foram encontradas 123 espécies de 77 gêneros e 33 famílias (9 espécies não identificadas). As famílias que apresentaram apenas uma espécie foram: Araliaceae, Caricaceae, Cecropiaceae, Celastraceae, Guttiferae, Malpighiaceae, Nyctaginaceae, Olacaceae, Simarubaceae, Tiliaceae e Violaceae, apresentando apenas uma espécie. As famílias que apresentaram mais de 10 espécies foram: Caesalpinaceae, Mimosaceae e Sapotaceae, com 12, 12 e 15 espécies respectivamente (Anexo 2).

$\mathrm{Na}$ colheita planejada houve uma redução de $2,5 \%$ no número de espécies logo após a exploração. As espécies que desapareceram foram: Micropholis melinoniana, Inga cf. pezizifera Benth, Sapium marmieri Hub. e Hieronyma sp. Uma espécie foi perdida diretamente pela colheita e as três restantes foram danificadas. Três anos após a intervenção foram recrutadas 2 espécies novas: Lecythis lurida (Miers) Mori e Stryphnodendrom paniculatum P. et. Endl. (Anexo 2).

$\mathrm{Na}$ exploração predatória, devido a intervenção, houve uma redução de $6,0 \%$ no número de espécies. As espécies que desapareceram foram: Brosimum potabile Ducke, Campsiandra laurifolia Benth, Micropholis melinoniana, Tabebuia insignis (Miq.) Sandw., Calophyllum brasiliense Camb., Astronium gracile Engl. e Ambelania sp. Cinco 
espécies foram danificadas e 2 duas foram perdida diretamente pela colheita. Três anos após a exploração foram recrutadas 2 espécies novas, Ocotea glomerata (Nees) Mez. e Tachigalia paniculata (Anexo 2).

Os resultados da pesquisa não são conclusivos, principalmente devido ao período curto amostrado. Para um período mais longo Condit et al (1992), observou para um período de 8 ano, em uma floresta primária na Ilha de Barro Colorado, que 10 das espécies presentes no início da pesquisa (1982) não foram encontradas no final (1990), e 9 espécies ausentes em 1982 estavam presentes em 1990.

$\mathrm{Na}$ colheita planejada todas as espécies que desapareceram são capazes de resistir a pressão madeireira, já na exploração predatória uma das espécies que desapareceram, Calophyllum brasiliense, é suscetível à redução de sua população pela pressão madeireira de acordo com a classificação de Martini et al (1994).

\subsubsection{Diversidade de espécies pelo índice de Shannon}

Quando comparado o índice de diversidade antes da exploração (1993) e logo após a exploração (1994), em cada tratamento, pode-se observar que houve diferenças altamente significativas (test $t ; \mathrm{p}=0,001$ ) nos tratamento colheita planejada e exploração predatória. Quando a comparação foi entre os períodos logo após exploração (1994) e três anos após (1996), incluindo aqui os indivíduos recrutados, houve diferenças altamente significativas (teste $t ; p<0,001$ ) no tratamento exploração predatória não acontecendo no tratamento colheita planejada (Tabela 1). Ou seja, a floresta remanescente do tratamento colheita planejada voltou a ter a mesma diversidade de espécies por este índice já com 3 anos após a colheita. 


\begin{tabular}{|c|c|c|c|c|c|c|c|c|c|}
\hline \multirow[b]{2}{*}{ Tratamentos } & \multicolumn{3}{|c|}{ Antes (1993) } & \multicolumn{3}{|c|}{ I ano após (1994) } & \multicolumn{3}{|c|}{3 anos após (1996) } \\
\hline & $\mathrm{n}$ & $\mathrm{N}$ & $\begin{array}{c}\text { Shannon } \\
\left(\mathrm{H}^{\prime}\right)\end{array}$ & $\mathrm{n}$ & $\mathrm{N}$ & $\begin{array}{c}\text { Shannon } \\
\left(\mathrm{H}^{\prime}\right)\end{array}$ & $\mathrm{n}$ & $\mathbf{N}$ & $\begin{array}{c}\text { Shannon } \\
\left(\mathrm{H}^{\prime}\right)\end{array}$ \\
\hline $\begin{array}{l}\text { Exploração } \\
\text { predatória }\end{array}$ & 3067 & 124 & $3,818^{* * *}$ & 2459 & 117 & $3,771^{* * *}$ & 2140 & 119 & $3,685^{* * *}$ \\
\hline $\begin{array}{l}\text { Colheita } \\
\text { planejada }\end{array}$ & 3311 & 156 & $3,839 * * *$ & 2812 & 151 & $3,832^{* * *}$ & 2845 & 154 & 3,904 \\
\hline
\end{tabular}

Notas:

$\mathrm{n}$ - número de indivíduos;

$\mathrm{N}$ - número de espécies

$* * *$, esses indices apresentaram diferenças altamente significativas (t-test, $\mathrm{p}<0,001)$ através do teste $t$ de Student quando comparados dentro de cada tratamento por período. Tabela 1. Número de indivíduos, número de espécies e índice de Shannon entre os tratamentos, colheita planejada e exploração predatória, na fazenda Agrosete, em Paragominas, Pará - Brasil.

\subsubsection{Estrutura diamétrica antes e após a intervenção}

O Anexo 3 demonstra como era a distribuição diamétrica da floresta e como esta foi modificada com os diferentes sistemas de manejo.

Observando o gráfico pode-se notar que no tratamento testemunha ocorre um pequeno crescimento de árvores na classe menor oriundo principalmente do recrutamento, ocorre uma redução na classe de $20-30 \mathrm{~cm}$ e mantém-se equilibrado a partir desta classe. Comparando a colheita planejada com a exploração predatória podese notar em ambas que o recrutamento recuperou o número de indivíduos na classe inferior, no entanto a exploração predatória não conseguiu recuperar o número de indivíduos perdidos pela retirada de madeira nas outras classes $(20-90 \mathrm{~cm})$, enquanto que na colheita planejada observa-se um pequeno crescimento no número de indivíduos até $70 \mathrm{~cm}$ de DAP. Isso indica um aumento do número de indivíduos das classes intermediárias $(10-70 \mathrm{~cm})$ após exploração no tratamento colheita planejada. Isso é positivo para o manejo florestal. Foi aberto um espaço para o crescimento das árvores intermediárias, árvores que possivelmente vão ser exploradas no segundo ciclo. 
O número de indivíduos eliminados pela intervenção, na exploração predatória, foi superior ao da colheita planejada, praticamente em todas as faixas de DAP, indicando a superioridade dos danos em todas as classes diamétricas.

\subsubsection{Mortalidade e recrutamento}

No tratamento testemunha a mortalidade foi de $3,6 \%$ e o recrutamento foi $2,44 \%$. No tratamento exploração predatória a mortalidade e recrutamento apresentaram dados semelhantes ao tratamento testemunha, com uma taxa de 3,3\% de mortalidade e $2,42 \%$ de recrutamento, para os 3 anos após a exploração Na colheita planejada o recrutamento foi superior a mortalidade, $2,82 \%$ e $2,4 \%$ para os três anos, respectivamente, (Figura 4). A mortalidade na área testemunha foi superior quando comparado a outros estudos em florestas tropicais como os de De Graaf (1986) e Jonkers (1988) que encontraram 1,5\% ao ano, Silva (1989), que encontrou $2,5 \%$ ao ano para um período de 13 anos. No entanto, os resultados encontrados neste trabalho ainda não são conclusivos dado o período curto amostrado.

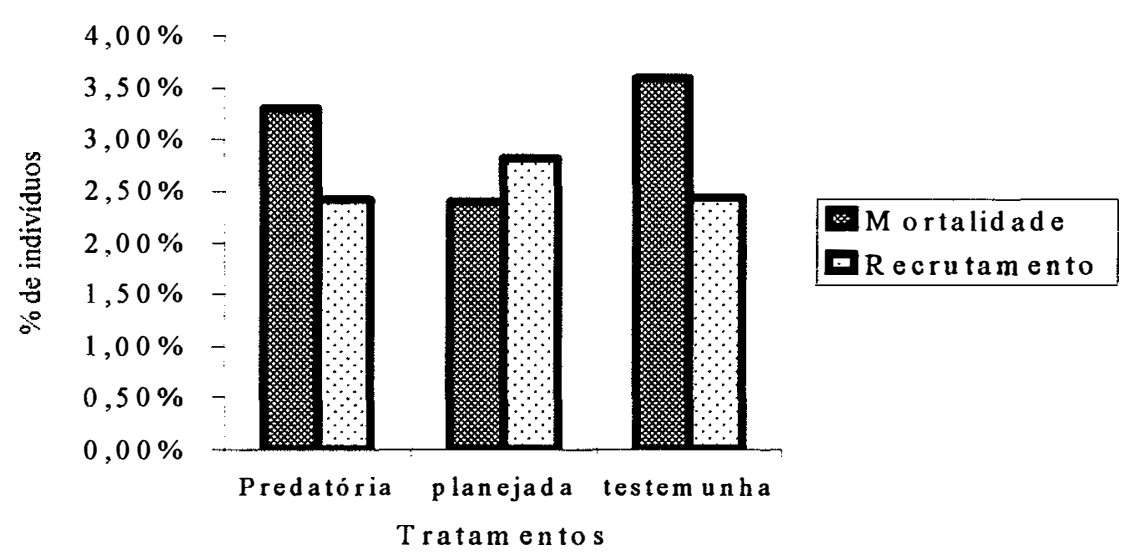

Figura 4. Mortalidade anual e recrutamento de árvores acima de $10 \mathrm{~cm}$ de diâmetro para um período de 3 anos na Fazenda Agrosete, em Paragominas, Pará-Brasil.

Não houve diferença significativa entre indivíduos recrutados nos tratamentos, sendo recrutados em média três anos após a exploração, 12 indivíduos/ha (ou 4 
indivíduos/ha/ano) no tratamento exploração predatória e testemunha e 14 indivíduos/ha (ou 5 indivíduos/ha/ano) no tratamento colheita planejada. Das 20 espécies recrutadas no tratamento testemunha, uma não existia na floresta original. No tratamento colheita planejada e exploração predatória das 30 espécies recrutadas duas não existiam na floresta original.

\subsection{CONCLUSÃO}

Há inúmeras vantagens que uma colheita planejada pode proporcionar, como redução de desperdícios (Gerwing et al. 1996; Vidal et al. 1997b), redução de danos (Johns et al. 1997), viabilidade e atratividade econômica (Barreto et al. no prelo) e maior crescimento das árvores (Vidal \& Viana, no prelo), além de não modificar muito a estrutura da floresta quando comparada com a exploração predatória.

$\mathrm{O}$ uso das técnicas de manejo na colheita planejada contribuiu para que 8 indivíduos por hectare não desaparecessem. $O$ recrutamento no período amostrado foi superior à mortalidade. Em síntese, na colheita planejada houve menor redução de diversidade de espécies do que na exploração predatória, ou seja, menores danos à biodiversidade. Os efeitos reduzidos da colheita planejada ainda não são conclusivos. A floresta tropical é muito dinâmica. É possível que o comportamento da diversidade seja modificado ao longo do tempo. Para isso, é necessário um acompanhamento a longo prazo da floresta, objetivando avaliar, com precisão, as mudanças.

Todavia, como foi observado, a remoção do grande número de árvores usadas produz um impacto negativo na estrutura e na diversidade de espécies e não garante que a regeneração tenha uma alta proporção de espécies madeireiras (Batista, 1989). Portanto, mesmo que a colheita seja cuidadosa e que medidas sejam tomadas para estimular a regeneração de espécies, a colheita modifica a composição e a dominância de espécies localmente. Dessa forma, existe uma grande necessidade de estudos que examinam como a colheita afeta a reprodução, sobrevivência e crescimento da vegetação e como estes efeitos, por sua vez, afetam a fauna. 


\subsection{AGRADECIMENTOS}

Ao WWF (Fundo Mundial para Natureza) e à USAID (Agência Norte Americana de Desenvolvimento Internacional), pela ajuda financeira para coleta dos dados no campo e ao CNPq pela bolsa de mestrado. A Damião Farias, à Leonor Aguiar, a Manuel Farias e a Miguel Lopes por suas contribuições na coleta de dados no campo. A Nelson de Araújo Rosa pela identificação botânica das espécies. A Adalberto Veríssimo, a Paulo Barreto, a Paulo Amaral e a José do Carmo pela troca de idéias e revisões dos manuscritos. Agradecimento especial ao Prof. Christopher Uhl, por ser o mentor do projeto que deu origem à este estudo. À Risonele Bahia e Robert Bushbacher (WWF Brasil) pelas revisões dos manuscritos. Aos colegas do laboratório de silvicultura tropical pelas discussões relacionadas com esse estudo. À colega Kátia Geórgia, pela incansável ajuda com o programa estatístico S_PLUS. A Rodney Roney, pela ajuda na confecção dos mapas no arqview. À administração do Imazon, pelo apoio logístico. E a Percio Lima, proprietário da área de estudo.

\subsection{BIBLIOGRAFIA}

AMARAL, P., BARRETO, P., VERÍSSIMO, A.; VIDAL, E. 1998. Floresta para sempre: um manual para produção de madeira na Amazônia. IMAZON. 150p.

BARRETO, P., UHL, C.; YARED, J. 1994. Avaliação do Potencial para Manejo Florestal em Paragominas, considerando Fatores Ecológicos e Econômicos. In: ANAIS DO VII CONGRESSO FLORESTAL BRASILEIRO E I CONGRESSO FLORESTAL PANAMERICANO, SBS-SBEF. Set.1993.p. 387-392.

BARRETO, P., AMARAL, P., VIDAL, E.; UHL, C. Costs and benefits of forest management for timber production in eastern Amazonia. Forest Ecology and Management. /No prelo/. 
BAWA, K.S. ASHTON, P.S. Conservation of rare trees in tropical rain forest: a genetic perspective. In: Genetics and conservation of rare plants. D.A FALK \& K.E. HOLSINGER (eds.). New York, Oxford, Oxford University Press, USA, 1991, p.6271.

BATISTA, J.L.F., A função Weibull como modelo para distribuição de diâmetro de espécies arbóreas tropicais. Piracicaba, 1989. 115p. Dissertação (M.S.) - Escola Superior de Agricultura "Luiz de Queiroz".

BRASI, Ministério das Minas e Energia. Departamento Nacional de Produção Mineral. Folha AS 22 Belém: geologia, geomorfologia, solos, vegetação e uso potencial da terra. Rio de Janeiro, 1974. (Projeto Radam. Levantamento de Recursos Naturais, 5).

CONDIT, R.; HUBBELL, S.; FOSTER, R. Short-term dynamics of a neotropical forest: chance within limits. BioScience. v.42, n. 11, p.822-828, 1992.

GAJASENI, J. ; BOONPRAGOB, K. 1995. Methods for measurement of species diversity. In: Measuring and monitoring biodiversity in tropical and temperate forests. Ed. Timothy J. B. Boyle and Boonchoob Boontaweee. CIFOR. Malaysia, cap 21, 303-307.

GERWING, J., JOHNS, J.; VIDAL, E. Reducing waste during logging and log processing towards forest conservation in Eastern Amazon. Unasylva, v.47, n. 187, p.17-25, 1996.

IBGE, 1993. Anuário Estatístico do Brasil. Rio de Janeiro. Secretaria de Planejamento, Orçamento e Coordenação. 
JOHNS, J., BARRETO, P.; UHL, C. Logging damage in planned and unplanned logging operations and its implications for sustainable timber production in the Eastern Amazon. Forest Ecology and Management, v.89, p.59-77, 1997.

KAGEYAMA, P.; GANDARA, F.B. 1994. Dinâmica de populações de espécies arbóreas; implicações para o manejo e conservação. III SIMPÓSIO DE ECOSSISTEMAS DA COSTA BRASILEIRA, ACIESP. Abril de 1994, 1-9.

MAGURRAN, E. A 1987. Ecological diversity and its measurement. Princeton University Press. 179 p.

MARTINI, A., ROSA, N.; UHL, C. An attempt to predict which Amazonian tree species may be threatened by logging activities. Environmental Conservation, v.21, p.152$162,1994$.

MARTINS, E.P., OLIVEIRA, A.D.; SCOLFORO, J.R.S. Avaliação dos danos causados pela exploração florestal à vegetação remanescente, em florestas naturais. Cerne. v. 3, p.014-024, 1997.

PIELOU, E.C. 1975. Ecological diversity. John Willey \& Sons. New York. 156 p.

PRADO, A.C. Diretrizes para uma política florestal no Brasil. MA/MMA. 1995. 171p.

SILVA, J.N.M.. The behavior of the tropical rain forest of the brazilian amazon after logging. Oxford, 1989. 325p. Thesis (PhD) - University of Oxford.

SILVA, J.N.M. 1993. A experiência do manejo sob rendimento sustentado em florestas tropicais úmidas. In: ANAIS DO VII CONGRESSO FLORESTAL BRASILEIRO E I CONGRESSO FLORESTAL PANAMERICANO, SBS-SBEF. Set.1993.p. 202206. 
SILVA, J.N.M, J.O.P. DE CARVALHO, J. DO C.A. LOPES, B.F. DE ALMEIDA, D.H.M. COSTA, L.C. DE OLIVEIRA, J.K. VANCLAY; J. P. SKOVSGAARD. Growth and yield of a tropical rain forest in the brazilian Amazon 13 years after logging. Forest Ecology and Management, v.71, p.267-274, 1995.

SOUTHWOOD, T.R.E. 1978. Ecological methods. Chapman \& Hall. London. 232 p.

UHL, C., VERÍSSIMO, A., BARRETO, P., MATTOS, M., TARIFA, R. O desafio da exploração sustentada. Ciência Hoje, v.14, p.53-59, 1992.

UHL, C., VERÍSSIMO, A., BRANDINO, Z.; VIEIRA, I. Social, economic, and ecological consequences of logging in the Amazon Frontier: The case of Tailandia. Forest Ecology and Management, v.46 p.243-273, 1991.

UHL, C. BARRETO, P., VERÍSSIMO, A., BARROS, A. C., AMARAL, P., VIDAL, E.; SOUZA Jr., C. Natural resource management in the brazilian Amazon: an integrated research approach. BioScience, v.47, p.160-199, 1997.

UHL, C. BUSCHBACHER, R.; SERRÃO, A.. Abandoned pastures in Eastern Amazônia. I. Patters of plant sucession. Journal of ecology, v.75, p.663-681. 1988.

UHL, C. BARRETO, P., VERÍSSIMO, A., BARROS, A. C., AMARAL, P., VIDAL, E.; SOUZA Jr., C. Uma abordagem integrada de pesquisa sobre manejo dos recursos naturais na Amazônia. Pg. 140-164. In: A. VERÍSSIMO e A. C. Barros, editores. A expansão da atividade madeireira na Amazônia: Impactos e perspectiva para o desenvolvimento do setor florestal no Pará. Belém, IMAZON, 1996, 168p. 
VERÍSSIMO, A., BARRETO, P., MATTOS, M., TARIFA, R.; UHL, C. Logging impacts and prospects for sustainable forest management in an old Amazonian frontier: the case of Paragominas. Forest Ecology and Management, v.55, p.169199, 1992.

VIDAL, E., BARRETO, P., JOHNS, J., GERWING, J.; UHL, C.. Vine management for reduced-impacts logging in Eastern Amazon. Forest Ecology and Management, v.98, p.105-114, 1997a

VIDAL, E., GERWING, J., BARRETO, P., AMARAL, P.; JOHNS, J. 1997b. Redução de desperdícios de madeira na Amazônia. IMAZON, Série Amazônia, n. 5.18 pg.

VIDAL, E.; VIANA, V. Crescimento de floresta tropical três anos após exploração madeireira predatória e planejada na Amazônia oriental./no prelo/.

WATRIN, O. dos S.; ROCHA, A.M.A. da. Levantamento da vegetação natural e uso da terra no município de Paragominas (PA) utilizando imagens TM/LANDSAT. Belém: EMBRAPA-CPATU, 1991. 40p. (EMBRAPA-CPATU. Boletim de Pesquisa, 124). 
Anexo 1: Densidade de indivíduos com e sem valor madeireiro que possuem DAP acima de $10 \mathrm{~cm}$ de diâmetro, por tratamento e por período de medição na fazenda Agrosete, em Paragominas, Pará-Brasil.

\begin{tabular}{|c|c|c|c|c|c|c|c|c|c|c|}
\hline \multirow[t]{2}{*}{ Tratamento } & \multirow[t]{2}{*}{$\begin{array}{c}\text { Classes } \\
\text { diamétrica }\end{array}$} & \multicolumn{3}{|c|}{$\begin{array}{l}\text { Árvores com valor } \\
\text { madeireiro (n/ha) }\end{array}$} & \multicolumn{3}{|c|}{$\begin{array}{l}\text { Árvores sem valor } \\
\text { madeireiro (n/ha) }\end{array}$} & \multicolumn{3}{|c|}{ Total (n/ha) } \\
\hline & & $1993^{1}$ & $1994^{2}$ & $1996^{3}$ & $1993^{1}$ & $1994^{2}$ & $1996^{3}$ & $1993^{1}$ & $1994^{2}$ & $1996^{3}$ \\
\hline \multirow[t]{3}{*}{ Testemunha } & $>10<30$ & 59 & 57 & 53 & 335 & 328 & 321 & 394 & 385 & 374 \\
\hline & $>30<50$ & 20 & 20 & 19 & 12 & 11 & 10 & 32 & 31 & 29 \\
\hline & $>50$ & 5 & 5 & 5 & 1 & 1 & 1 & 6 & 6 & 6 \\
\hline \multicolumn{2}{|c|}{ total em todas as classes } & 84 & 82 & 77 & 348 & 340 & 332 & 432 & 422 & 409 \\
\hline \multirow[t]{3}{*}{ Manejo } & $>10<30$ & 88 & 79 & 77 & 346 & 283 & 268 & 434 & 362 & 345 \\
\hline & $>30<50$ & 37 & 32 & 31 & 14 & 14 & 14 & 51 & 46 & 45 \\
\hline & $>50$ & 11 & 6 & 6 & 2 & 2 & 2 & 13 & 8 & 8 \\
\hline \multicolumn{2}{|c|}{ total em todas as classes } & 136 & 117 & 114 & 362 & 299 & 284 & 498 & 416 & 398 \\
\hline Exploração & $>10<30$ & 65 & 54 & 51 & 322 & 260 & 244 & 387 & 314 & 295 \\
\hline \multirow[t]{2}{*}{ Predatória } & $>30<50$ & 26 & 23 & 21 & 20 & 16 & 16 & 46 & 39 & 37 \\
\hline & $>50$ & 14 & 5 & 5 & 2 & 1 & 1 & 16 & 6 & 6 \\
\hline \multicolumn{2}{|c|}{ total em todas as classes } & 105 & 82 & 77 & 344 & 277 & 261 & 449 & 359 & 338 \\
\hline
\end{tabular}

Notas:

1 - dados coletados antes da exploração;

2 - dados coletados 1 ano após a exploração;

3 - dados coletados 3 anos após a exploração. 
Anexo 2: Nomes científicos, famílias e densidade (indivíduos/ha) com DAP $>10 \mathrm{~cm}$ das espécies encontradas nos tratamentos testemunha, colheita planejada e exploração predatória (I) antes, (II) logo após e três anos após a exploração em Paragominas, Pará.

\begin{tabular}{|c|c|c|c|c|c|c|c|c|c|c|}
\hline \multirow{3}{*}{ NOME CIENTÍFICO AUTOR } & \multirow[b]{3}{*}{ FAMÍLIA } & \multicolumn{9}{|c|}{ TRATAMENTOS } \\
\hline & & \multicolumn{3}{|c|}{ Testemunha } & \multicolumn{3}{|c|}{ Planejada } & \multicolumn{3}{|c|}{ Predatória } \\
\hline & & I & II & III & I & II & III & I & II & III \\
\hline Anacardium giganteum Hanc. ex Engl. & ANACARDIACEAE & 0,1 & 0,1 & 0,1 & & & & & & \\
\hline Aiouea att. densiflora Nees & LAURACEAE & & & & 0,1 & 0,1 & 0,1 & & & \\
\hline Aiouea sp & LAURACEAE & & & & 0,1 & 0,1 & 0,1 & & & \\
\hline Allophylus florisbunda & SAPOTACEAE & 2,0 & 2,0 & 2,0 & $\overline{1,6}$ & 1,0 & 1,0 & 2,0 & 1,4 & 1,4 \\
\hline Ambelania sp & APOCYNACEAE & & & & & & & 0,2 & 0,0 & 0,0 \\
\hline Annona sp & ANNONACEAE & 1,8 & 1,8 & 1,8 & 2,2 & $\overline{2,2}$ & 1,2 & $\overline{2,6}$ & 2,0 & 2,0 \\
\hline Apeiba burchelli Sprague & TILIACEAE & 1,8 & 1,8 & 1,8 & 2,2 & 1,7 & 1,7 & 3,0 & 2,6 & 2,7 \\
\hline Apeiba echinata Gaertn. & TILIACEAE & 0,6 & 0,6 & 0,6 & 0,3 & 0,3 & 0,3 & & & \\
\hline Aspidosperma album Jacq. & APOCYNACEAE & & & & 0,3 & 0,3 & 0,3 & 0,4 & 0,4 & 0,4 \\
\hline Aspidosperma desmanthum Benth & APOCYNACEAE & 4,2 & 4,2 & 3,8 & 3,8 & 3,0 & 3,0 & 5,2 & 4,2 & 4,2 \\
\hline Aspidosperma oblongum A.DC. & APOCYNACEAE & & & & 0,1 & 0,1 & 0,1 & & & \\
\hline Astronium gracile Engl. & ANACARDIACEAE & 0,1 & 0,1 & 0,1 & 0,6 & 0,6 & 0,6 & 0,2 & 0,0 & 0,0 \\
\hline Bagassa guianensis Aubl. & MORACEAE & 0,6 & 0,6 & 0,6 & 0,5 & 0,3 & 0,4 & 0,2 & 0,1 & 0,2 \\
\hline Bellucia grossucaroides & MELASTOMAT ACEAE & 0,3 & 0,3 & 0,3 & 0,3 & 0,3 & 0,3 & & & \\
\hline Bixa arborea Huber & BIXACEAE & & & & 0,1 & 0,1 & 0,1 & & & \\
\hline Bombax longipedicellatum Ducke & BOMBACACEAE & 0,3 & 0,3 & 0,6 & & & & 0,8 & 0,7 & 0,9 \\
\hline Bombax paraensis Ducke & BOMBACACEAE & & & & 0,1 & 0,1 & 0,1 & 0,2 & 0,2 & 0,2 \\
\hline Bowdichia virgilioides H.B.K. & FABACEAE & & & & & & & 0,1 & 0,1 & 0,1 \\
\hline Brosimum acutifolium Huber & MORACEAE & & & & 0,1 & 0,1 & 0,1 & & & \\
\hline Brosimum guianensis Aubl. & MORACEAE & 1,5 & 1,5 & 1,4 & 0,1 & 0,1 & 0,1 & & & \\
\hline Brosimum potabile Ducke & MORACEAE & 0,1 & 0,1 & 0,1 & & & & 0,1 & 0,0 & $\overline{0,0}$ \\
\hline Buchenavia capitata Eichl. & COMBRETACEAE & & & & 0,8 & 0,5 & 0,5 & & & \\
\hline Byrsonima aerugo Sagot. & MALPIGHIACEAE & 0,6 & 0,6 & 0,6 & & & & 0,3 & 0,3 & 0,3 \\
\hline Calophyllum brasiliense Camb. & GUTTIFERAE & & & & & & & 0,1 & 0,0 & 0,0 \\
\hline Campsiandra laurifolia Bth. & CAESALPINIACEAE & & & & & & & 0,2 & 0,0 & 0,0 \\
\hline Carapa guianensis Aubl. & MELIACEAE & & & & 1,0 & 0,8 & 0,9 & & & \\
\hline Caryocar glabrum (Aubl.)Pers. & CARYOCARACEAE & 0,8 & 0,8 & 0,8 & 0,7 & 0,5 & 0,5 & 0,8 & 0,8 & 0,8 \\
\hline Caryocar villosum (Aubl.)Pers. & CARYOCARACEAE & 0,1 & 0,1 & 0,1 & 0,6 & 0,6 & 0,9 & 0,6 & 0,0 & 0,1 \\
\hline Cazearia arborea & FLACOURTIACEAE & & & & 0,2 & 0,2 & 0,2 & 0,2 & 0,2 & 0,2 \\
\hline Cecropia obtusa & MORACEAE & 2,5 & 2,1 & 1,9 & 1,2 & 0,8 & 0,8 & 2,6 & 1,8 & 1,8 \\
\hline Cecropia sciadophylla Mart. & MORACEAE & 8,0 & 8,0 & 7,8 & 4,2 & 2,4 & 2,4 & 3,6 & 3,2 & 3,2 \\
\hline Cedrela odorata L. & MELIACEAE & 0,3 & 0,3 & 0,3 & 0,4 & 0,4 & 0,4 & & & \\
\hline Chamaecrista xinguensis & CAESALPINIACEAE & 0,5 & 0,5 & 0,5 & 0,1 & 0,1 & 0,1 & & & \\
\hline Chaunochiton Kappleri (Sag. ex Engl.)Ducke & OLACACEAE & & & & 0,1 & 0,1 & 0,1 & & & \\
\hline Clarisia racemosa Ruiz e Pav. & MORACEAE & 1,0 & 1,0 & 1,0 & 2,6 & 1,8 & 1,8 & 3,5 & 2,8 & 2,8 \\
\hline Copaifera duckei $\quad$ Dwyer & CAESALPINIACEAE & 0,2 & 0,2 & 0,3 & 0,6 & 0,3 & 0,4 & 1,3 & 0,4 & $\overline{0,4}$ \\
\hline Cordia bicolor D.C. & BORAGINACEAE & 9,0 & 8,8 & 8,5 & 8,7 & 7,7 & 7,9 & 8,6 & 7,1 & 7,3 \\
\hline Cordia goeldiana Huber & BORAGINACEAE & 2,3 & 2,3 & 2,3 & 5,0 & 4,3 & 4,7 & 1,6 & 1,4 & 2,3 \\
\hline Cordia scabrifolia A.DC. & BORAGINACEAE & 2,2 & 2,2 & 2,1 & 1,0 & 1,0 & 1,0 & & & \\
\hline Couepia bracteosa Benth. & CHRYSOBALANACEAE & 0,1 & 0,1 & 0,1 & & & & & & \\
\hline Couratari guianensis Aubl. & LECYTHIDACEAE & 0,1 & 0,1 & 0,1 & 0,2 & 0,2 & 0,2 & 0,7 & 0,2 & 0,2 \\
\hline Couratari multiflora (Smith)Eyma & LECYTHIDACEAE & 0,1 & 0,1 & 0,1 & 0,1 & 0,1 & 0,1 & & & \\
\hline Couratari oblongfolia Ducke et Knuth. & LECYTHIDACEAE & & & & 0,3 & 0,2 & 0,2 & & & \\
\hline Dendrobangia boliviana Rusbi & ICACINACEAE & 0,2 & 0,2 & 0,2 & & & & & & \\
\hline Dialium guianensis (Aubl.)Sandw. & CAESALPINIACEAE & 0,4 & 0,4 & 0,4 & 0,2 & 0,1 & 0,1 & 0,1 & 0,1 & 0,1 \\
\hline
\end{tabular}




\begin{tabular}{|c|c|c|c|c|c|c|c|c|c|c|}
\hline Didymopanax morototoni (Aubl)Decne\&Planch. & ARALIACEA & 0,5 & 0,5 & 0,6 & 0,8 & 0,7 & 0,9 & 0,8 & 0,7 & 0,9 \\
\hline Dinizia excelsa Ducke & MIMOSACEAE & & & & & & & 0,1 & 0,1 & 0,1 \\
\hline Diospyros mellinoni (Hierne)A.C. Smith & EBENACEAE & 0,2 & 0,2 & 0,2 & & & & 0,1 & 0,1 & 0,1 \\
\hline Diospyros praetermissa Sandwith & EBENACEAE & & & & & & & 0,4 & 0,0 & 0,1 \\
\hline Diospyros tectranda Hiem & EBENACEAE & 14,2 & 14,2 & 13,1 & 28,7 & 21,3 & 21,3 & 15,8 & 12,4 & 12,4 \\
\hline Diploon venezuelana & SAPOTACEAE & 0,1 & 0,1 & 0,1 & 0,2 & 0,2 & 0,2 & & & \\
\hline Dipteryx odorata Willd. & FABACEAE & & & & 0,8 & 0,3 & 0,4 & & & \\
\hline Drypetes amazonica Steyerm. & EUPHORBIACEAE & & & & 0,9 & 0,7 & 0,7 & & & \\
\hline Endopleura uchi (Huber)Cuatr. & HUMIRIACEAE & & & & 0,1 & 0,0 & 0,0 & & & \\
\hline Eschweilera apiculata & LECYTHIDACEAE & 0,4 & 0,4 & 0,4 & 0,2 & 0,2 & 0,2 & & & \\
\hline Eschweilera colina & LECYTHIDACEAE & 0,1 & 0,1 & 0,1 & 0,1 & 0,1 & 0,1 & & & \\
\hline Eschweilera coriacea (Ap.Decand)Mart.ex Berg. & LECYTHIDACEAE & 0,9 & 0,9 & 0,9 & 12,2 & 9,1 & 9,1 & 4,1 & 3,7 & 3,7 \\
\hline Eschweilera grandiflora (Aubl)Sandw. & LECYTHIDACEAE & 1,2 & 1,2 & 1,2 & 0,6 & 0,6 & 0,6 & 0,6 & 0,6 & 0,6 \\
\hline Eschweilera pedicelata & LECYTHIDACEAE & 12,7 & 12,7 & 12,3 & 21,6 & 18,7 & 18,7 & 21,9 & 18,1 & 18,1 \\
\hline Franchetella jariense & SAPOTACEAE & 0,4 & 0,4 & 0,4 & & & & & & \\
\hline Franchetella saugatiana & SAPOTACEAE & 0,9 & 0,9 & 0,8 & 0,3 & 0,3 & 0,3 & & & \\
\hline Franchetella sp & SAPOTACEAE & & & & 0,4 & 0,3 & 0,3 & & & \\
\hline Glycoxilon $s p$ & SAPOTACEAE & 0,1 & 0,1 & 0,1 & & & & & & \\
\hline Guarea kunthiana A.Juss. & MELIACEAE & & & & 0,1 & 0,1 & 0,1 & & & \\
\hline Guatteria olivacea R.E.Fries & ANNONACEAE & 1,3 & 1,3 & 1,3 & 0,2 & 0,2 & 0,2 & & & \\
\hline Guatteria poeppigiana Mart. & ANNONACEAE & 3,1 & 2,8 & 2,7 & 5,0 & 4,4 & 5,2 & 7,6 & 5,3 & 5,7 \\
\hline Guatteria schuburgkiana & ANNONACEAE & 1,0 & 1,0 & 1,0 & 0,6 & 0,5 & 0,5 & & & \\
\hline Guatteria sp & ANNONACEAE & 19,5 & 19,4 & 18,3 & 3,7 & 2,3 & 2,3 & 19,0 & 14,6 & 14,6 \\
\hline Helicostylis pedunculata R.Ben. & MORACEAE & & & & 0,1 & 0,1 & 0,1 & & & \\
\hline Hieronyma alchorneoides Fr.All. & EUPHORBIACEAE & 1,0 & 1,0 & 1,0 & & & & 0,4 & 0,4 & 0,4 \\
\hline Hieronyma sp & EUPHORBIACEAE & 0,8 & 0,8 & 0,8 & 0,2 & 0,0 & 0,0 & 0,4 & 0,2 & 0,2 \\
\hline Himatanthus sucuuba (Spruce)Woodson & APOCYNACEAE & 1,2 & 1,2 & 1,2 & 0,2 & 0,2 & 0,2 & 1,4 & 1,4 & 1,4 \\
\hline Hymenaea courbaril L. & CAESALPINIACEAE & 0,5 & 0,5 & 0,9 & 1,6 & 1,1 & 1,7 & 1,1 & 0,7 & 0,9 \\
\hline Hymenaea palustris Ducke & CAESALPINIACEAE & 0,2 & 0,2 & 0,2 & 0,8 & 0,6 & 0,6 & 0,9 & 0,7 & 0,7 \\
\hline Hymenaea parvifolia Huber & CAESALPINIACEAE & 0,5 & 0,5 & 0,5 & 0,4 & 0,4 & 0,4 & & & \\
\hline $\begin{array}{ll}\text { Inga alba } & \text { (SW) Willd. } \\
\end{array}$ & MIMOSACEAE & 6,4 & 6,1 & 5,9 & 18,4 & 15,1 & 15,1 & 6,4 & 3,7 & 3,7 \\
\hline Inga capitata Desv. & MIMOSACEAE & 0,6 & 0,6 & 0,6 & 0,5 & 0,1 & 0,1 & & & \\
\hline Inga cf. cylindrica Mart. & MIMOSACEAE & 44,1 & 44,0 & 41,6 & 36,0 & 25,8 & 25,8 & 33,0 & 25,3 & 25,3 \\
\hline Inga cf. pezizifera Benth. & MIMOSACEAE & & & & 0,1 & 0,0 & 0,0 & & & \\
\hline Inga cf. strigilosa Spr. ex. Benth & MIMOSACEAE & & & & 0,2 & 0,2 & 0,2 & & & \\
\hline Inga dumosa Benth & MIMOSACEAE & & & & 0,2 & 0,2 & 0,2 & 4,1 & 3,8 & 3,8 \\
\hline Inga edulis Mart. & MIMOSACEAE & 0,6 & 0,6 & 0,5 & 0,5 & 0,5 & 0,5 & & & \\
\hline Inga falcistipula Ducke & MIMOSACEAE & & & & 0,2 & 0,2 & 0,2 & & & \\
\hline Inga gracilifolia Benth & MIMOSACEAE & & & & 0,1 & 0,1 & 0,1 & & & \\
\hline Inga paraensis Ducke & MIMOSACEAE & 0,2 & 0,2 & 0,2 & 1,7 & 1,6 & 1,6 & & & \\
\hline Inga rubiginosa (Rich) DC. & MIMOSACEAE & 1,0 & 1,0 & 0,9 & 0,7 & 0,7 & 0,7 & & & \\
\hline Inga thibaldiana $\mathrm{DC}$. & MIMOSACEAE & 0,3 & 0,3 & 0,3 & & & & & & \\
\hline Jacaranda copaia (Aubl.) D.Don & BIGNONIACEAE & 1,0 & 1,0 & 1,0 & 0,5 & 0,5 & 0,7 & 0,8 & 0,4 & 0,5 \\
\hline Jacaratia spinosa (Aubl.) A. DC. & CARICACEAE & 0,2 & 0,2 & 0,2 & 0,3 & 0,3 & 0,3 & 0,5 & 0,5 & 0,5 \\
\hline Lacmella sculenta (Duck) Monach. & MORACEAE & 1,8 & 1,8 & 1,8 & 0,6 & 0,4 & 0,4 & 1,6 & 1,0 & 1,0 \\
\hline Laetia procera (P. et E.)Eichl. & FLACOURTIACEAE & 2,6 & 2,6 & 2,6 & 3,7 & 3,5 & 3,6 & 3,5 & 2,8 & 3,0 \\
\hline Lecythis idatimon Aubl. & LECYTHIDACEAE & & & & 33,2 & 29,8 & 29,8 & 46,2 & 35,3 & 35,3 \\
\hline Lecythis latifolium(A.C.Smith) Rich & LECYTHIDACEAE & & & & 2,5 & 2,2 & 2,2 & & & \\
\hline Lecythis lurida (Miers)Mori & LECYTHIDACEAE & & & & 0,0 & 0,0 & 0,3 & 2,5 & 2,1 & 2,2 \\
\hline Lecythis paraensis Ducke & LECYTHIDACEAE & 37,4 & 37,4 & 35,8 & 0,4 & 0,4 & 0,4 & & & \\
\hline Lecythis pisonis Cambess & LECYTHIDACEAE & 0,4 & 0,4 & 0,4 & & & & 1,2 & 1,1 & 1,1 \\
\hline Licania heteromorpha Bth. & CHRYSOBALANACEAE & & & & 0,1 & 0,1 & 0,1 & & & \\
\hline Licania pallida Spruce ex. Sagot. & CHRYSOBALANACEAE & 0,3 & 0,3 & 0,3 & 0,4 & 0,2 & 0,2 & 0,4 & 0,4 & 0,4 \\
\hline Macrolobium angustifolium & CAESALPINIACEAE & 2,5 & 2,5 & 2,4 & 0,4 & 0,3 & 0,3 & 1,9 & 1,3 & 1,3 \\
\hline Macrolobium bifolium (Aubl.)Pers. & CAESALPINIACEAE & & & & 1,5 & 1,3 & 1,3 & & & \\
\hline
\end{tabular}




\begin{tabular}{|c|c|c|c|c|c|c|c|c|c|c|}
\hline Macrolobium campestre Hub. & CAESALPINIACEAE & 0,6 & 0,6 & 0,6 & & & & 1,3 & 1,1 & 1,1 \\
\hline Macrolobium sp & CAESALPINIACEAE & 23,2 & 23,2 & 22,2 & 16,8 & 13,0 & 13,0 & 13,4 & 11,8 & 11,8 \\
\hline Manilkara amazonica (Huber)Standley & SAPOT ACEAE & 0,9 & 0,9 & 1,0 & 1,2 & 1,0 & 1,1 & 0,4 & 0,2 & 0,2 \\
\hline Manilkara bidentata D.C. Chev. & SAPOTACEAE & & & & 2,6 & 2,1 & $\overline{2,5}$ & & & \\
\hline Manilkara huberi Standley & SAPOT ACEAE & 1,4 & 1,4 & 1,6 & 0,0 & 0,0 & 0,0 & 2,9 & 1,5 & 1,7 \\
\hline Manilkara paraensis & SAPOTACEAE & 0,2 & 0,2 & 0,2 & 0,3 & 0,3 & 0,3 & & & \\
\hline Maytenus guianense & CELASTRACEAE & 1,0 & 1,0 & 1,0 & & & & 0,3 & 0,1 & 0,1 \\
\hline Micrandra elata Benth & EUPHORBIACEAE & & & & & & & 0,1 & 0,1 & 0,1 \\
\hline Micropholis melinoniana & SAPOTACEAE & & & & 0,1 & 0,0 & 0,0 & 0,4 & 0,0 & 0,0 \\
\hline Micropholis venulosa (Mart \&Eichl)Pierre & SAPOT ACEAE & & & & & & & 0,1 & 0,1 & 0,1 \\
\hline Minquartia guianensis Aubl. & OLACACEAE & & & & & & & 1,5 & 1,1 & 1,1 \\
\hline Moronobea coccinea Aubl. & GUTTIFERAE & 0,3 & 0,3 & 0,4 & 0,2 & 0,2 & 0,2 & & & \\
\hline Mouriria guianensis Aubl. & MELASTOMATACEAE & 1,4 & 1,4 & 1,4 & & & & & & \\
\hline Nectandra cuspidata Nees & LAURACEAE & 0,4 & 0,4 & 0,2 & & & & & & \\
\hline Neea sp 1 & NYCTAGINACEAE & 24,0 & 24,0 & 22,9 & 35,9 & 28,5 & 28,5 & 25,1 & 20,9 & 20,9 \\
\hline Newtonia psilostachya (DC.)Brenan & MIMOSACEAE & 0,6 & 0,6 & 0,6 & 0,3 & 0,3 & 0,3 & 1,5 & 0,8 & 1,3 \\
\hline Newtonia suaveolens (Miq.)Brenan & MIMOSACEAE & 1,3 & 1,3 & 1,9 & 0,9 & 0,8 & 1,4 & 0,7 & 0,3 & 0,3 \\
\hline Ocotea cajumari & LAURACEAE & 0,3 & 0,2 & 0,2 & 0,3 & 0,3 & 0,3 & & & \\
\hline Ocotea caudata Mez. & LAURACEAE & 1,8 & 1,8 & 1,4 & 0,2 & 0,2 & 0,2 & & & \\
\hline Ocotea costulata (Nees)Mez. & LAURACEAE & 0,4 & 0,4 & 0,4 & 1,3 & 0,9 & 1,0 & 0,6 & 0,4 & 0,5 \\
\hline Ocotea glomerata (Nees)Mez. & LAURACEAE & 1,1 & 1,1 & 1,0 & 0,3 & 0,0 & 0,5 & 0,0 & 0,0 & 1,2 \\
\hline Ocotea guianensis Aubl. & LAURACEAE & & & & 0,5 & 0,3 & 0,3 & & & \\
\hline Ocotea longifolia H.B.K. & LAURACEAE & 0,4 & 0,4 & 0,4 & & & & & & \\
\hline Ocotea petalante & LAURACEAE & & & & 0,1 & 0,1 & 0,1 & & & \\
\hline Ocotea rubra Mez & LAURACEAE & 2,1 & 2,1 & 1,6 & 3,6 & 3,2 & 3,2 & 3,0 & 2,0 & 2,0 \\
\hline Ormosia coutinhoi Ducke & FABACEAE & 0,6 & 0,6 & 0,6 & 1,1 & 0,7 & 0,7 & 0,3 & 0,3 & 0,3 \\
\hline Parkia gigantocarpa Ducke & MIMOSACEAE & & & & 3,6 & 3,1 & 3,1 & & & \\
\hline Parkia multijuga Benth & MIMOSACEAE & 0,7 & 0,7 & 0,6 & 0,1 & 0,1 & 0,1 & 0,6 & 0,4 & 0,4 \\
\hline Parkia nitida & MIMOSACEAE & 1,2 & 1,1 & 2,0 & 0,5 & 0,2 & 0,6 & 1,3 & 1,2 & 2,4 \\
\hline Parkia pendula Benth & MIMOSACEAE & 0,3 & 0,3 & 0,3 & 0,4 & 0,4 & $\overline{0,6}$ & 0,9 & 0,8 & 0,8 \\
\hline Perebea guianensis Aubl & MORACEAE & 5,8 & 5,8 & 5,7 & 4,8 & 4,1 & 4,1 & 9,0 & 7,0 & 7,0 \\
\hline Pithecellobium pedicellare (DC)Bth & MIMOSACEAE & 0,2 & 0,2 & 0,2 & & & & 0,1 & 0,1 & 0,1 \\
\hline Pithecellobium racemosum Ducke & MIMOSACEAE & & & & 0,4 & 0,4 & 0,7 & 0,7 & 0,4 & 0,6 \\
\hline Platymiscium trinitatis Bth. & FABACEAE & & & & & & & 0,2 & 0,2 & 0,2 \\
\hline Pourouma guianensis Aubl. & CECROPIACAEA & 3,2 & 2,9 & 2,6 & 3,5 & 2,3 & 2,3 & 4,1 & 3,3 & 3,3 \\
\hline Pouteria esprucia & SAPOTACEAE & & & & 1,4 & 1,4 & 1,4 & 0,4 & 0,4 & 0,4 \\
\hline Pouteria guianensis Aubl. & SAPOTACEAE & 8,5 & 8,5 & 8,3 & 8,0 & 6,8 & 6,8 & 4,2 & 2,5 & 2,5 \\
\hline Pouteria lasiocarpa Gomes & SAPOTACEAE & 37,2 & 37,1 & 35,8 & 36,8 & 29,0 & 29,0 & 27,7 & 17,5 & 17,5 \\
\hline Pouteria macrophylla Eyma & SAPOTACEAE & 1,6 & 1,6 & 1,6 & 0,2 & 0,2 & 0,2 & 4,0 & 3,0 & 3,0 \\
\hline Pouteria sp (abiu guajará) & SAPOTACEAE & 0,3 & 0,3 & 0,3 & & & & 4,4 & 2,4 & 2,4 \\
\hline Pouteria sp (abiu sem casca) & SAPOT ACEAE & 0,8 & 0,8 & 0,8 & 1,6 & 1,6 & 1,6 & 0,7 & 0,2 & 0,2 \\
\hline Pouteria sp (abiu solta casca) & SAPOTACEAE & 0,8 & 0,8 & 0,8 & $\overline{1,6}$ & 1,0 & 1,0 & 1,4 & 0,8 & $\overline{0,8}$ \\
\hline Protium altsoni Sandw. & BURSERACEAE & 0,1 & 0,1 & 0,1 & & & & 0,1 & 0,1 & 0,1 \\
\hline Protium decandrum (Aubl)March. & BURSERACEAE & & & & 0,1 & 0,1 & 0,1 & & & \\
\hline Protium opacum $\quad$ Swart. & BURSERACEAE & & & & 0,1 & 0,1 & 0,1 & & & \\
\hline Protium sagotianum March. & BURSERACEAE & 8,8 & 8,8 & 8,8 & 6,8 & 5,4 & 5,4 & 4,8 & 3,4 & 3,4 \\
\hline Pterocarpus amazonicus Hub. & FABACEAE & 0,4 & 0,4 & 0,4 & & & & & & \\
\hline Pterocarpus rohrii Vahl. & FABACEAE & 0,1 & 0,1 & 0,1 & 0,8 & 0,8 & 0,8 & 3,1 & 2,4 & 2,4 \\
\hline Pterodon pubescens Benth & FABACEAE & & & & 6,5 & 4,8 & 4,8 & & & \\
\hline Qualea acuminata Spruce & VOCHYSIACEAE & 0,2 & 0,2 & 0,1 & & & & 0,1 & 0,1 & 0,1 \\
\hline Radlkoferella macrocarpa (Hub) Aubl. & SAPOTACEAE & 3,7 & 3,7 & 3,5 & & & & 2,7 & 2,1 & 2,1 \\
\hline Raputia paraenses & RUTACEAE & 15,4 & 15,4 & 14,4 & 14,2 & 11,4 & 11,4 & 16,5 & 13,2 & 13,2 \\
\hline Richardella manauense & SAPOTACEAE & 0,1 & 0,1 & 0,1 & & & & & & \\
\hline Rinorea guianensis (Aubl)Schum. & VIOLACEAE & 2,1 & 2,1 & 2,1 & 0,9 & 0,9 & 0,9 & 2,4 & 1,8 & 1,8 \\
\hline Rollinia exsucca (Dun)A.DC. & ANNONACEAE & 0,2 & 0,2 & 0,2 & & & & & & \\
\hline
\end{tabular}




\begin{tabular}{|c|c|c|c|c|c|c|c|c|c|c|}
\hline Sacoglotis amazonica Benth & HUMIRIACEAE & & & & 0,3 & 0,3 & 0,3 & 0,8 & 0,7 & 0,7 \\
\hline Sacoglotis sp & HUMIRIACEAE & 1,0 & 1,0 & 1,0 & 0,8 & 0,8 & 0,8 & 1,2 & 0,6 & 0,6 \\
\hline Sandwithiodoxa egregia (Sandw.)Aubr.\&Pelleg. & SAPOTACEAE & 0,2 & 0,2 & 0,2 & & & & & & \\
\hline Sapium marmieri Hub. & EUPHORBIACEAE & 0,1 & 0,1 & 0,1 & 0,4 & 0,0 & 0,0 & 0,2 & 0,2 & 0,2 \\
\hline Sarcaulus brasiliensis Eyma & SAPOTACEAE & 0,1 & 0,1 & 0,1 & & & & & & \\
\hline Sclerolobium paraense Huber & CAESALPINIACEAE & 1,1 & 1,1 & 0,9 & 1,4 & 1,2 & 1,2 & 1,1 & 0,7 & 1,5 \\
\hline Simaruba amara Aubl. & SIMARUBACEAE & 0,2 & 0,1 & 0,1 & 0,6 & 0,5 & 0,7 & 0,4 & 0,3 & 0,3 \\
\hline Sterculia pilosa Ducke & STERCULIACEAE & & & & 8,4 & 6,8 & 6,8 & & & \\
\hline Sterculia pruriens (Aubl.)Schum. & STERCULIACEAE & 0,5 & 0,5 & 0,4 & 0,3 & 0,3 & 2,1 & 1,2 & 1,0 & 2,3 \\
\hline $\begin{array}{l}\text { Sterculia speciosa } \quad \text { K.Schum. } \\
\end{array}$ & STERCULIACEAE & 0,3 & 0,3 & 1,4 & & & & 0,5 & 0,3 & 0,4 \\
\hline Stryphnodendron palystachium & MIMOSACEAE & 0,1 & 0,1 & 0,1 & 0,7 & 0,5 & 0,5 & & & \\
\hline Stryphnodendron paniculatum P. at Endl. & MIMOSACEAE & & & & 0,0 & 0,0 & 0,4 & 1,1 & 1,0 & 1,7 \\
\hline Syzygiopsis oppositifolia $\quad$ Ducke & SAPOTACEAE & 0,4 & 0,4 & 0,4 & 1,5 & 1,2 & 1,2 & 1,5 & 0,3 & 0,3 \\
\hline Syzygiopsis pachycarpa Pires & SAPOTACEAE & 5,3 & 5,3 & 6,5 & 7,2 & 6,3 & $\overrightarrow{7,0}$ & 9,6 & 7,0 & $\overline{7,6}$ \\
\hline Tabebuia impetiginosa (Mart)Standl. & BIGNONIACEAE & 0,2 & 0,2 & 0,2 & 0,4 & 0,2 & 0,2 & & & \\
\hline Tabebuia insignis (Miq.)Sandw. & BIGNONIACEAE & & & & 0,4 & 0,4 & 0,4 & 0,3 & 0,0 & 0,0 \\
\hline Tabebuia serratifolia (Vahl.)Nicholes & BIGNONIACEAE & 0,5 & 0,5 & 0,5 & & & & 0,5 & 0,3 & $\overline{0,3}$ \\
\hline Tachigalia myrmecophylla Ducke & CAESALPINIACEAE & 4,5 & 4,4 & 4,0 & 7,7 & 6,4 & 7,1 & 5,1 & 3,5 & 4,3 \\
\hline Tachigalia paniculata & CAESALPINIACEAE & 3,7 & 3,7 & 5,7 & 0,5 & 0,5 & 4,0 & 0,0 & 0,0 & $\overline{0,2}$ \\
\hline Tapirira guianensis Aubl. & ANACARDIACEAE & 1,4 & 1,4 & 1,4 & 2,3 & 1,9 & 1,9 & & & \\
\hline Tapura singularis Ducke & DIDIAPETALACEAE & & & & 0,1 & 0,1 & 0,1 & & & \\
\hline Tavomita att. Brevistaminea Engl. & GUTTIFERAE & 0,2 & 0,2 & 0,2 & & & & & & \\
\hline Terminalia argentea & COMBRETACEAE & 0,2 & 0,2 & 0,2 & & & & & & \\
\hline Tetragastris altissima (Aubl.)Swartz & BURSERACEAE & 7,8 & 7,7 & 7,8 & 8,5 & 8,2 & 8,2 & 11,4 & 10,1 & 10,2 \\
\hline Theobroma speciosa Willd. ex. Spreng. & STERCULIACEAE & 2,4 & 2,4 & 2,4 & 2,4 & 2,4 & 2,4 & 2,6 & 2,4 & 2,4 \\
\hline $\begin{array}{ll}\text { Trattinickia rhoifolia } & \text { Willd. } \\
\end{array}$ & BURSERACEAE & 0,9 & 0,7 & 0,8 & 3,3 & 3,3 & 3,3 & 1,8 & 1,7 & 1,8 \\
\hline Trichilia micrantha & MELIACEAE & 0,6 & 0,6 & 0,6 & & & & & & \\
\hline Trymatococcus amazonicus P.\&E. & MORACEAE & 0,0 & 0,0 & 0,1 & 0,2 & 0,2 & 0,2 & 0,7 & 0,4 & 0,5 \\
\hline $\begin{array}{ll}\text { Vatairea sericea } & \text { Ducke } \\
\end{array}$ & FABACEAE & 0,2 & 0,1 & 0,1 & 0,3 & 0,2 & 0,2 & 0,6 & 0,6 & $\overline{0,6}$ \\
\hline Virola michelii Hechel & MYRISTICACEAE & 1,8 & 1,8 & 2,2 & 3,3 & 3,2 & 3,9 & 3,7 & 3,1 & $\overline{3,4}$ \\
\hline Vismia $s p$ & GUTTIFERAE & 1,2 & 1,2 & 1,0 & 1,4 & 0,4 & 0,4 & 0,4 & 0,2 & 0,2 \\
\hline Vochysia inundata Ducke & VOCHYSIACEAE & & & & & & & 0,1 & 0,1 & 0,1 \\
\hline Xylopia nitida Dun. & ANNONACEAE & 4,9 & 4,9 & 4,9 & 10,9 & 8,3 & 8,3 & 7,4 & 5,3 & 5,3 \\
\hline Zanthoxylum reguineliana & RUTACEAE & 2,2 & 2,1 & 1,7 & 2,3 & 1,6 & 1,6 & 2,2 & 1,8 & 1,8 \\
\hline Zanthoxylum rhoifolia & RUTACEAE & 0,2 & 0,2 & 0,2 & & & & & & \\
\hline $\begin{array}{ll}\text { Zizyphus itacaiunensis } & \text { Fróes }\end{array}$ & RHAMNACEAE & 0,6 & 0,6 & 0,6 & & & & & & \\
\hline \begin{tabular}{|ll} 
Zollernia paraensis $\quad$ Hub. \\
\end{tabular} & CAESALPINIACEAE & 2,2 & 2,2 & 2,2 & 1,8 & 1,5 & 1,5 & 1,8 & 1,2 & 1,2 \\
\hline Arataciu & n.i. & 19,4 & 19,4 & 19,0 & 28,2 & 23,4 & 23,4 & 28,6 & 20,8 & 20,8 \\
\hline Gema de ovo & n.i. & 5,6 & 5,6 & 5,2 & 4,2 & 3,0 & 3,0 & 6,0 & 3,6 & 3,6 \\
\hline Caniseiro & n.i. & 1,0 & 1,0 & 1,0 & 1,0 & 0,6 & 0,6 & 1,2 & 0,8 & 0,8 \\
\hline Galhudinho & n.i. & 0,2 & 0,2 & 0,2 & 0,2 & 0,2 & 0,2 & 1,1 & 0,7 & 0,7 \\
\hline Pau gafanhoto & n.i. & 0,4 & 0,4 & 0,2 & 2,4 & 2,2 & 2,2 & 1,0 & 0,6 & $\overline{0,6}$ \\
\hline Tinteiro & n.i. & 2,8 & 2,8 & 2,6 & 6,9 & 4,8 & 4,8 & 5,0 & 3,6 & 3,6 \\
\hline n.i. & n.i. & 17,3 & 17,3 & 16,8 & 14,4 & 10,2 & 10,2 & 13,9 & 11,8 & 11,8 \\
\hline
\end{tabular}

Notas:

I - Antes da exploração, no caso da testemunha, as medidas foram coletadas no mesmo periodo.

II - Logo após a exploração.

III - Três anos após a exploração. 
Ảnexo 3: Distribuição đôs indivííuios por classe diamétrica ântes da exploração, logo após e três anos após por tratamento em Parāgominas, Pará/Brasisil.

\section{A - TESTEMUNHA}

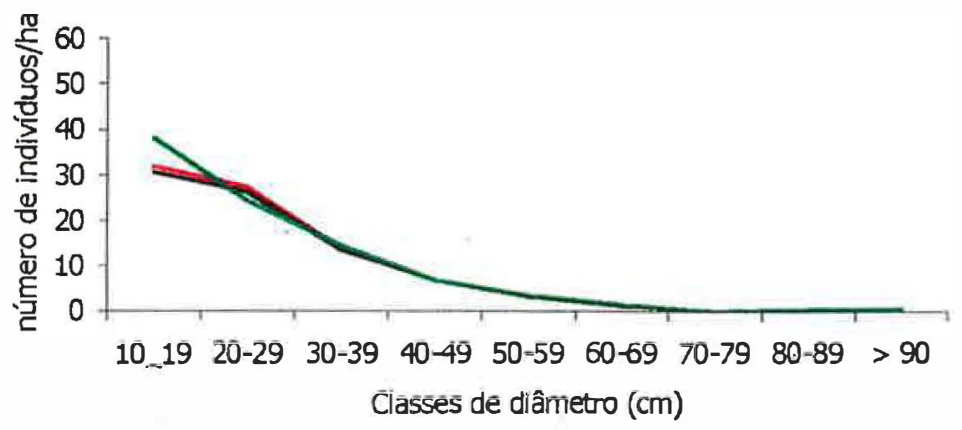

\section{B - COLHEITA PLANEJADA}
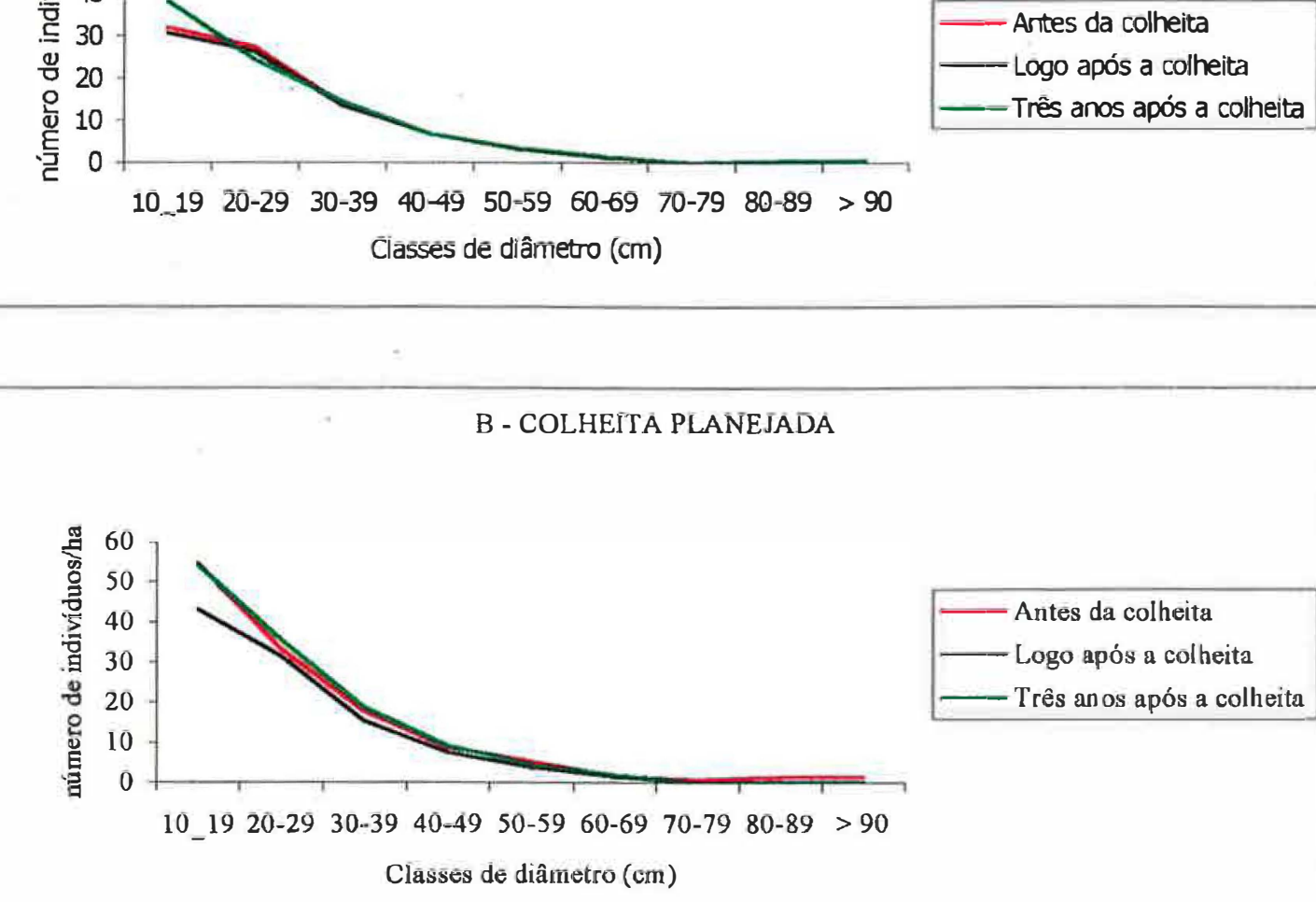

\section{C - EXPLORAÇÃO PREDATÓRIA}

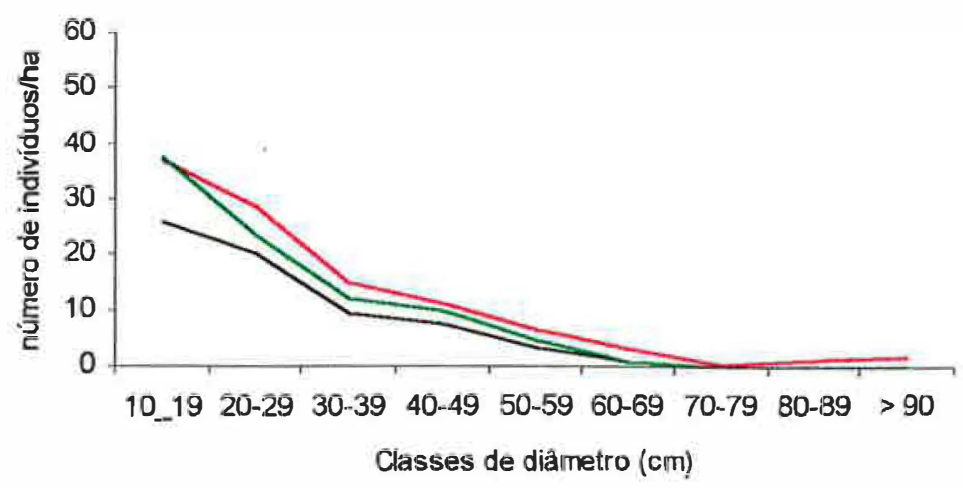

Antes da collheita Logo após a coineita Três anos após a colheita

Classes de diâmetro (cm) 


\title{
CAPÍtULO 5 \\ CONCLUSÕES E RECOMENDAÇÕES
}

\subsection{AS VANTAGENS DA COLHEITA PLANEJADA DE MADEIRA NA AMAZÔNIA}

\author{
Edson Vidal $^{1,2}$, Paulo Barreto ${ }^{2}$, Paulo Amaral ${ }^{2}$, Virgilio Viana ${ }^{3}$
}

Existem na Amazônia diversos usos do solo. Todavia, a grande maioria não é sustentável a longo prazo, por mudar drasticamente a paisagem, o microclima e o habitat de diversas espécies animais e vegetais. A atividade madeireira convencional, apesar de menos nociva, transforma profundamente as florestas primárias, comprometendo-as quanto à regeneração e produtividade. No entanto, a floresta pode ser manejada com o uso de técnicas de manejo florestal. O uso comparativo de extração predatória com o uso de técnicas de manejo florestal foi testado numa indústria madeireira pelo Instituto do Homem e do Meio Ambiente da Amazônia (IMAZON) e uma madeireira em Paragominas-Pará, na Amazônia oriental.

A atividade madeireira predatória afeta drásticamente o ecossistema florestal. Os impactos começam com a destruição ou danos às árvores pela preparação da infraestrutura da exploração (p. ex.: vias de acesso, ramais de arraste), pátios de estocagem de madeira na floresta, movimentação das máquinas e derrubada das árvores.

No entanto, a colheita de madeira não precisa ser assim. Se for empregado o planejamento da colheita com as seguintes medidas: censo das árvores de valor madeireiro com DAP $>25 \mathrm{~cm}$; preparação de um mapa de colheita com o traçado de estradas, ramais de arraste e localização de pátios de estocagem; o uso da derrubada 
direcional; o corte de cipós 1,5 anos antes da colheita; o arraste feito com tratores florestais, com guincho e com torre.

As vantagens da colheita planejada são evidentes, como observaremos a seguir. A redução em área basal na exploração predatória foi de $31 \%$, enquanto que na colheita planejada foi de apenas $17 \%$. E, mesmo assim, a produção na colheita planejada foi superior em relação à exploração predatória $\left(38,6 \mathrm{~m}^{3} / \mathrm{ha}\right.$ e $29,7 \mathrm{~m}^{3} / \mathrm{ha}$, respectivamente). A explicação para esta diferença é o aumento de danos e de desperdícios na exploração predatória ( $25 \%$ do que é derrubado é desperdiçado na floresta). O incremento em área basal 3 anos após a colheita foi de 2,2 vezes superior na colheita planejada em relação à exploração predatória. Se o incremento médio em área basal continuar como está atualmente, a colheita planejada recuperará a área basal perdida durante a colheita num prazo de 9 anos, enquanto que a exploração predatória precisará de pelo menos 40 anos.

As aberturas no dossel da floresta criadas pela derrubada das árvores são $50 \%$ menores na colheita planejada do que na exploração predatória. Isso deixa essas áreas menos suscetíveis ao fogo, ao longo do ano. O número de dias, ao longo do ano, em que a floresta é capaz de incendiar é bem menor se compararmos com a exploração predatória, onde a extensiva abertura do dossel da floresta torna o seu interior mais seco, aumentando os riscos da expansão de incêndios oriundos de terras agrícolas.

$\mathrm{O}$ crescimento em diâmetro das árvores na área com colheita planejada chega a ser $70 \%$ superior ao da exploração predatória $(0,63 \mathrm{~cm} / \mathrm{ano}$ e $0,37 \mathrm{~cm} / \mathrm{ano}$, respectivamente). 


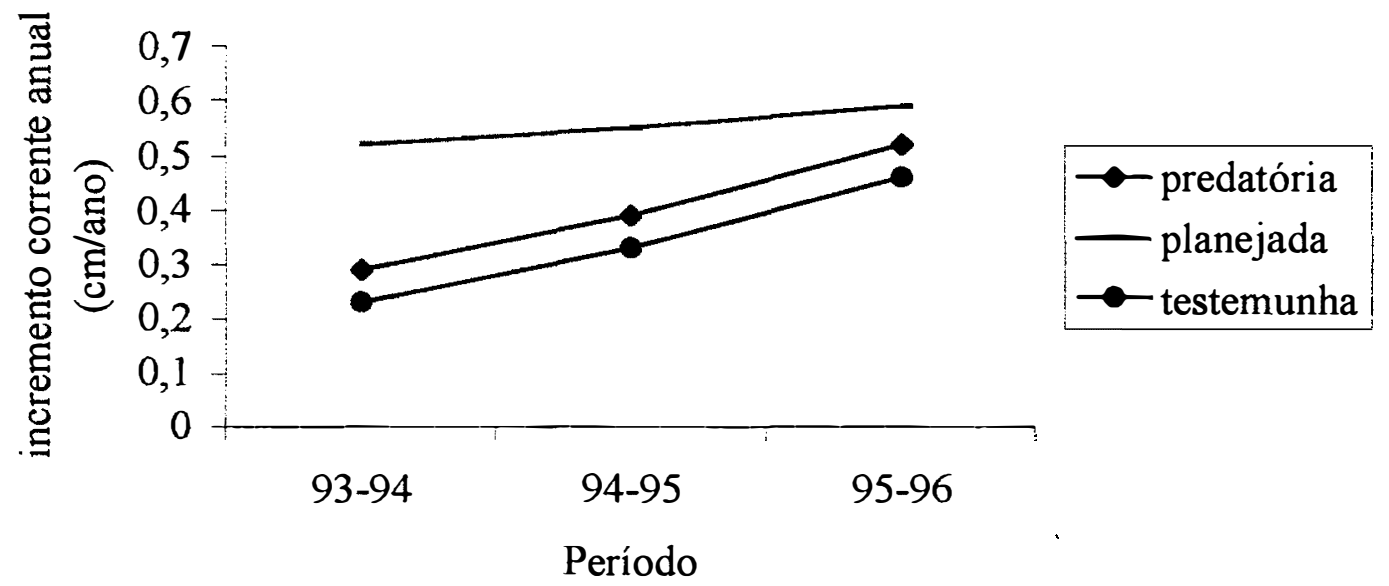

Figura 1: Incremento Corrente Anual por tipo de intervenção na floresta (exploração predatória, colheita planejada) e testemunha nos três períodos de medição na fazenda Agrosete em Paragominas/Pará.

As árvores sadias crescem sem competição com cipós, já que estes foram cortados antes da colheita. É evidente a competição entre cipós e árvores. Num período de 3 anos, as árvores sem cipós na copa, cresceram $44 \%$ a mais que as árvores com muito cipós na copa (Tabela 1).

Crescimento em diâmetro de árvores com e sem cipós na copa (cm/ano)

\begin{tabular}{cccc} 
Situação & média & desvio & $\mathrm{n}^{\mathbf{o}}$. árvores \\
\hline Com cipós & $0,23^{\mathrm{a}}$ & 0,26 & 893 \\
\cline { 2 - 4 } Sem cipós & $0,52^{\mathrm{b}}$ & 0,46 & 1584
\end{tabular}

Nota: os números com letras diferentes foram altamente significativos $(\mathrm{p}<0,0001)$ através do teste $t$ de Student.

Tabela 1: Crescimento em DAP das árvores com e sem cipós, durante 3 anos, em Paragominas, Pará.

$\mathrm{Na}$ colheita planejada houve menor redução de diversidade de espécies do que na exploração predatória (Tabela 3). Avaliando a diversidade de espécies pelo índice de 
Shannon, notamos que, na colheita planejada, os impactos da derrubada das árvores não ocasionaram perdas na diversidade de espécies. Entretanto, ocorreram mudanças de diversidade na área com exploração predatória.

\begin{tabular}{lccc}
\hline \multicolumn{1}{c}{ Intervenção } & Desapareceram & Recrutadas & Balanço \\
Testemunha & 0 & 1 & +1 \\
\hline Colheita planejada & $4(2,5 \%)$ & 2 & -2 \\
\hline Exploração predatória & $7(6,0 \%)$ & 2 & -5 \\
\hline
\end{tabular}

Tabela 2: Balanço do número de espécies por tipo de intervenção na floresta 3 anos após a exploração, na Fazenda, Agrosete em Paragominas, Pará.

Mesmo que a colheita seja cuidadosa e que medidas sejam tomadas para estimular a regeneração de espécies, a colheita modifica a composição e a dominância de espécies localmente (tabela 3). Desta forma, existe uma demanda muito grande, de estudos que examinem como a colheita afeta a reprodução, sobrevivência e crescimento da vegetação e como esses efeitos, por sua vez, poderiam afetar a fauna.

Os efeitos reduzidos da colheita planejada são animadores, mas devem ser vistos com cautela. A floresta tropical é muito dinâmica. É possível que o comportamento da diversidade seja modificado ao longo do tempo. Para isso, é necessário um acompanhamento a longo prazo da floresta, objetivando avaliar, com precisão, as mudanças.

Esta pesquisa revela vantagens significativas da colheita planejada de madeira comparada com exploração predatória, em floresta de terra firme na Amazônia brasileira, num período de 3 anos após a colheita. Os benefícios do emprego da colheita planejada são evidentes. Isso reforça a necessidade de formulação de políticas públicas apropriadas à adoção deste sistema de manejo para a produção de madeira na Amazônia. 


\section{CAPÍTULO 6 \\ BIBLIOGRAFIA GERAL}

ABDUL RASHID, M. A. The implementation of the selective management system in Peninsular Malaysia. Oxford, 1983. Dissertação (M.S.) - University of Oxford.

AMARAL, P., VERÍSSIMO, A., BARRETO, P. \& VIDAL, E. Floresta para sempre: um manual para produção da madeira na Amazônia. Belém: IMAZON, 1998. $137 \mathrm{p}$.

ATTIWILL, P. M.. The disturbance of forest ecosystems: the ecological basis for conservative management. Forest Ecology and Management, v.63, p.247-270, 1994.

BARROS, A.; UHL, C. Logging along the Amazon River and Estuary: patterns, problens and potential. Forest Ecology and Management. v.77, p.87-105, 1995.

BARRETO, P., AMARAL, P., VIDAL, E. \& UHL, C. Costs and benefits of forest management for timber production in eastern Amazonia. Forest Ecology and Management. /No prelo/

BARReto, P., UHL, C. \& YARED, J. 1994. Avaliação do Potencial para Manejo Florestal em Paragominas, considerando Fatores Ecológicos e Econômicos. In: ANAIS DO VII CONGRESSO FLORESTAL BRASILEIRO E I CONGRESSO FLORESTAL PANAMERICANO, SBS-SBEF. Set. 1993. p. 387-392. 
BARRETO, P. ; VERÍSSIMO, A.; HIRAKURI, S. A exploração madeireira na Amazônia brasileira: situação e perspectivas. Belém, 1998, 23p. (Relatório elaborado para a Instituição Greenpeace).

BAZZAZ, F. A. Characteristics of population in relation to disturbance in natural and man-modified ecosystem. In: H. A. MOONEY \& M. GODRON (eds.). Disturbance and Ecosystems. Springer-Valag, Berlim Herdelberg, New York, 1983, p.259-275.

BAWA, K.S. ASHTON, P.S. Conservation of rare trees in tropical rain forest: a genetic perspective. In: D.A FALK \& K.E. HOLSINGER (eds.). Genetics and conservation of rare plants. New York, Oxford, Oxford University Press, USA, 1991, p.62-71.

BATISTA, J.L.F., A função Weibull como modelo para distribuição de diâmetro de espécies arbóreas tropicais. Piracicaba, 1989. 115p. Dissertação (M.S.) - Escola Superior de Agricultura "Luiz de Queiroz".

BRASIL, Ministério das Minas e Energia. Departamento Nacional de Produção Mineral. Folha AS 22 Belém: geologia, geomorfologia, solos, vegetação e uso potencial da terra. Rio de Janeiro, 1974. (Projeto Radam. Levantamento de Recursos Naturais, 5).

BROKAW, N.V.L. Gap-phase regeneration of three pioneer tree species in a tropical forest. Journal of ecology, v.75, p.9-19, 1987.

BRYAN, M. B. Studies of timber growth and mortality in the mixed dipterocap forest in Sarawak. FAO Report, nº. FO:MAL/76/008. Field Document 11. 56 pp. 1981.

DE CARVALHO, J. O. P. Anelagem de árvores indesejáveis em floresta tropical densa da Amazônia. EMBRAPA/CPATU, Belém. 1981' Boletim de Pesquisa 22. 11p. 
DE CARVALHO, J.O.P. Structure and dynamics of a logged over Brazilian Amazonian rain forest. Oxford, 1992. Thesis (PhD), Oxford University, 1992.

DE GRAAF, N. R. 1986. A silvicultural system for natural regeneration of tropical rain forest in Suriname. Wageningem, The Netherlands: Agricultural University.

DENSLOW, J. S. Tropical rainforest gaps and tree species diversity. An. Review of Ecology and System, v.18, p.431-451, 1987.

DUBOIS, J.L.C. Silvicultural research in the Amazon. FAO REPORT. FO: SF/BRA 4. Techincal Report 3, 1971.

FIGUEROA, S. N.; NOBRE, C. A. Precipitation distribution over central and western tropical South America. Climanálise, v.5, n.6, p.36-45, 1990.

FOX, J. E. D. Constraints on the natural regeneration of tropical moist forest. Forest Ecology and Management, v.1, p.37-65, 1976.

GAJASENI, J. \& BOONPRAGOB, K. 1995. Methods for measurement of species diversity. In: Measuring and monitoring biodiversity in tropical and temperate forests. Ed. Timothy J. B. BOYLE and Boonchoob BOONTAWEEE. CIFOR. Malaysia, cap 21, 303-307.

GERWING, J., JOHNS, J. \& VIDAL, E. 1996. Reducing waste during logging and log processing towards forest conservation in Eastern Amazon. Unasylva, v. 47, n. 187 $17-25$.

HIGUCHI, N.. Short-term growth of man undisturbed tropical moist forest in the Brazilian Amazon. Michigan, 1987, Thesis (Ph.D) - Michigan State University. 
HIGUCHI, N., SANTOS, J., RIBEIRO, R.J., FREITAS, J.V., VIEIRA, G., COIC, A. \& MINETTE, L.J. Crescimento e incremento de uma floresta amazônica de terra-firme manejada experimentalmente. In: N. HIGUCHI, J.B.S.FERRAZ, L. ANTONY, F. LUIZÃO, R. LUIZÃO, Y. BIOT, I. HUNTER, J. PROCTOR \& S. ROSS (eds.). Biomassa e nutrientes florestais: Relatório Final. Manaus, INPA/DFID. 1997, p. $88-132$.

HOLDSWORTH, A. R.; UHL, C. Fire in Amazonian selectively logged rain forest and the potential for fire rediction. Ecological Applications, v.7, p.173-725, 1997.

HUTCHINSON, I.D. Approach adopted to define interim guidelines for silviculture and management of mixed dipterocarp forest in Sarawak. FAO Report, no 4, 1981.

HUTCHINSON, I.D. The management of humid tropical forest to produce wood. In: Management of the forest of tropical america: prospects and tecnologies. Proceedings of a conference. Institute of Tropical Forestry. Puerto Rico. p.121-156, 1986.

HUTCHINSON, I. D.. Improvement thining in natural tropical forests: aspects and institucionalization. In: Natural management of tropical moist forest. Silvicultura and Management Prospects of Sustained Utilization. F. Mergen \& J. R. Vicent. Yale University. School of Forest and Envinomental Studies, New Haven. C. T. 1987, p. 113-133.

IBGE, 1993. Anuário Estatístico do Brasil. Rio de Janeiro. Secretaria de Planejamento, Orçamento e Coordenação.

JOHNS, J., BARRETO, P. \& UHL, C. Logging damage in planned and unplanned logging operations and its implications for sustainable timber production in the Eastern Amazon. Forest Ecology and management, v.89, p.59-77, 1997. 
JONKERS, W. B. J. 1987. Vegetation structure logging damade and silviculture in a tropical rain forest in Suriname. Agricultural University, Wageningen. $172 \mathrm{p}$.

JOHNSON, N. E.; DYCKSTRA, G. F. Maintanig forest production in east Kalimantan. Indonesia. In: Eight World Forest Congress. Anais, 1978, Jakarta, Indonesia, 1978 $11 \mathrm{p}$.

KAGEYAMA, P. \& GANDARA, F.B. 1994. Dinâmica de populações de espécies arbóreas; implicações para o manejo e conservação. III SIMPÓSIO DE ECOSSISTEMAS DA COSTA BRASILEIRA, ACIESP. Abril de 1994, 1-9.

LISBOA, P. L. B., TEREZO, E. F. M. \& SILVA, J. C. A . Madeiras amazônicas: considerações sobre exploração, extinção de espécies e conservação. Boletim do museu paraense Emílio Goeldi: Série Botânica v.7, n.2, p.521-542, 1991.

LOWE, R. G. Experience with the tropical shelterwood system of regeneration in natural forest in Nigeria. Forest Ecology and Management, v. 1, p. 129-136, 1978.

LUGO, A. E. Management of tropical biodiversity. Ecological Applications, v.5, n.4, p.956-961, 1995.

MAGURRAN, E. A 1987. Ecological diversity and its measurement. Princeton University Press. 179 p.

MARTINI, A., ROSA, N. \& UHL, C. An attempt to predict which Amazonian tree species may be threatened by logging activities. Environmental Conservation, 21 (2): 152-162, 1994. 
MEVART, J. 1974. Appendix to the paper on growth and mortality rates in the natural high forest of western Nigeria. Nigerian Forest Information Bulletin, n. 28. 30 pp.

MILLER, T. B. Growth and yeild of a logged-over mixed dipterocarp forest in East Kalimatan. Malaysian Forest v.44, p.419-424, 1981.

NELSON, B. W. Natural forest disturbance and change in the brazilian Amazon. Remote Sensing Reviews, v. 10, p.105-124, 1994.

OLIVER, C.D. \& LARSON, B. C. 1990. Forest stand dynanmics. Biological Resource Management Series. Mcgraw-Hill. New York. 467p

OLIVER, C.D. \& LARSON, B. C. 1996. Forest stand dynanmics. New York. \& Sons. New York. 520p.

OSAFO, E.D. The development of silvicultura techiniques applied to natural forest in gana. Technical Note Forest Products Research Institute Ghana, v.13, p.18, 1970.

PERES, C.A. Diet and feeding ecology of saddle-back (Saguinus fuscicollis)and moustached ( $S$. mystax)tamarins in na Amazonian terra firme forest. Journal of Zoology v.230, p.567-592, 1993.

PIELOU, E.C. 1975. Ecological diversity. John Willey \& Sons. New York. 156 p.

POSEY, D.; BALÉE, W. Resource management in Amazonian: indigenous and folk strategies. Advances in Economic Botanic. New York: The New York Botanical garden, 1989 , v. 7.

PRADO, A.C. Diretrizes para uma política florestal no Brasil. MA/MMA. 1995. 171p. 
PUTZ, F.E. The natural history of lianas on Barro Colorado, Island, Panama. Ecology v.65, p.1713-1724, 1984.

REICE, S. R. Nonequilibruium determinants of biological community structure. American Scientist, v.82, n.5, p.424-435, 1994

ROBERTS, M. R.; GILLIAM, F. S. Patterns and mechanisms of plant diversity in forest ecosystems: implications for forest management. Ecological Application v.5, n.4, p.969-977, 1995.

SILVA, J.N.M, J.O.P. de Carvalho, J. do C.A. LOPES, B.F. de Almeida, D.H.M. Costa, L.C. de Oliveira, J.K. Vanclay \& J. P. Skovsgaard. Growth and yield of a tropical rain forest in the brazilian Amazon 13 years after logging. Forest Ecology and management, v.71, n.3, p.267-274, 1995.

SILVA, J.N.M. 1993. A experiência do manejo sob rendimento sustentado em florestas tropicais úmidas. In: ANAIS DO VII CONGRESSO FLORESTAL BRASILEIRO E I CONGRESSO FLORESTAL PANAMERICANO, SBS-SBEF. Set.1993.p. 202206.

SILVA, J.N.M. The behavior of the tropical rain forest of the brazilian amazon after logging. Oxford, 1989. Thesis ( $\mathrm{PhD})$, University of Oxford.

SOUTHWOOD, T.R.E. 1978. Ecological methods. Chapman \& Hall. London. 232 p.

STONE, S. Growth of the timber industry in the eastern Amazon: economic trends and implication for policy. Ithaca, 1997, Thesis (PhD), Cornell University, NY, USA. 
TANG, H. T. 1987. Problens and strategies for regenerating dipterocarp forest in Malaysia. In: F. Mergen and J. Vincent (eds.), Natural Management of Tropical Moist Forest: Silvicultural and Management Prospects of Sustained Utilization. New Haven, CT, USA, Yale University School of Forestry and Environmental Studies.

UHL, C. BARRETO, P., VERÍSSIMO, A., BARROS, A. C., AMARAL, P., VIDAL, E. \& SOUZA Jr., C. Uma abordagem integrada de pesquisa sobre manejo dos recursos naturais na Amazônia. In: A. VERÍSSIMO e A. C. Barros, editores. A expansão da atividade madeireira na Amazônia: Impactos $e$ perspectiva para o desenvolvimento do setor florestal no Pará. Belém: IMAZON, 1996, cap. 5, p. 140-164.

UHL, C. BARRETO, P., VERÍSSIMO, A., BARROS, A. C., AMAKAL, P., VIDAL, E. \& SOUZA Jr., C. Natural resource management in the brazilian Amazon: an integrated research approach. BioScience, v.47, n.3, p.160-199. 1997.

UHL, C. ; CLARK, N.; DEZZEO, N.; MAQUINO, P. Vegetation dynamics in Amazonian treefall gaps. Ecology, v.69, p.751-763, 1988.

UHL, C. BUSCHBACHER, R. \& SERRÃO, A.. Abandoned pastures in Eastern Amazônia. I. Patters of plant sucession. Journal of ecology, v.75, p.663-681. 1988

UHL, C., VERÍSSIMO, A., BARRETO, P., MATTOS, M., TARIFA, R. O desafio da exploração sustentada. Ciência Hoje, v. 14, p.53-59, 1992.

UHL, C., VERÍSSIMO, A., BRANDINO, Z. \& VIEIRA, I. Social, economic, and ecological consequences of logging in the Amazon Frontier: The case of Tailandia. Forest Ecology and Management, v.46, p.243-273, 1991. 
VERÍSSIMO, A., BARRETO, P., MATTOS, M., TARIFA, R. \& UHL, C.. Logging impacts and prospects for sustainable forest management in an old Amazonian frontier: the case of Paragominas. Forest Ecology and management, v.55, p.169199, 1992.

VERÍSSIMO, A., BARRETO, P., TARIFA, R. \& UHL, C. Extration of a high-value natural resource from Amazonia: o case of mahogany. Forest Ecology and Management, v.72, p.39-60, 1995.

VERÍSSIMO, A.; LIMA, E. Pólos de exploração madeireira na Amazônia. Belém, IMAZON, 1998, 30 p (Relatório interno do IMAZON).

VIDAL ${ }^{\text {a }}$, E., BARRETO, P., JOHNS, J., GERWING, J. \& UHL, C. Vine management for reduced-impacts logging in Eastern Amazon. Forest Ecology and Management, v. 98, p. $105-114,1997 \mathrm{a}$.

VIDAL, E., GERWING, J., BARRETO, P., AMARAL, P. \& JOHNS, J. Redução de desperdícios de madeira na Amazônia. IMAZON, Série Amazônia, n. 5. 1997b. 18 pg.

WATRIN, O. dos S. \& ROCHA, A.M.A. da. Levantamento da vegetação natural e uso da terra no município de Paragominas (PA) utilizando imagens TM/LANDSAT. Belém: EMBRAPA-CPATU, 1991. 40p. (EMBRAPA-CPATU. Boletim de Pesquisa, 124).

WEAVER, P. L. Tree growth in several tropical forests of Puerto Rico. Research Paper Southern Forest Experiment Station SO-152. 15 p. 1979. 
WHITE, P. S., PICKETT, S. T. A. Natural disturbance and patch dynamics: na introduction. In: S. T. A. PICKETT \& P. S. WHITE (eds.). The ecology of natural disturbance and patch dynamics. Orlando, Academic Press, 1985. P.3-13.

WHITMORE, T. C.; PRANCE, G. T. Biogeography and quaternary history in tropical America. Oxford: Clarendon Press. 1987. 